Supporting Information for

\title{
Highly Stable Zr(IV)-Based Metal-Organic Frameworks for Chiral Separation in Reversed-Phase Liquid Chromatography
}

Hong Jiang, ${ }^{\dagger}$ Kuiwei Yang, ${ }^{\star}$ Xiangxiang Zhao, ${ }^{\dagger}$ Wenqiang Zhang, ${ }^{\dagger}$ Yan Liu,,${ }^{*} \dagger$ Jianwen Jiang, ${ }^{*}+\star$ and Yong Cui ${ }^{*}, \dagger$

'School of Chemistry and Chemical Engineering, Frontiers Science Center for Transformative Molecules and State Key Laboratory of Metal Matrix Composites, Shanghai Jiao Tong University, Shanghai 200240, China

Department of Chemical and Biomolecular Engineering, National University of Singapore, 117576, Singapore

Email: 1iuy@sjtu.edu.cn; cheji@nus.edu.sg; yongcui@sjtu.edu.cn.

\section{Table of Content}

1. Materials and general procedures

2. Synthesis

3. General procedure for column packing

4. Figures S1-S4. ${ }^{1} \mathrm{H}$ NMR of digested MOFs

5. Tables S1 and S2. Dye inclusion experiments

6. Table S3. Crystal data and structural refinement

7. Table S4. Selected bond lengths and angles

8. Figure S5. Additional X-ray crystallographic structures

9. Figure S6. CD spectra

10. Figure S7. FT-IR spectra

11. Figure S8. Additional PXRD patterns

12. Figure $\mathbf{S 9} . \mathrm{N}_{2}$ adsorption isotherms

13. Figure S10. SEM images

14. Figure S11. Molecular simulation of bulky analyte

15. Figure S12. Optimization of the separation conditions

16. Figure S13. Effect of the injected mass

17. Figure S14. Additional HPLC chromatograms for chiral separation

18. Tables S5-S8. Summary of selectivity factor and chromatographic resolution factor

19. Figures S15-S20. DFT calculations

20. Figure S21. TGA curve

21. References 


\section{Materials and general procedures}

All of the chemicals are commercial available, and used without further purification. Elemental analyses of $\mathrm{C}, \mathrm{H}$ and $\mathrm{N}$ were performed with an EA1110 CHNS-0 CE elemental analyzer. The IR ( $\mathrm{KBr}$ pellet) spectra were recorded $\left(400-4000 \mathrm{~cm}^{-1}\right.$ region) on a Nicolet Magna 750 FT-IR spectrometer. The CD spectra were recorded on a J-800 spectropolarimeter (Jasco, Japan). Thermogravimetric analyses (TGA) were carried out in an air atmosphere with a heating rate of 10 ${ }^{\circ} \mathrm{C} /$ min on a STA449C integration thermal analyzer. Powder X-ray diffraction (PXRD) data were collected on a D8 Advance diffractometer using $\mathrm{Cu} \mathrm{K} \alpha$ radiation. The calculated PXRD patterns were produced using the Mercury program and single crystal reflection data. ${ }^{1} \mathrm{H}$ and ${ }^{13} \mathrm{C}$ NMR experiments were carried out on a MERCURYplus 400 spectrometer operating at resonance frequencies of $400 \mathrm{MHz}$ or on a Bruker 500 spectrometer operating at resonance frequencies of $500 \mathrm{MHz}$. ESI-MS were recorded on a Finnigan LCQ mass spectrometer or fourier transform ion cyclotron resonance mass spectrometer. For MALDI-FT ICR MS analysis, a Bruker 7.0T SolariX FTICR hybrid quadrupole-FT ICR mass spectrometer (Bruker Daltonics, Bremen, Germany), equipped with an MALDI ion source, DCTB was used as a matrix mix. Analytical high performance liquid chromatography (HPLC) was performed on a LC-2010A HT (Shimadzu) with UV detection. $\mathrm{N}_{2}$ adsorption isotherms of MOFs were measured using a Micrometritics ASAP 2020 system at $77 \mathrm{~K}$ with liquid $\mathrm{N}_{2}$ bath. The activation procedure refers to the reported literature. ${ }^{[1]}$

Single-crystal X-ray Crystallography. Single-crystal XRD data for CE-1 were collected on a Bruker Smart APEX II CCD diffractometer with $\mathrm{Cu}-\mathrm{K} \alpha(\lambda=1.54178 \AA)$ at $173 \mathrm{~K}$, while crystal data for CE-2 and CE-3 were collected at National Facility for Protein Science at Shanghai Synchrotron Radiation Facility (SSRF) at $100 \mathrm{~K}$. For these three CE MOFs, the best fit of the systemic absences and the $\left|\mathrm{E}^{2}-1\right|$ value $(0.970,1.060$ and 1.052 for CE-1, CE-2 and CE-3, respectively) are given by the centrosymmetric Fmmm space group. However, this space group cannot be strictly correct because it contains symmetry elements that are incompatible with the enantiopure biphenol ligand. The chiral space group $P 2_{1} 2_{1} 2_{1}$ is also a viable choice. However, the refinement was still carried out in Fmmm for the following reasons: 1) The biphenol ligand is highly symmetric, and the crown ether groups are highly disorder. 2) Refinement in Fmmm 
resulted in reasonable bond length values. However, refinement in $P 22_{1} 2_{1} 2_{1}$ resulted in an unstable model. Thus, the Fmmm space group was used for CE MOFs on the basis of the above discussion. The empirical absorption correction was applied by using the SADABS program (G. M. Sheldrick, SADABS, program for empirical absorption correction of area detector data; University of Götingen, Götingen, Germany, 1996). All the structures were solved using direct method, and refined by full-matrix least-squares on $F^{2}$ by the SHELXTL-2015 software package. DFIX, SADI, FLAT, DANG, EADP and SIMU restrains were used to obtain reasonable parameters due to the poor quality of crystal data. The contributions of highly disordered solvents were removed using SQUEEZE routine PLATON software or the solvent mask program of Olex2. Crystal data and refinement results are shown in Table S3, while the selected bond distances and angles are presented in Table S4. The CIF files have been deposited in the Cambridge Crystallographic Data Centre (CCDC) under deposition number 2036507 (CE-1), 2036508 (CE-2) and 2036509 (CE-3).

\section{Synthesis}

\subsection{Synthesis of $(S)-H_{4} L^{1}$}

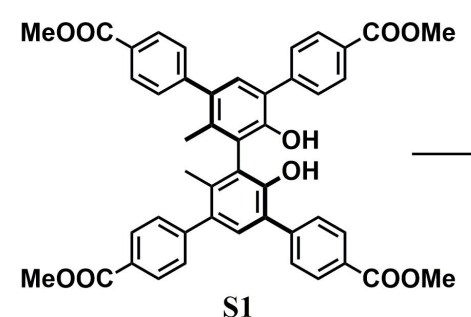

S1

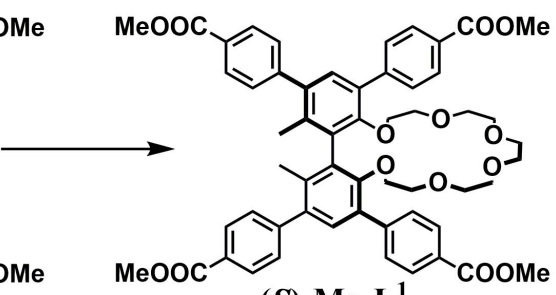

$(S)-\mathrm{Me}_{4} \mathrm{~L}^{1}$

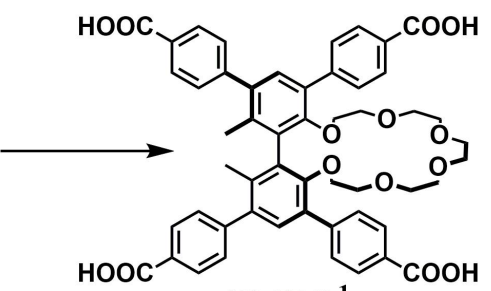

$(S)-\mathrm{H}_{4} \mathrm{~L}^{1}$

Synthesis of $(\boldsymbol{S})-\mathbf{M e}_{4} \mathbf{L}^{1}$. S1 was synthesized according to our previous report. ${ }^{[2]} \mathbf{S 1}(1.90 \mathrm{~g}$, $2.0 \mathrm{mmol})$ and $60 \%$ wt. $\mathrm{NaH}(176 \mathrm{mg}, 4.4 \mathrm{mmol})$ were added into a $100 \mathrm{~mL}$ three-necked round-bottom flask. The flask was degassed and refilled with $\mathrm{N}_{2}$ for three times, and then $50 \mathrm{~mL}$ THF was added. After stirring for $15 \mathrm{~min}$, a solution of pentaethylene glycol ditosylate $(1.31 \mathrm{~g}$, $2.4 \mathrm{mmol})$ in THF $(25 \mathrm{~mL}$ ) was slowly added. Then the mixture was allowed to reflux overnight. After cooling to room temperature, the mixture was extracted with EtOAc. The combined extracts were washed with water, dried over anhydrous $\mathrm{Na}_{2} \mathrm{SO}_{4}$, and then concentrated under reduced pressure. The crude product was purified by column chromatography on silica gel (EtOAc/petroleum ether, 1:1, v/v, $\left.R_{\mathrm{f}}=0.3\right)$ to afford $(S)-\mathrm{Me}_{4} \mathbf{L}^{1}$ as a white solid $(1.18 \mathrm{~g}, 62 \%) .{ }^{1} \mathrm{H}$ NMR (400 MHz, $\left.\mathrm{CDCl}_{3}\right) \delta: 8.09(\mathrm{dd}, J=8.4,2.5 \mathrm{~Hz}, 8 \mathrm{H}), 7.77(\mathrm{~d}, J=8.3 \mathrm{~Hz}, 4 \mathrm{H}), 7.45(\mathrm{~d}, J=$ 
$8.2 \mathrm{~Hz}, 4 \mathrm{H}), 7.30(\mathrm{~s}, 2 \mathrm{H}), 3.93(\mathrm{~d}, J=2.9 \mathrm{~Hz}, 12 \mathrm{H}), 3.72-3.68(\mathrm{~m}, 2 \mathrm{H}), 3.56-3.53(\mathrm{~m}, 6 \mathrm{H})$, 3.46-3.27 (m, 12H), $2.04(\mathrm{~s}, 6 \mathrm{H}) .{ }^{13} \mathrm{C}$ NMR $\left(101 \mathrm{MHz}, \mathrm{CDCl}_{3}\right) \delta 167.1,167.0,154.0,146.5,143.3$, 137.6, 135.4, 132.9, 131.3, 131.2, 129.7, 129.5, 129.3, 128.7, 71.8, 70.6, 70.5, 70.3, 69.9, 52.19, 52.15, 18.5. MALDI-MS: m/z $975.3562\left(\right.$ Calcd m/z 975.3568 for $\left.[\mathrm{M}+\mathrm{Na}]^{+}\right)$.

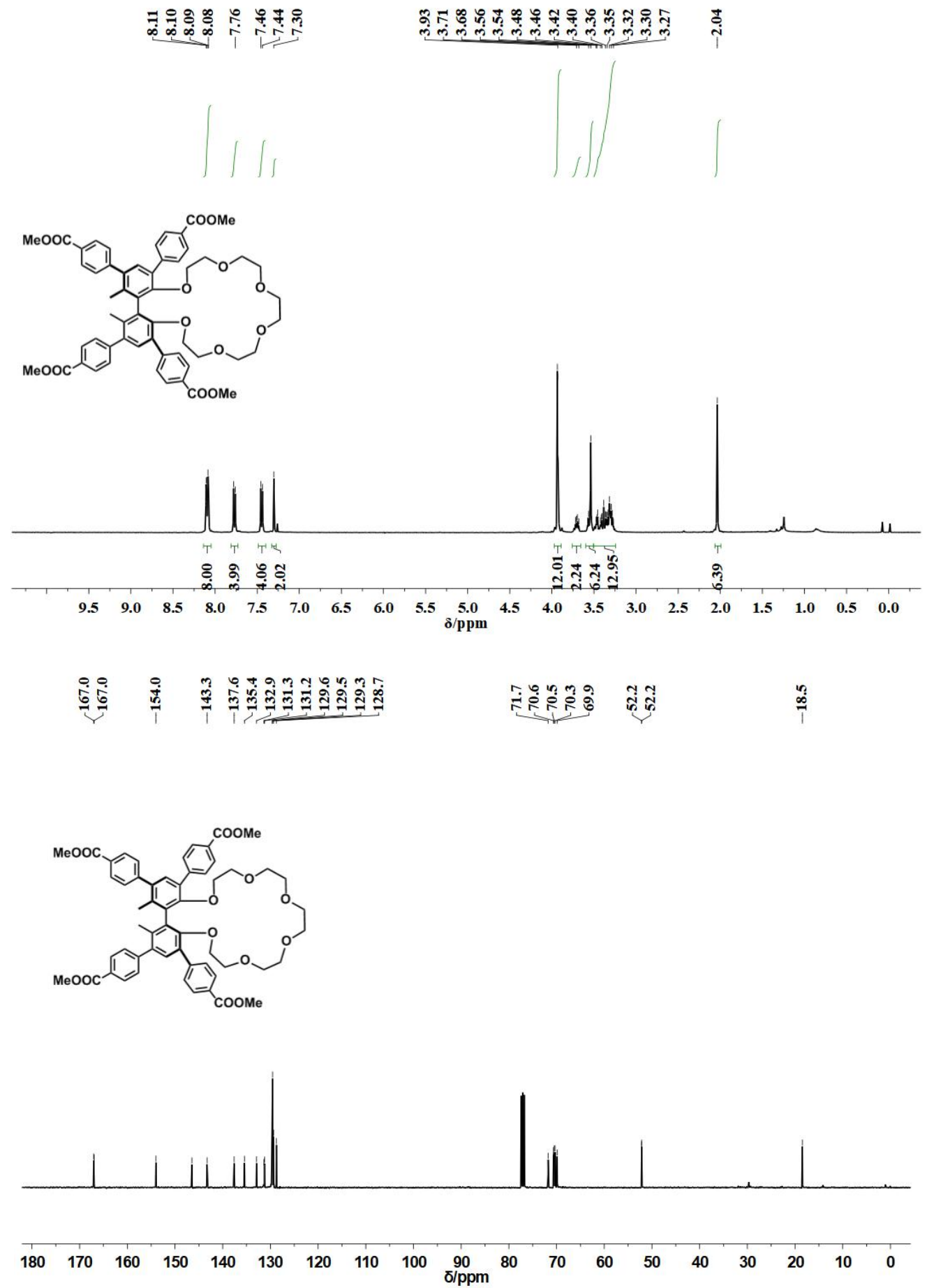

Synthesis of $(S)-\mathbf{H}_{4} \mathbf{L}^{1}$. A solution of $(S)-\mathrm{Me}_{4} \mathbf{L}^{1}(1.90 \mathrm{~g}, 2.0 \mathrm{mmol})$ and $\mathrm{LiOH} \cdot \mathrm{H}_{2} \mathrm{O}(1.68 \mathrm{~g}, 40$ mmol) in THF $(15 \mathrm{~mL})$, $\mathrm{MeOH}(45 \mathrm{~mL})$ and $\mathrm{H}_{2} \mathrm{O}(45 \mathrm{~mL})$ was heated at $75{ }^{\circ} \mathrm{C}$ for $6 \mathrm{~h}$. The 
solution was cooled to room temperature, acidified to $\mathrm{pH}=1 \sim 2$ with $6 \mathrm{M} \mathrm{HCl}$ and extracted with EtOAc. The organic phase was dried over $\mathrm{Na}_{2} \mathrm{SO}_{4}$ and the solvent was evaporated under reduced pressure to give $(S)-\mathrm{H}_{4} \mathbf{L}^{1}$ as a white solid $(1.70 \mathrm{~g}, 95 \%) .{ }^{1} \mathrm{H}$ NMR (400 MHz, DMSO-d $\left.d^{6}\right) \delta$ : 13.01(br, 4H), 8.02 (dd, $J=8.2,3.3 \mathrm{~Hz}, 8 \mathrm{H}), 7.82(\mathrm{~d}, J=8.2 \mathrm{~Hz}, 4 \mathrm{H}), 7.55(\mathrm{~d}, J=8.1 \mathrm{~Hz}, 4 \mathrm{H})$, $7.34(\mathrm{~s}, 2 \mathrm{H}), 3.66-3.62(\mathrm{~m}, 2 \mathrm{H}), 3.43-3.38(\mathrm{~m}, 8 \mathrm{H}), 3.32-3.24(\mathrm{~m}, 8 \mathrm{H}), 3.15-3.10(\mathrm{~m}, 2 \mathrm{H}), 1.99(\mathrm{~s}$, 6H). ${ }^{13} \mathrm{C}$ NMR (101 MHz, DMSO- $\left.d^{6}\right) \delta: 167.71,167.66,154.1,145.9,142.8,137.6,135.3,133.1$, 131.4, 131.2, 130.0, 129.92, 129.86, 129.8, 129.6, 71.9, 70.3, 70.3, 70.2, 69.6, 18.7. MALDI-MS: $\mathrm{m} / \mathrm{z} 914.3427\left(\right.$ Calcd m/z 914.3388 for $\left.\left[\mathrm{H}_{4} \mathbf{L}^{1}+\mathrm{NH}_{4}\right]^{+}\right)$.

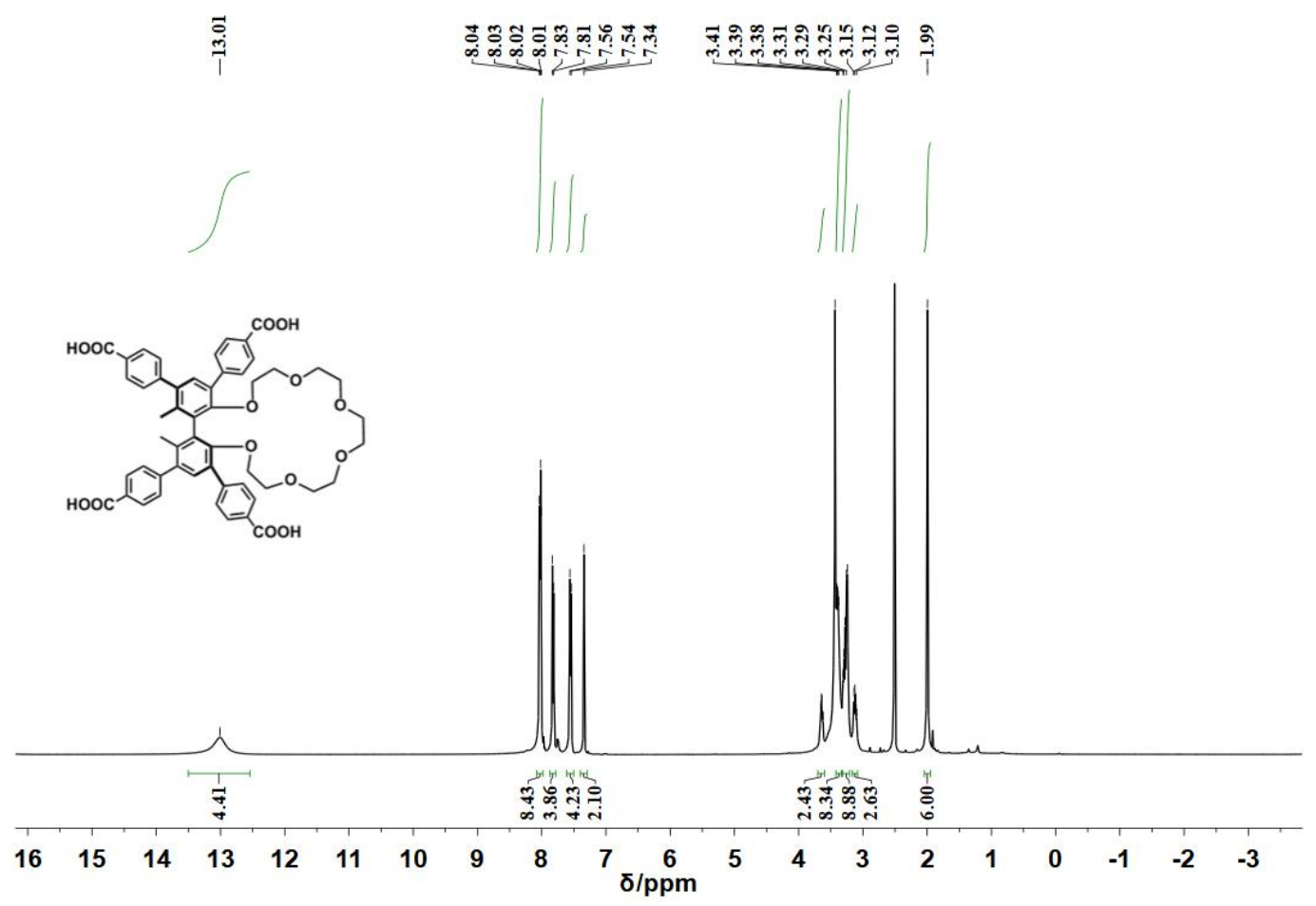




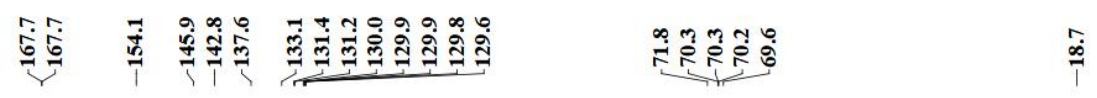
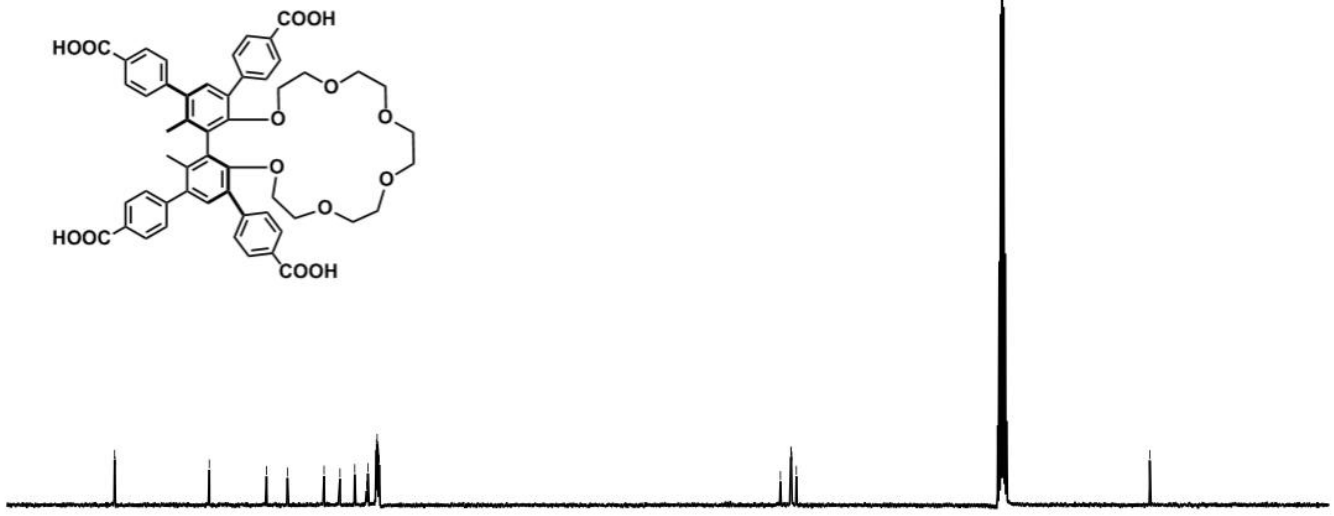

$\begin{array}{lllllllllllllllllll}180 & 170 & 160 & 150 & 140 & 130 & 120 & 110 & 100 & \underset{6 / p p m}{90} & 80 & 70 & 60 & 50 & 40 & 30 & 20 & 10 & 0\end{array}$

\subsection{Synthesis of $(S)-\mathrm{H}_{4} \mathrm{~L}^{2}$}

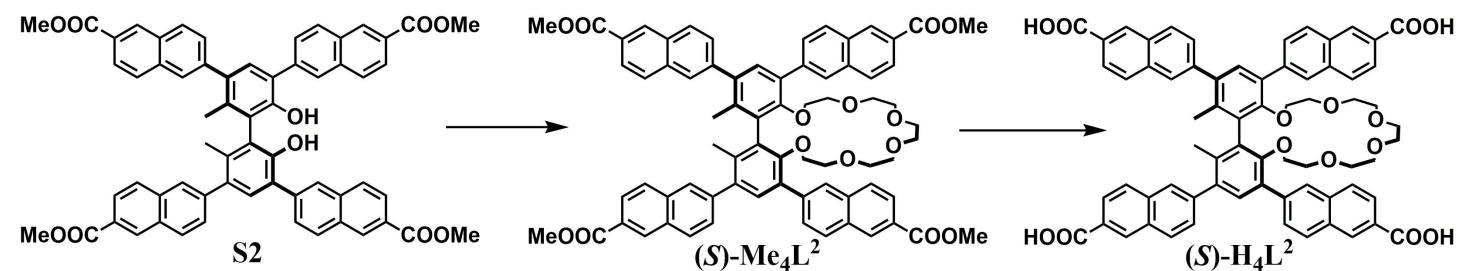

Synthesis of $(\boldsymbol{S})-\mathbf{M e}_{4} \mathbf{L}^{2}$. S2 was synthesized according to our previous report. ${ }^{[3]} \mathbf{S 2}$ (1.90 g, 2.0 mmol) and 60\% wt. NaH (176 mg, $4.4 \mathrm{mmol})$ were added into a $100 \mathrm{~mL}$ three-necked round-bottom flask. The flask was degassed and refilled with $\mathrm{N}_{2}$ for three times, and then $50 \mathrm{~mL}$ THF was added. After stirring for $15 \mathrm{~min}$, a solution of pentaethylene glycol ditosylate $(1.31 \mathrm{~g}, 2.4$ mmol, 1.2 eq.) in THF $(25 \mathrm{~mL})$ was slowly added. Then the mixture was allowed to reflux overnight. After cooling to room temperature, the mixture was extracted with EtOAc. The combined extracts were washed with water, dried over anhydrous $\mathrm{Na}_{2} \mathrm{SO}_{4}$, and then concentrated under reduced pressure. The crude product was purified by column chromatography on silica gel (EtOAc/petroleum ether, 1:1, v/v, $\left.\mathrm{R}_{\mathrm{f}}=0.25\right)$ to give $(S)-\mathrm{Me}_{4} \mathbf{L}^{2}$ as a white $\operatorname{solid}(1.34 \mathrm{~g}, 58 \%) .{ }^{1} \mathrm{H}$ NMR (500 MHz, CDCl $) \delta 8.66(\mathrm{~d}, J=5.1 \mathrm{~Hz}, 4 \mathrm{H}), 8.24(\mathrm{~s}, 2 \mathrm{H}), 8.09(\mathrm{t}, J=8.4 \mathrm{~Hz}, 4 \mathrm{H}), 8.00$ (dt, $J=18.0,8.7 \mathrm{~Hz}, 8 \mathrm{H}), 7.91(\mathrm{~d}, J=7.8 \mathrm{~Hz}, 4 \mathrm{H}), 7.64(\mathrm{~d}, J=8.4 \mathrm{~Hz}, 2 \mathrm{H}), 7.55(\mathrm{~s}, 2 \mathrm{H}), 3.98(\mathrm{~s}$, $12 \mathrm{H}), 3.85(\mathrm{dd}, J=10.2,5.2 \mathrm{~Hz}, 2 \mathrm{H}), 3.68(\mathrm{dd}, J=10.1,5.0 \mathrm{~Hz}, 2 \mathrm{H}), 3.52-3.41(\mathrm{~m}, 6 \mathrm{H}), 3.38(\mathrm{dd}$, $J=11.4,6.8 \mathrm{~Hz}, 6 \mathrm{H}), 3.33-3.22(\mathrm{~m}, 4 \mathrm{H}), 2.21(\mathrm{~s}, 6 \mathrm{H}) .{ }^{13} \mathrm{C} \mathrm{NMR}\left(126 \mathrm{MHz}, \mathrm{CDCl}_{3}\right) \delta 167.3$, 167.2, 154.2, 142.0, 138.9, 138.2, 135.7, 135.54, 135.52, 133.1, 132.10, 131.7, 131.6, 131.4, 130.9, $130.8,129.2,129.1,128.9,128.8,128.4,128.2,127.9,127.7,127.5,127.4,125.7,125.5,71.9$, 70.6, 70.5, 70.3, 70.1, 52.3, 52.2, 18.7. MALDI-MS: m/z $1175.4188($ Calcd m/z 1175.4194 for $\left.[\mathrm{M}+\mathrm{Na}]^{+}\right)$. 

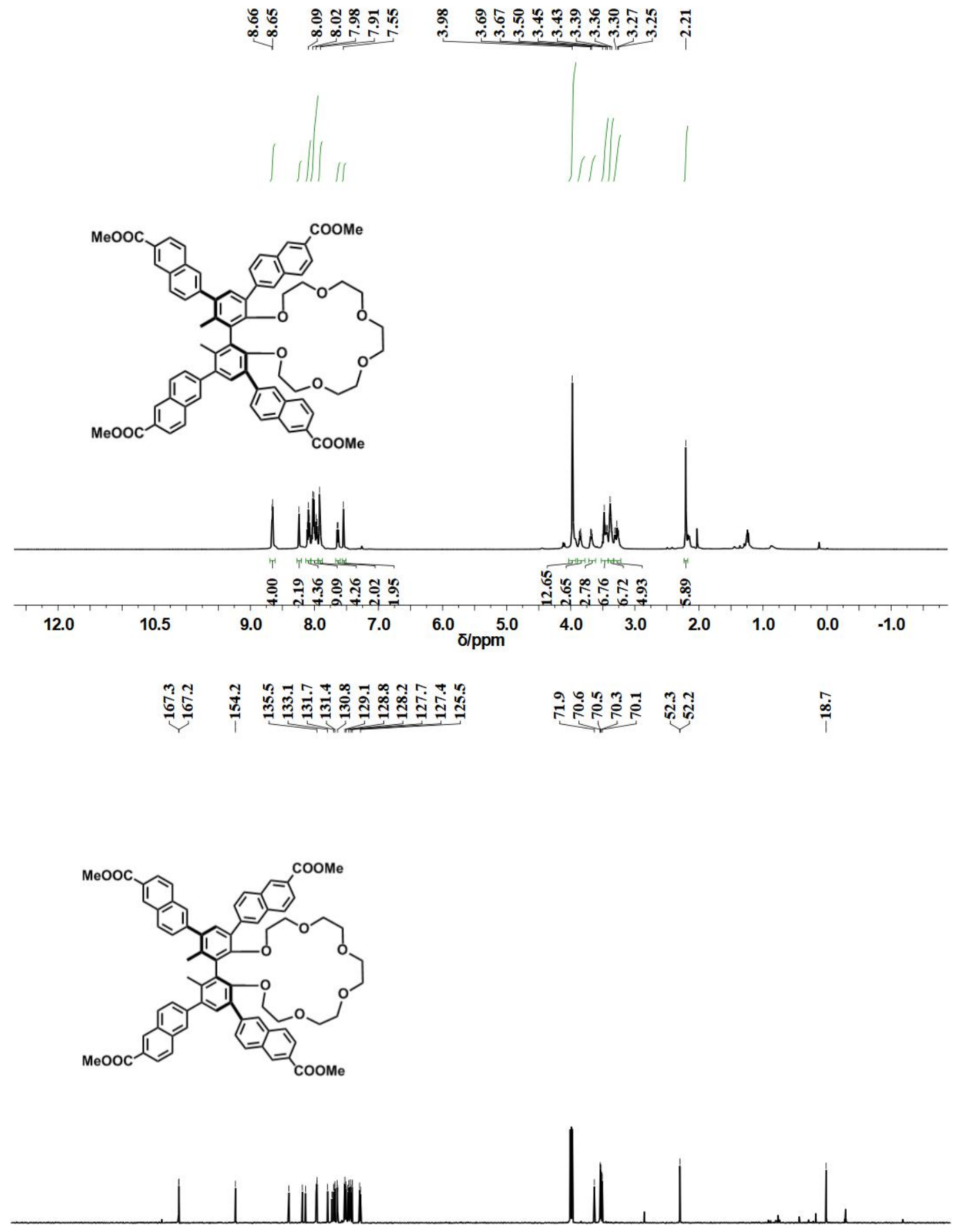

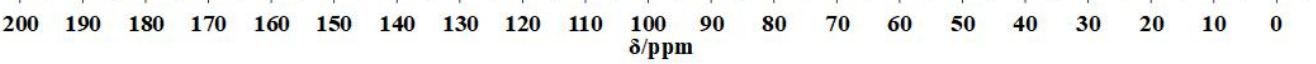

Synthesis of $(S)-\mathbf{H}_{4} \mathbf{L}^{2}$. A solution of $(S)-\mathrm{Me}_{4} \mathbf{L}^{2}(2.30 \mathrm{~g}, 2.0 \mathrm{mmol})$, and $\mathrm{LiOH} \cdot \mathrm{H}_{2} \mathrm{O}(1.68 \mathrm{~g}, 40$ mmol) in THF $(15 \mathrm{~mL})$, $\mathrm{MeOH}(45 \mathrm{~mL})$ and $\mathrm{H}_{2} \mathrm{O}(45 \mathrm{~mL})$ was heated at $75{ }^{\circ} \mathrm{C}$ for $6 \mathrm{~h}$. The solution was cooled to room temperature, acidified to $\mathrm{pH}=1 \sim 2$ with $6 \mathrm{M} \mathrm{HCl}$ and extracted with EtOAc. The organic phase was dried over $\mathrm{Na}_{2} \mathrm{SO}_{4}$ and the solvent was evaporated under reduced pressure to give $(S)-\mathrm{H}_{4} \mathbf{L}^{2}$ as a white solid (2.10 g, 95\%), ${ }^{1} \mathrm{H}$ NMR (400 MHz, DMSO- $\left.d^{6}\right) \delta 13.12$ 
(br, 4H), $8.67(\mathrm{~d}, J=12.1 \mathrm{~Hz}, 4 \mathrm{H}), 8.37(\mathrm{~s}, 2 \mathrm{H}), 8.20(\mathrm{t}, J=9.2 \mathrm{~Hz}, 4 \mathrm{H}), 8.14-8.08(\mathrm{~m}, 6 \mathrm{H})$, 8.04-7.98 (m, 6H), $7.73(\mathrm{~d}, J=8.4 \mathrm{~Hz}, 2 \mathrm{H}), 7.60(\mathrm{~s}, 2 \mathrm{H}), 3.79-3.74(\mathrm{~m}, 2 \mathrm{H}), 3.55-3.50(\mathrm{~m}, 4 \mathrm{H})$, 3.35-3.22 (m, 14H), $2.14(\mathrm{~s}, 6 \mathrm{H}) .{ }^{13} \mathrm{C}$ NMR (126 MHz, DMSO- $\left.d^{6}\right) \delta 167.5,153.9,141.1,138.2$, 137.7, 135.2, 135.0, 132.9, 131.1, 130.4, 129.1, 128.8, 128.2, 127.8, 127.5, 125.7, 125.5, 71.6, 69.9, 69.3, 18.4. MALDI-MS: m/z $1114.4041\left(\right.$ Calcd m/z 1114.4014 for $\left.\left[\mathrm{H}_{4} \mathbf{L}^{2}+\mathrm{NH}_{4}\right]^{+}\right)$.

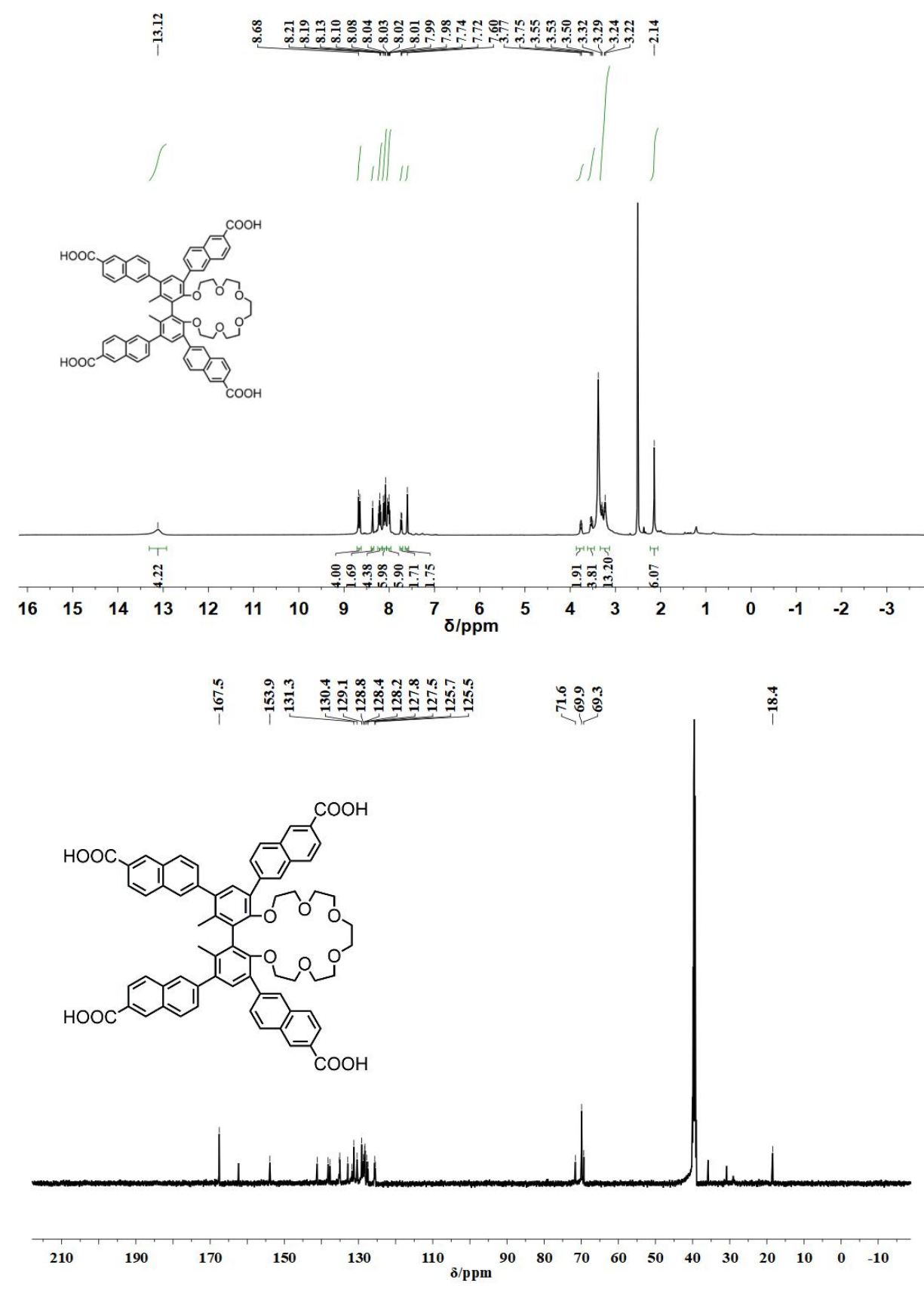




\subsection{Synthesis of $(S)-\mathrm{H}_{4} \mathrm{~L}^{3}$}
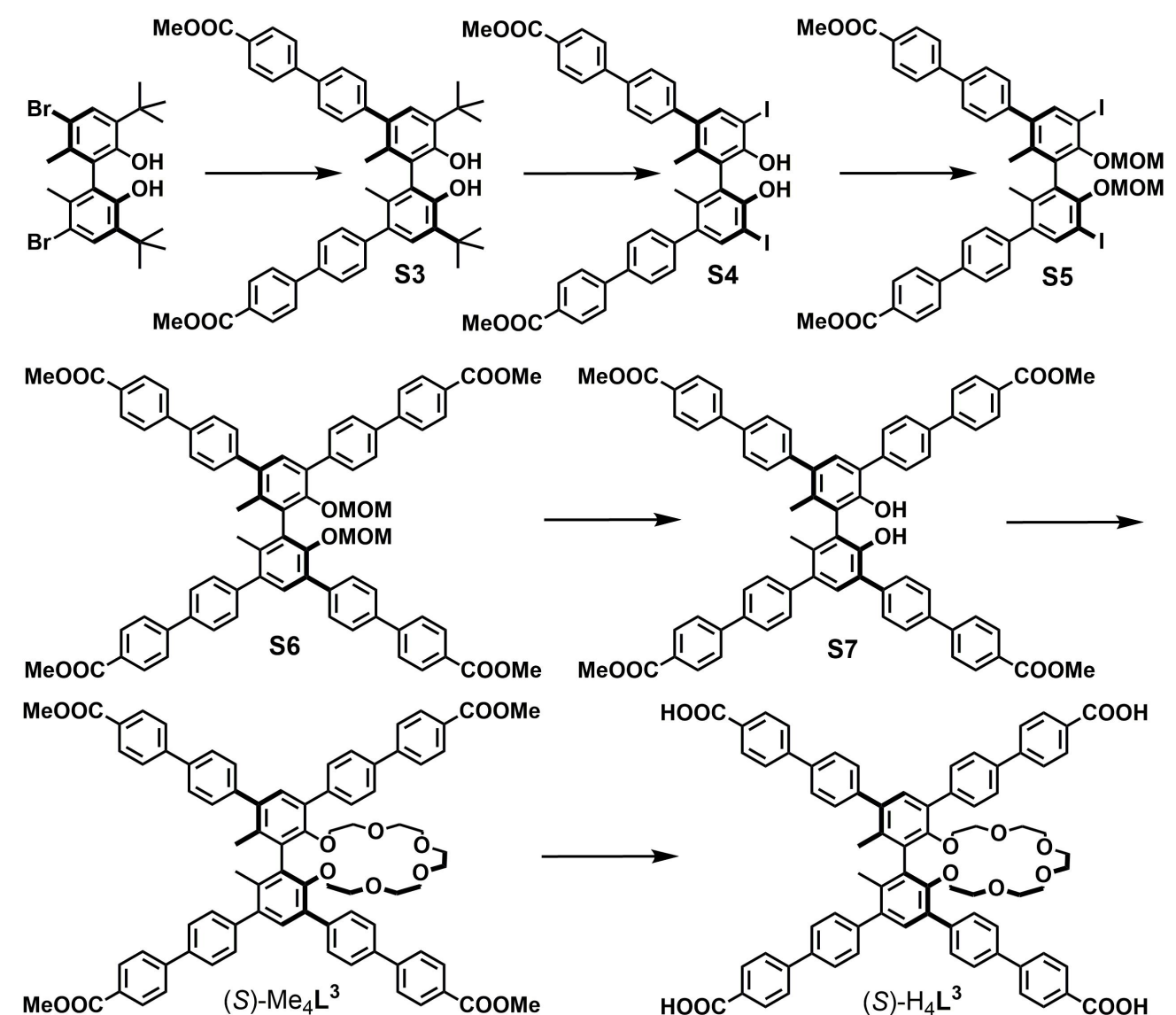

Synthesis of S3. A $250 \mathrm{~mL}$ flame-dried round-bottom flask was charged with (S)-5,5'-dibromo-3,3'-di-tert-butyl-6,6'-dimethyl-1,1'-biphenyl-2,2'-diol (4.8 g, $10 \mathrm{mmol}$ ), methyl 4'-(4,4,5,5-tetramethyl-1,3,2-dioxaborolan-2-yl)-1,1'-biphenyl-4-carboxylate (9.4 g, $30 \mathrm{mmol})$, $\mathrm{K}_{2} \mathrm{CO}_{3}(13.8 \mathrm{~g}, 100 \mathrm{mmol})$, and $\mathrm{Pd}(\mathrm{dppf}) \mathrm{Cl}_{2} \cdot \mathrm{CH}_{2} \mathrm{Cl}_{2}(244.5 \mathrm{mg}, 0.3 \mathrm{mmol})$. The flask was degassed and refilled with $\mathrm{N}_{2}$ for three times, and then degassed DME/ $\mathrm{H}_{2} \mathrm{O}(\mathrm{v} / \mathrm{v}=2 / 1,120 \mathrm{~mL})$ was added. The suspension was heated at $95{ }^{\circ} \mathrm{C}$ for $24 \mathrm{~h}$. After cooling to room temperature, the resulting mixture was extracted with EtOAc. The combined organic extracts were washed with water, dried over $\mathrm{Na}_{2} \mathrm{SO}_{4}$, and then concentrated under reduced pressure. The crude product was purified by column chromatography on silica gel (EtOAc/petroleum ether, $1: 15, \mathrm{v} / \mathrm{v}, \mathrm{R}_{\mathrm{f}}=0.23$ ) to afford $\mathbf{S 3}$ as a white solid (5.28 g, 76\%). ${ }^{1} \mathrm{H}$ NMR $\left(500 \mathrm{MHz}, \mathrm{CDCl}_{3}\right) \delta: 8.15(\mathrm{~d}, \mathrm{~J}=8.4 \mathrm{~Hz}, 4 \mathrm{H})$, $7.73(\mathrm{dd}, \mathrm{J}=16.6,8.3 \mathrm{~Hz}, 8 \mathrm{H}), 7.49$ (d, J = 8.2 Hz, 4H), 7.33 (s, 2H), 5.22 (s, 2H), 3.96 (s, 6H), $1.98(\mathrm{~s}, 6 \mathrm{H}), 1.48(\mathrm{~s}, 18 \mathrm{H}) .{ }^{13} \mathrm{C}$ NMR $\left(126 \mathrm{MHz}, \mathrm{CDCl}_{3}\right) \delta: 167.1,151.9,145.3,142.3,138.1$, 134.20, 134.18, 133.3, 130.3, 130.2, 129.5, 128.9, 127.00, 126.96, 121.2, 52.2, 34.8, 29.6, 17.4. MALDI-MS: $\mathrm{m} / \mathrm{z} 746.3597$ (Calcd m/z 746.3607 for $\mathrm{M}^{+}$). 

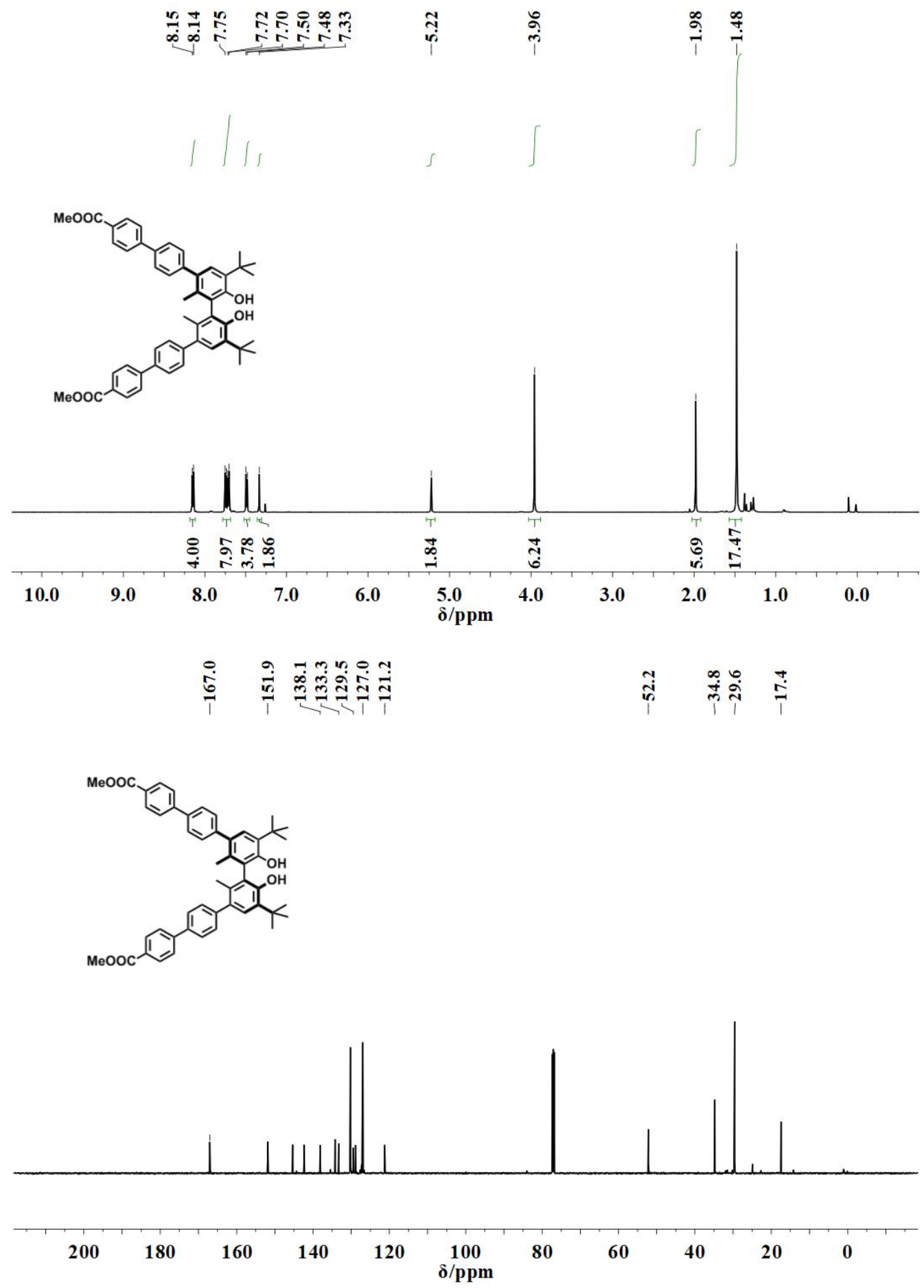

Synthesis of S4. S3 $(1.38 \mathrm{~g}, 2.0 \mathrm{mmol})$ was dissolved in $\mathrm{CH}_{2} \mathrm{Cl}_{2}(30 \mathrm{~mL})$. Anhydrous $\mathrm{AlCl}_{3}$ $(3.2 \mathrm{~g}, 24 \mathrm{mmol})$ dissolved in nitromethane $(30 \mathrm{~mL})$ was added slowly at $0{ }^{\circ} \mathrm{C}$. After that, the mixture was stirred at room temperature overnight. $6 \mathrm{M} \mathrm{HCl}$ was added and the mixture was stirred for $30 \mathrm{~min}$. The aqueous layer was extracted with $\mathrm{CH}_{2} \mathrm{Cl}_{2}$ and the combined organic layer was washed with brine, dried over $\mathrm{Na}_{2} \mathrm{SO}_{4}$ and then concentrated under reduced pressure. The crude product was dissolved in $\mathrm{CH}_{2} \mathrm{Cl}_{2}(40 \mathrm{~mL})$, and then morpholine $(1.04 \mathrm{~mL}, 12 \mathrm{mmol})$ and $\mathrm{I}_{2}$ $(1.27 \mathrm{~g}, 5 \mathrm{mmol})$ were added at room temperature. The mixture was stirred for $10 \mathrm{~h}$, and then $2 \mathrm{M}$ 
$\mathrm{HCl}$ was added. The aqueous layer was extracted with $\mathrm{CH}_{2} \mathrm{Cl}_{2}$, and the combined organic layer was washed with saturated $\mathrm{Na}_{2} \mathrm{~S}_{2} \mathrm{O}_{3}$ solution and brine, dried over $\mathrm{Na}_{2} \mathrm{SO}_{4}$ and concentrated under reduced pressure. The crude product was purified by column chromatography on silica gel $\left(\mathrm{CH}_{2} \mathrm{Cl}_{2}\right.$ /petroleum ether, 1:1, v/v, $\left.\mathrm{R}_{\mathrm{f}}=0.42\right)$ to afford $\mathbf{S 4}$ as a light-yellow solid $(1.38 \mathrm{~g}, 83 \%) .{ }^{1} \mathrm{H}$ NMR $\left(500 \mathrm{MHz}, \mathrm{CDCl}_{3}\right) \delta: 8.14(\mathrm{~d}, J=7.1 \mathrm{~Hz}, 4 \mathrm{H}), 7.75-7.68(\mathrm{~m}, 10 \mathrm{H}), 7.43(\mathrm{~d}, J=8.1 \mathrm{~Hz}, 4 \mathrm{H})$, $5.55(\mathrm{~s}, 2 \mathrm{H}), 3.96(\mathrm{~d}, J=1.9 \mathrm{~Hz}, 6 \mathrm{H}), 2.01(\mathrm{~s}, 6 \mathrm{H}) .{ }^{13} \mathrm{C} \mathrm{NMR}\left(126 \mathrm{MHz}, \mathrm{CDCl}_{3}\right) \delta: 167.0,151.8$, 151.7, 145.0, 140.2, 139.8, 138.7, 136.9, 136.7, 130.2, 130.1, 129.0, 127.1, 127.0, 122.8, 81.7, 67.3, 65.9, 52.3, 17.8. MALDI-MS: $\mathrm{m} / \mathrm{z} 886.0296\left(\right.$ Calcd m/z 886.0288 for $\left.\mathrm{M}^{+}\right)$.

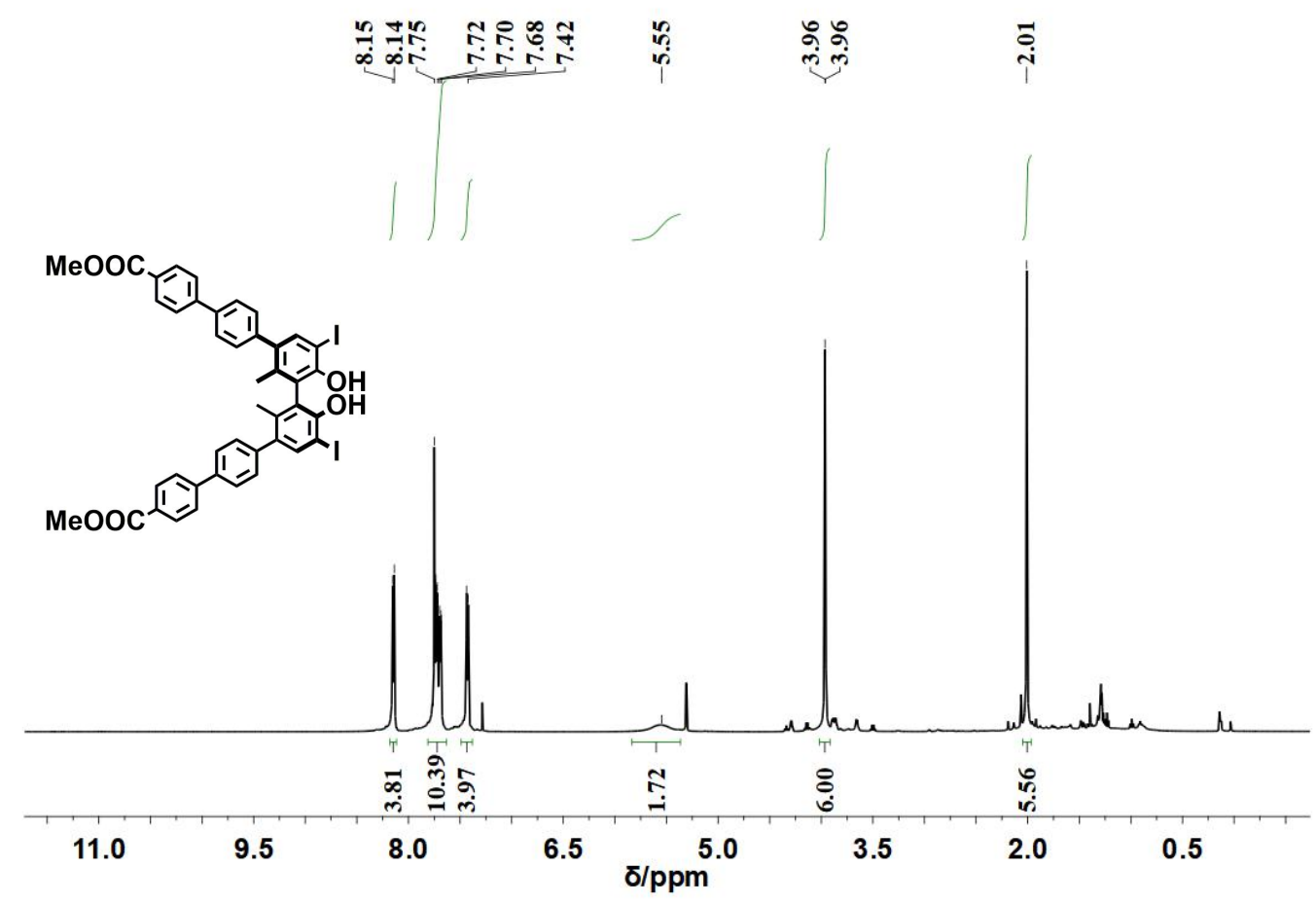




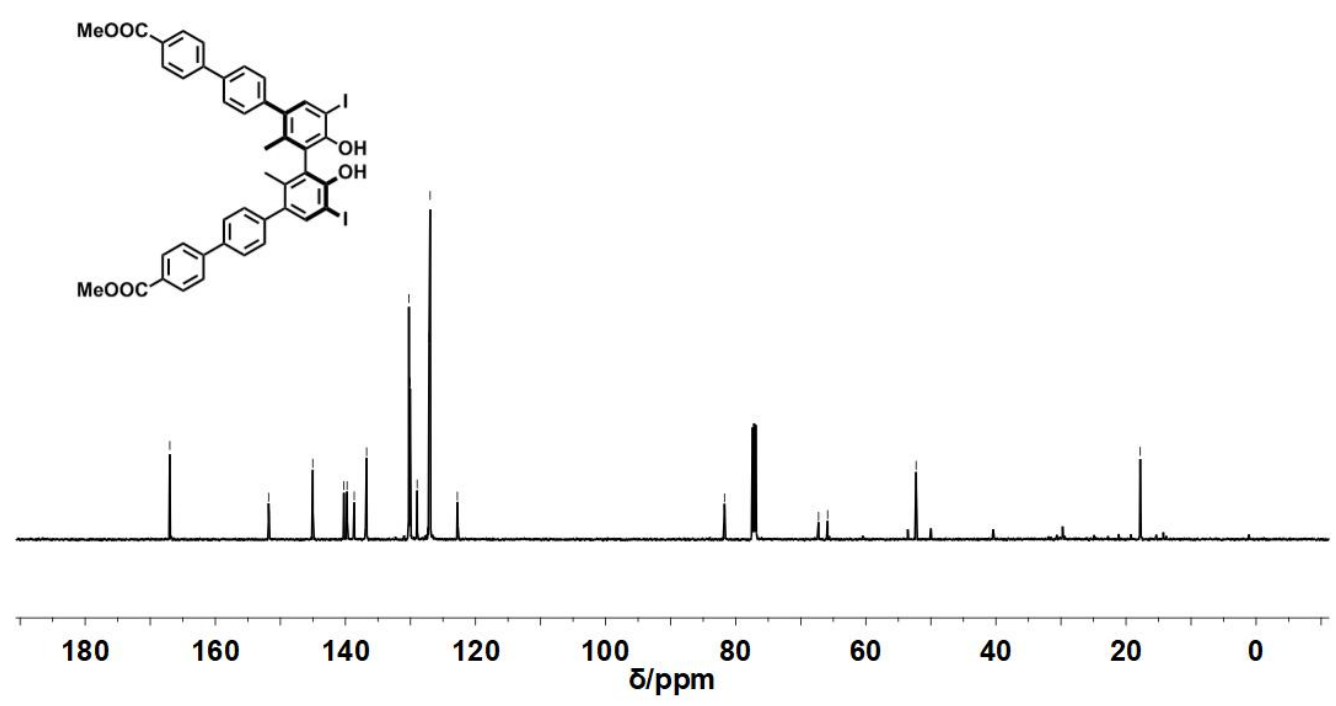

Synthesis of S5. S4 (1.77 g, $2 \mathrm{mmol})$ was dissolved in $\mathrm{CH}_{2} \mathrm{Cl}_{2}(20 \mathrm{~mL})$, and ${ }^{i} \operatorname{Pr}_{2} \mathrm{NEt}(1.98 \mathrm{~mL}$, $12 \mathrm{mmol}$ ) was added slowly. The mixture was stirred at room temperature for $10 \mathrm{~min}$, and then $\mathrm{MOMCl}(0.46 \mathrm{~mL}, 6 \mathrm{mmol})$ was added. The reaction mixture was stirred overnight, and then the saturated $\mathrm{NH}_{4} \mathrm{Cl}$ solution was added. The aqueous layer was extracted with EtOAc, and the combined organic layer was washed with brine, dried over anhydrous $\mathrm{Na}_{2} \mathrm{SO}_{4}$ and concentrated under reduced pressure. The crude product was purified by column chromatography on silica gel $\left(\mathrm{CH}_{2} \mathrm{Cl}_{2} /\right.$ petroleum, 1:1, v/v, $\left.\mathrm{R}_{\mathrm{f}}=0.35\right)$ to give $\mathbf{S 5}$ as light-yellow solid $(1.71 \mathrm{~g}, 88 \%) .{ }^{1} \mathrm{H}$ NMR $\left(500 \mathrm{MHz}, \mathrm{CDCl}_{3}\right) \delta: 8.16(\mathrm{~m}, 4 \mathrm{H}), 7.83(\mathrm{~s}, 2 \mathrm{H}), 7.72(\mathrm{dd}, J=12.0,8.4 \mathrm{~Hz}, 8 \mathrm{H}), 7.44(\mathrm{~d}, J=8.3$ $\mathrm{Hz}, 4 \mathrm{H}), 5.01(\mathrm{q}, J=6.1 \mathrm{~Hz}, 4 \mathrm{H}), 3.96(\mathrm{~s}, 6 \mathrm{H}), 3.00(\mathrm{~s}, 6 \mathrm{H}), 2.05(\mathrm{~s}, 6 \mathrm{H}) .{ }^{13} \mathrm{C}$ NMR $(126 \mathrm{MHz}$, $\left.\mathrm{CDCl}_{3}\right) \delta: 166.9,155.0,145.0,140.3,140.1,139.8,138.9,137.0,133.6,130.2,129.8,129.1,127.2$, 127.0, 99.8, 88.9, 56.6, 52.2, 18.6. MALDI-MS: m/z $974.0830\left(\right.$ Calcd m/z 974.0813 for $\mathrm{M}^{+}$). 

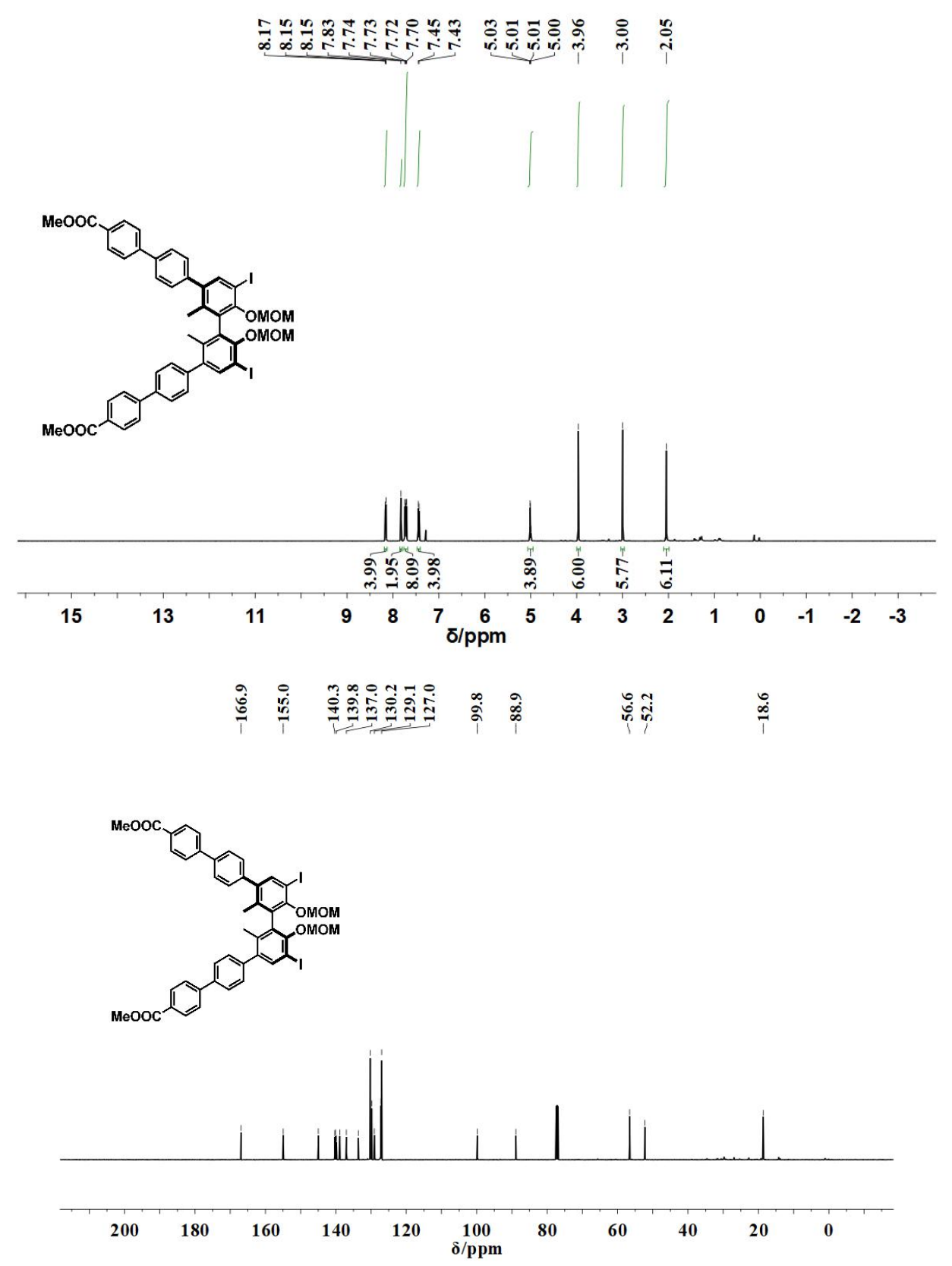

$\begin{array}{lllllllll}\text { Synthesis } & \text { of } & \text { S6. } & \text { S5 } & (1.47 \quad \text { g, } & 2.0 & \text { mmol }), & \text { methyl }\end{array}$ 4'-(4,4,5,5-tetramethyl-1,3,2-dioxaborolan-2-yl)-1,1'-biphenyl-4-carboxylate (1.87 g, $6 \mathrm{mmol}$ ), $\mathrm{K}_{2} \mathrm{CO}_{3}(2.54 \mathrm{~g}, 12 \mathrm{mmol})$ and $\mathrm{Pd}(\mathrm{dppf}) \mathrm{Cl}_{2} \cdot \mathrm{CH}_{2} \mathrm{Cl}_{2}(275 \mathrm{mg}, 0.3 \mathrm{mmol})$ were added into a $100 \mathrm{~mL}$ flame-dried round-bottom flask. The flask was degassed and refilled with $\mathrm{N}_{2}$ for three times, and then degassed toluene/EtOH $/ \mathrm{H}_{2} \mathrm{O}(3: 1: 1, \mathrm{v} / \mathrm{v} / \mathrm{v}, 60 \mathrm{~mL})$ was added. The suspension was heated at $100{ }^{\circ} \mathrm{C}$ for $24 \mathrm{~h}$. After cooling to room temperature, the resulting mixture was extracted with EtOAc. The combined organic extracts were washed with water, dried over anhydrous $\mathrm{Na}_{2} \mathrm{SO}_{4}$, and then concentrated under reduced pressure. The crude product was purified by column chromatography on silica gel (EtOAc/petroleum ether, 1:10, v/v, $\mathbf{R}_{\mathrm{f}}=0.2$ ) to afford $\mathbf{S 6}$ as a white solid (1.33 g, 70\%). ${ }^{1} \mathrm{H}$ NMR (500 MHz, $\left.\mathrm{CDCl}_{3}\right) \delta: 8.13(\mathrm{t}, J=8.5 \mathrm{~Hz}, 8 \mathrm{H}), 7.85-7.62(\mathrm{~m}, 20 \mathrm{H})$, 7.56-7.46 (m, 6H), $3.94(\mathrm{~d}, J=5.6 \mathrm{~Hz}, 12 \mathrm{H}), 2.17(\mathrm{~s}, 6 \mathrm{H}) .{ }^{13} \mathrm{C} \mathrm{NMR}\left(126 \mathrm{MHz}, \mathrm{CDCl}_{3}\right) \delta: 167.0$, 
152.2, 145.2, 145.1, 141.8, 138.8, 138.6, 138.5, 138.2, 135.9, 133.4, 131.8, 131.6, 130.2, 130.1, 129.9, 129.0, 127.1, 127.0, 126.9, 98.8, 56.2, 52.2, 18.8. MALDI-MS: m/z 1142.4236 (Calcd m/z 1142.4241 for $\mathrm{M}^{+}$).
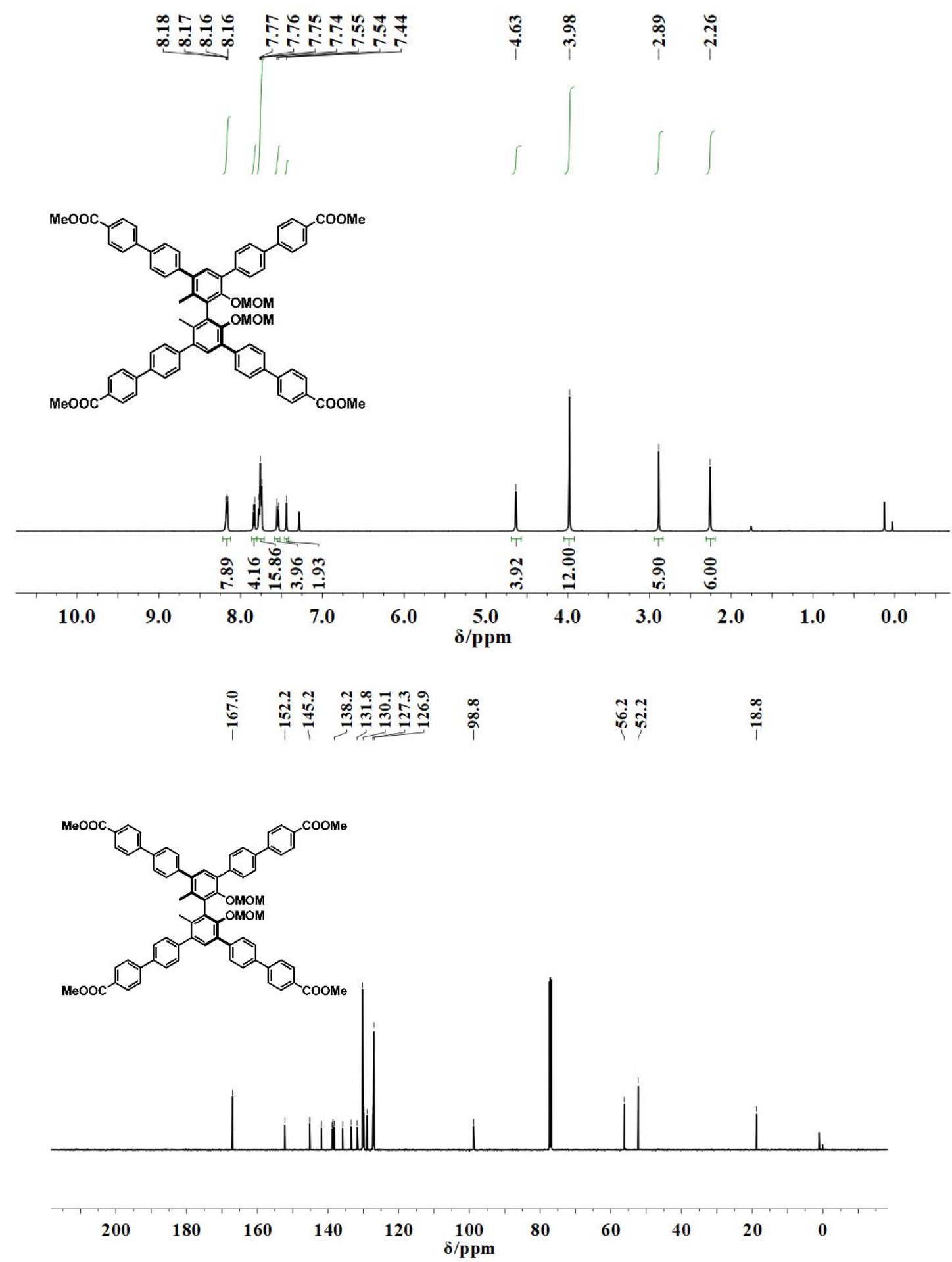

Synthesis of S7. To a solution of $\mathbf{S 6}(2.29 \mathrm{~g}, 2 \mathrm{mmol})$ in $\mathrm{CH}_{2} \mathrm{Cl}_{2}(30 \mathrm{~mL})$ was added $\mathrm{CF}_{3} \mathrm{COOH}$ ( $3 \mathrm{~mL}, 40 \mathrm{mmol}$ ) slowly. The mixture was stirred at room temperature overnight. After that, saturated $\mathrm{NaHCO}_{3}$ solution was added and the reaction mixture was stirred for $30 \mathrm{~min}$. The aqueous layer was extracted with $\mathrm{CH}_{2} \mathrm{Cl}_{2}$ and the combined organic layer was washed with 
saturated $\mathrm{Na}_{2} \mathrm{~S}_{2} \mathrm{O}_{3}$ solution and brine, dried over $\mathrm{Na}_{2} \mathrm{SO}_{4}$ and concentrated under reduced pressure. The crude product was purified by column chromatography on silica gel (EtOAc/petroleum ether, $\left.1: 10, \mathrm{v} / \mathrm{v}, \mathrm{R}_{\mathrm{f}}=0.32\right)$ to afford $\mathbf{S} 7$ as a light-yellow solid $(1.9 \mathrm{~g}, 90 \%) .{ }^{1} \mathrm{H}$ NMR (500 MHz, $\mathrm{CDCl}_{3}$ ) $\delta: 8.15(\mathrm{dd}, J=16.6,7.2 \mathrm{~Hz}, 8 \mathrm{H}), 7.82(\mathrm{t}, J=10.6 \mathrm{~Hz}, 4 \mathrm{H}), 7.75(\mathrm{~m}, 16 \mathrm{H}), 7.55(\mathrm{~m}, 6 \mathrm{H}), 5.52(\mathrm{~s}$, 2H), 3.95 (t, $J=9.2 \mathrm{~Hz}, 12 \mathrm{H}), 2.21(\mathrm{~s}, 6 \mathrm{H}) .{ }^{13} \mathrm{C} \mathrm{NMR}\left(126 \mathrm{MHz}, \mathrm{CDCl}_{3}\right) \delta 167.0,150.1,145.1$, 141.4, 138.9, 138.4, 137.4, 135.8, 135.4, 132.6, 130.2, 130.2, 129.9, 128.9, 127.4, 127.1, 127.0, 125.8, 122.2, 52.2, 18.0. MALDI-MS: m/z $1054.3670\left(\right.$ Calcd m/z 1054.3717 for $\left.\mathrm{M}^{+}\right)$.

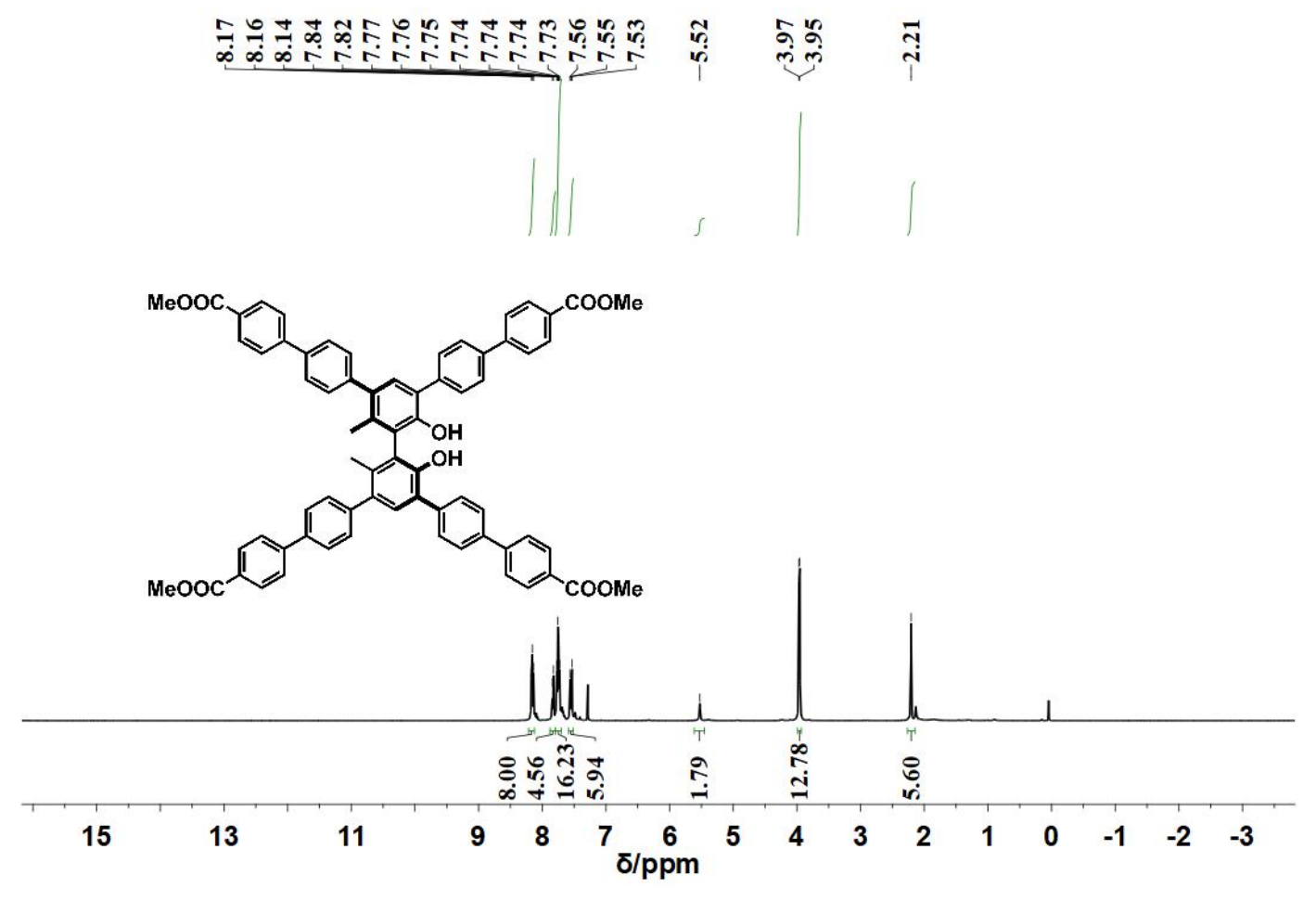




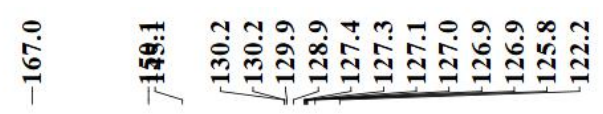

iี
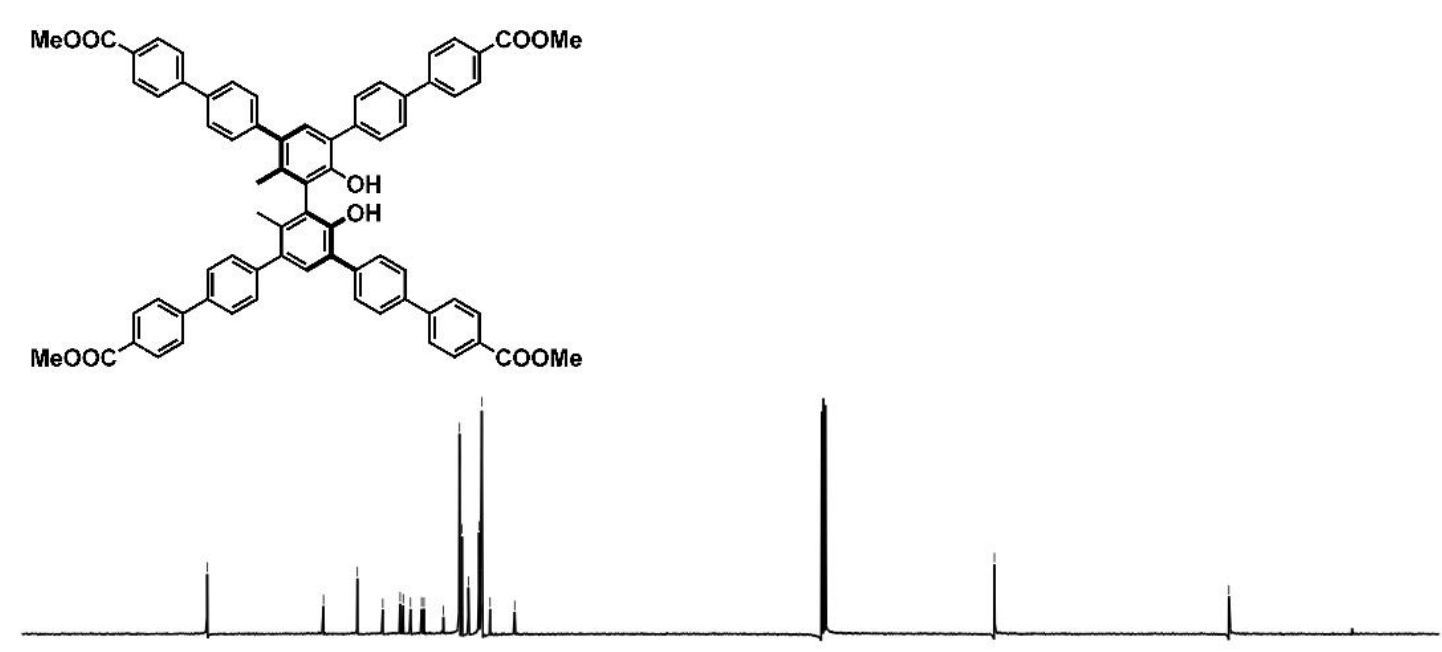

\begin{tabular}{|c|c|c|c|c|c|c|c|c|c|c|c|c|c|}
\hline 190 & 170 & 150 & 130 & 110 & $\underset{\delta / p p m}{90} 80$ & 70 & 60 & 50 & 40 & 30 & 20 & 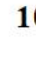 & 0 \\
\hline
\end{tabular}

Synthesis of (S)-Me $\mathbf{L}^{3}$. S7 (2.10 g, $\left.2.0 \mathrm{mmol}\right)$ and $60 \%$ wt. NaH (176 mg, $\left.4.4 \mathrm{mmol}\right)$ were added into a $100 \mathrm{~mL}$ three-necked round-bottom flask. The flask was degassed for three times and refilled with $\mathrm{N}_{2}$ for three times, and then $50 \mathrm{~mL}$ THF was added. After stirring for $15 \mathrm{~min}$, a solution of pentaethylene glycol ditosylate $(1.31 \mathrm{~g}, 2.4 \mathrm{mmol})$ in THF $(25 \mathrm{~mL})$ was slowly added. Then the mixture was allowed to reflux overnight. After cooling to room temperature, the mixture was extracted with EtOAc. The combined extracts were washed with water, dried over anhydrous $\mathrm{Na}_{2} \mathrm{SO}_{4}$, and then concentrated under reduced pressure. The crude product was purified by column chromatography on silica gel (EtOAc/petroleum ether, 1:1, v/v) to give $(S)-\mathrm{Me}_{4} \mathbf{L}^{3}$ as a white solid (1.38 g, 55\%). ${ }^{1} \mathrm{H}$ NMR (400 MHz, $\left.\mathrm{CDCl}_{3}\right) \delta 8.13(\mathrm{dd}, \mathrm{J}=8.4,2.9 \mathrm{~Hz}, 8 \mathrm{H}), 7.84(\mathrm{~d}, \mathrm{~J}=8.3 \mathrm{~Hz}$, 4H), $7.73(\mathrm{~m}, 16 \mathrm{H}), 7.51(\mathrm{~d}, \mathrm{~J}=8.2 \mathrm{~Hz}, 4 \mathrm{H}), 7.41(\mathrm{~s}, 2 \mathrm{H}), 3.95(\mathrm{~s}, 12 \mathrm{H}), 3.84(\mathrm{~m}, 2 \mathrm{H}), 3.66(\mathrm{~m}$, $2 \mathrm{H}), 3.53(\mathrm{~m}, 6 \mathrm{H}), 3.39(\mathrm{~m}, 10 \mathrm{H}), 2.15(\mathrm{~s}, 6 \mathrm{H}) .{ }^{13} \mathrm{C} \mathrm{NMR}\left(101 \mathrm{MHz}, \mathrm{CDCl}_{3}\right) \delta 167.2,154.1$, $145.5,145.4,142.1,139.0,138.8,138.6,138.1,135.3,133.3,131.7,131.6,130.4,130.1,129.1$, $129.1,127.4,127.3,127.2,127.1,71.9,70.9,70.8,70.6,70.3,52.4,18.8$. MALDI-MS: $\mathrm{m} / \mathrm{z}$ 1279.4814 (Calcd m/z 1279.4820 for $\left.[\mathrm{M}+\mathrm{Na}]^{+}\right)$. 

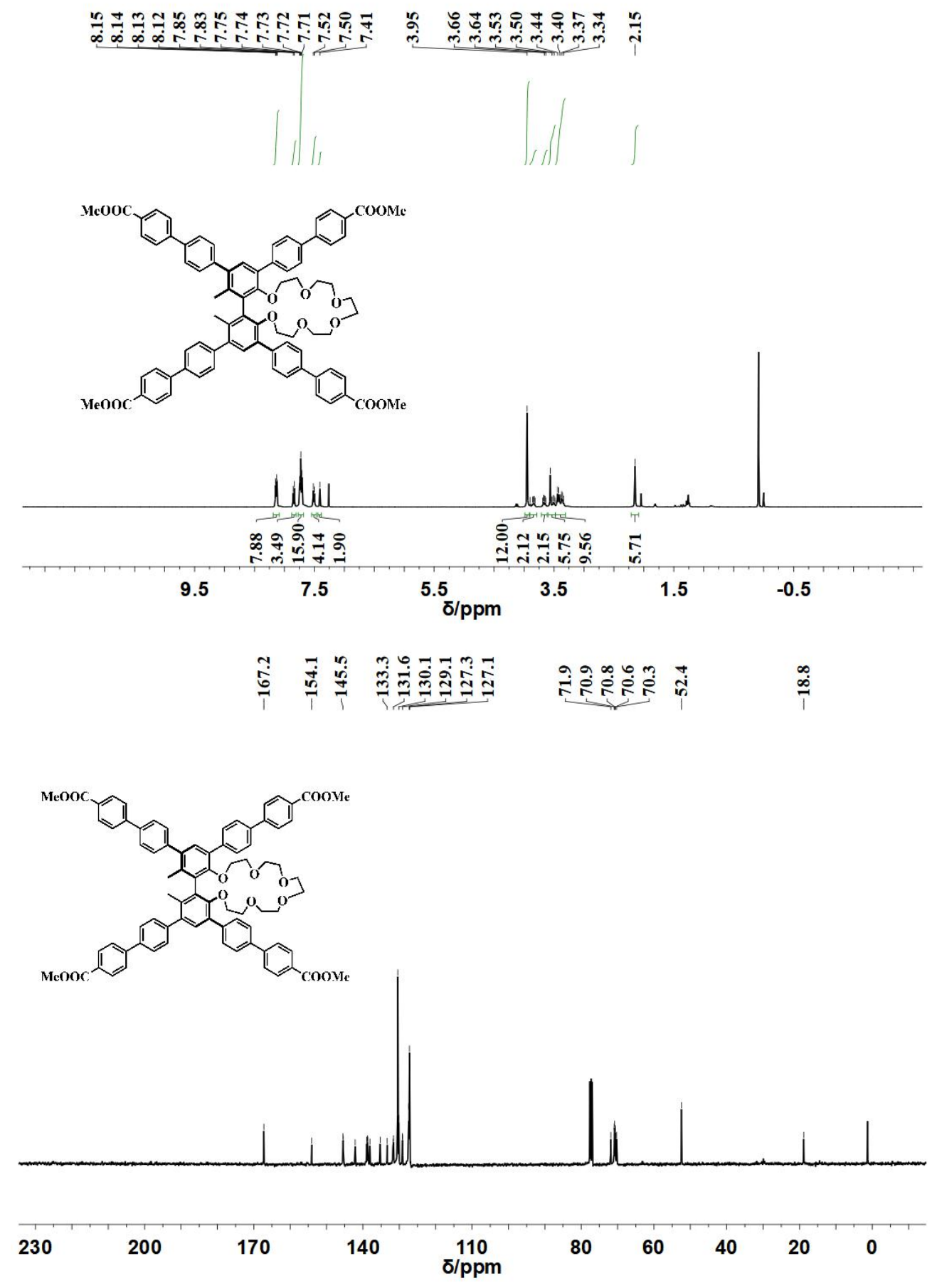

Synthesis of $(\boldsymbol{S})-\mathbf{H}_{4} \mathbf{L}^{3}$. A solution of $\mathrm{Me}_{4} \mathbf{L}^{3}(2.50 \mathrm{~g}, 2.0 \mathrm{mmol})$, and $\mathrm{LiOH} \cdot \mathrm{H}_{2} \mathrm{O}(1.68 \mathrm{~g}, 40$ mmol) in THF $(15 \mathrm{~mL}), \mathrm{MeOH}(45 \mathrm{~mL})$ and $\mathrm{H}_{2} \mathrm{O}(45 \mathrm{~mL})$ was heated at $75{ }^{\circ} \mathrm{C}$ for $6 \mathrm{~h}$. The solution was cooling to room temperature, acidified to $\mathrm{pH}=1 \sim 2$ with $6 \mathrm{M} \mathrm{HCl}$ and extracted with EtOAc. The organic phase was dried over $\mathrm{Na}_{2} \mathrm{SO}_{4}$ and the solvent was evaporated under reduced pressure to give (S)- $\mathrm{H}_{4} \mathbf{L}^{3}$ as a white solid (, $\left.2.20 \mathrm{~g}, 92 \%\right),{ }^{1} \mathrm{H}$ NMR (400 MHz, DMSO- $\left.d^{6}\right) \delta$ : 12.98(s, 4H), 8.03-7.98 (m, 8H), 7.81-7.73 (m, 20H), 7.47-7.26 (m, 6H), 3.77-3.24 (m, 20H), 
2.01-1.91 (m, 6H). ${ }^{13} \mathrm{C}$ NMR (101 MHz, DMSO- $\left.d^{6}\right) \delta: 167.8,154.2,144.6,144.5,141.8,138.9$, $138.3,138.0,138.0,134.9,133.5,131.6,130.6,130.4,130.24,130.20,127.6,127.3,72.0,70.5$, 70.3, 69.8, 18.8. ESI-MS: m/z $1223.4286\left(\right.$ Calcd m/z 1223.4194 for $\left.\left[\mathrm{H}_{4} \mathbf{L}^{3}+\mathrm{Na}\right]^{+}\right)$.
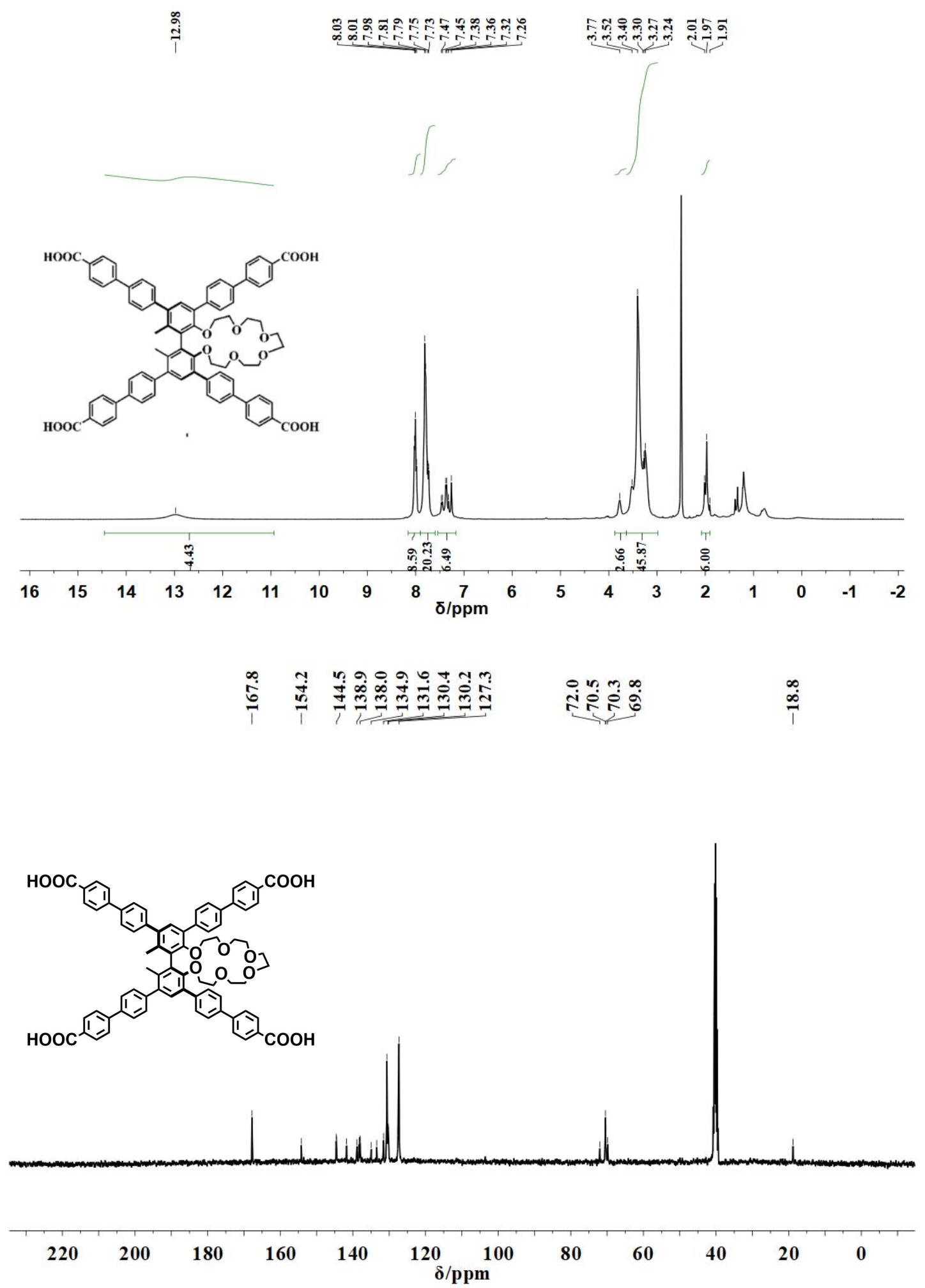
2.4 Synthesis of $(S)-\mathrm{H}_{4} \mathrm{~L}^{4}$

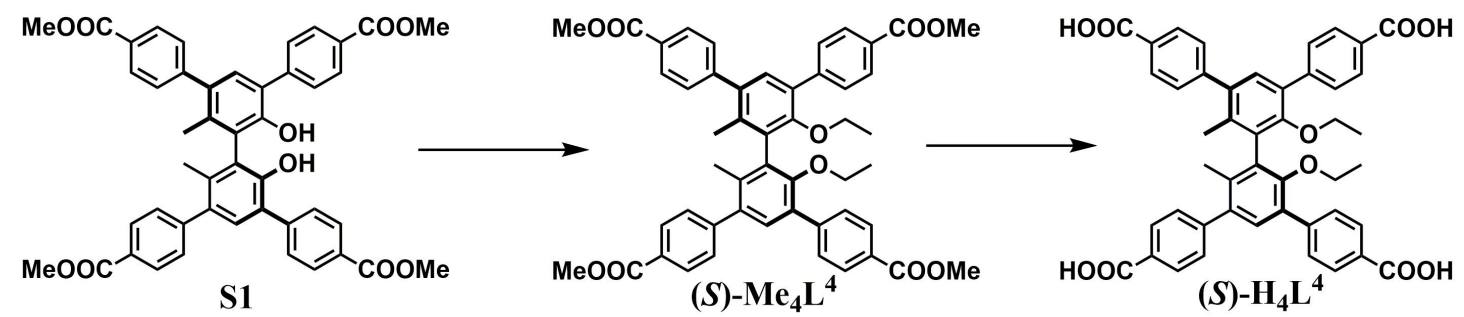

Synthesis of $(\boldsymbol{S})-\mathbf{M e}_{4} \mathbf{L}^{4}$. To a mixture of $\mathbf{S} 1(1.5 \mathrm{~g}, 2 \mathrm{mmol})$ and $\mathrm{K}_{2} \mathrm{CO}_{3}(1.7 \mathrm{~g}, 12 \mathrm{mmol})$ in acetone $(30 \mathrm{~mL})$ was added $\mathrm{EtBr}(0.45 \mathrm{~mL}, 6 \mathrm{mmol})$ slowly. The mixture was heated at $70{ }^{\circ} \mathrm{C}$ overnight. After cooling to room temperature, the mixture was concentrated under reduced pressure. The resulting solid was dissolved in EtOAc, washed with brine, and dried over anhydrous $\mathrm{Na}_{2} \mathrm{SO}_{4}$. The solvent was evaporated under reduced pressure to give $(S)-\mathrm{Me}_{4} \mathbf{L}^{4}$ as a white solid (1.5 g, 93\%). ${ }^{1} \mathrm{H}$ NMR $\left(400 \mathrm{MHz}, \mathrm{CDCl}_{3}\right) \delta 8.09(\mathrm{t}, J=7.7 \mathrm{~Hz}, 8 \mathrm{H}), 7.73(\mathrm{~d}, J=8.2$ $\mathrm{Hz}, 4 \mathrm{H}), 7.45(\mathrm{~d}, J=8.1 \mathrm{~Hz}, 4 \mathrm{H}), 7.26(\mathrm{~s}, 2 \mathrm{H}), 3.94(\mathrm{~d}, J=3.4 \mathrm{~Hz}, 12 \mathrm{H}), 3.50(\mathrm{~m}, 2 \mathrm{H}), 3.37(\mathrm{~m}$, 2H), $2.05(\mathrm{~s}, 6 \mathrm{H}), 0.84(\mathrm{t}, J=6.8 \mathrm{~Hz}, 6 \mathrm{H}) .{ }^{13} \mathrm{C} \mathrm{NMR}\left(101 \mathrm{MHz}, \mathrm{CDCl}_{3}\right) \delta 162.54,162.47,149.7$, 142.1, 139.1, 132.9, 130.8, 128.8, 126.8, 126.6, 125.0, 124.6, 124.2, 64.1, 47.6, 13.9, 11.0.

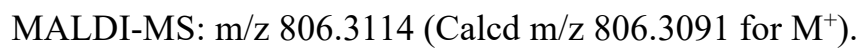

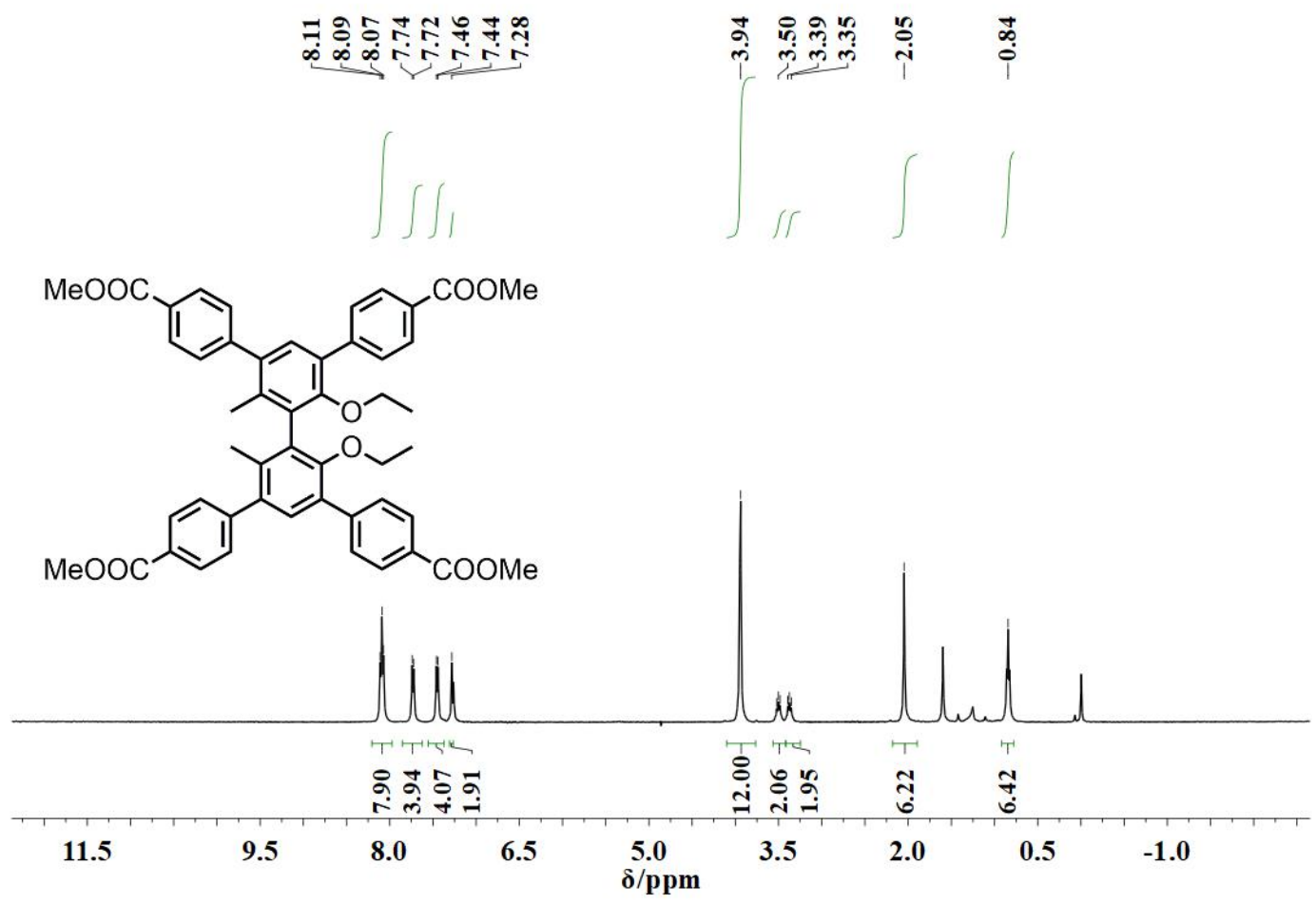




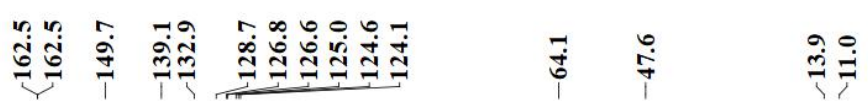

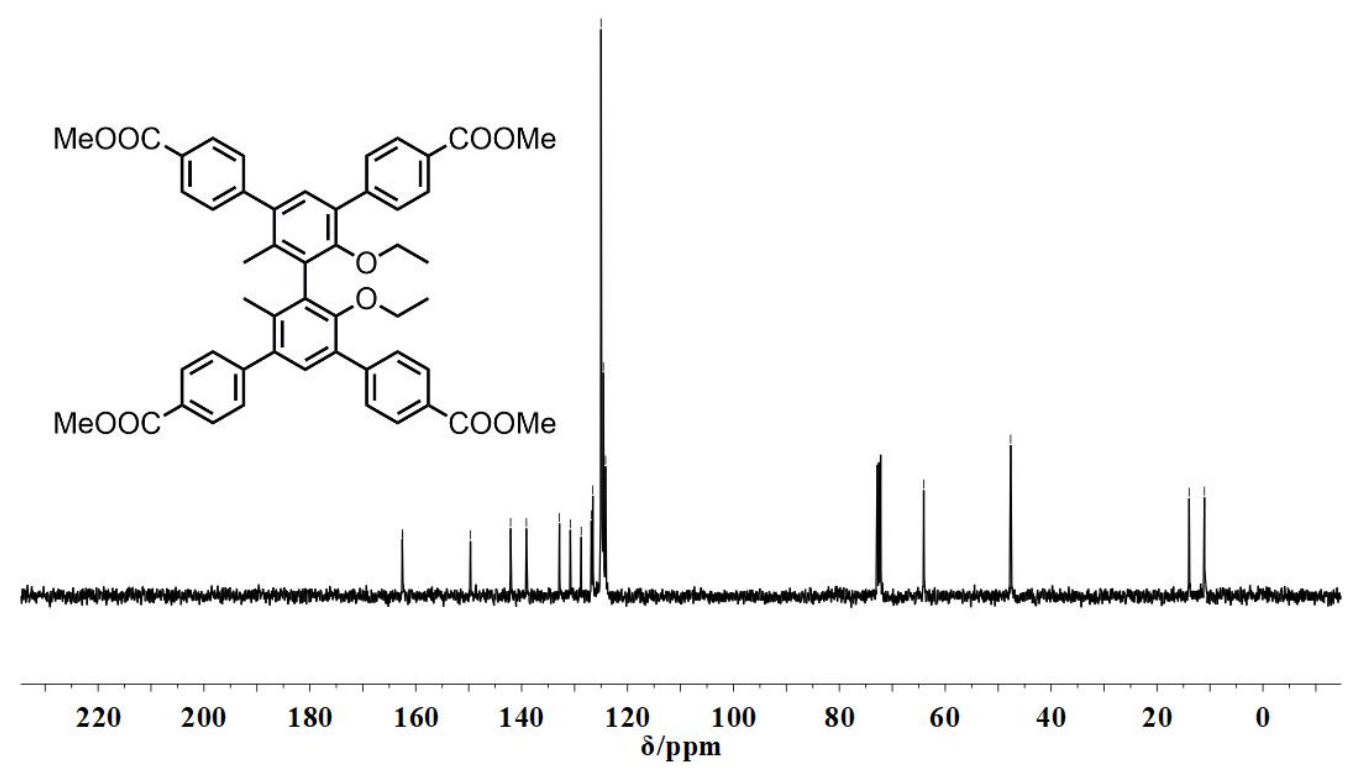

Synthesis of $(\boldsymbol{S})-\mathbf{H}_{4} \mathbf{L}^{4}$. A solution of $(S)-\mathrm{Me}_{4} \mathbf{L}^{4}(1.60 \mathrm{~g}, 2.0 \mathrm{mmol})$, and $\mathrm{LiOH} \cdot \mathrm{H}_{2} \mathrm{O}(1.68 \mathrm{~g}, 40$ mmol) in THF $(15 \mathrm{~mL})$, $\mathrm{MeOH}(45 \mathrm{~mL})$ and $\mathrm{H}_{2} \mathrm{O}(45 \mathrm{~mL})$ was heated at $75{ }^{\circ} \mathrm{C}$ for $6 \mathrm{~h}$. The solution was cooling to room temperature, acidified to $\mathrm{pH}=1 \sim 2$ with $6 \mathrm{M} \mathrm{HCl}$ and extracted with EtOAc. The organic phase was dried over anhydrous $\mathrm{Na}_{2} \mathrm{SO}_{4}$ and the solvent was evaporated under reduced pressure to give $(S)-\mathrm{H}_{4} \mathbf{L}^{4}$ as a white solid $(1.40 \mathrm{~g}, 95 \%) .{ }^{1} \mathrm{H}$ NMR (400 $\mathrm{MHz}$, DMSO- $\left.d^{6}\right) \delta 12.99(\mathrm{~s}, 4 \mathrm{H}), 8.02(\mathrm{dd}, J=8.4,3.0 \mathrm{~Hz}, 8 \mathrm{H}), 7.77$ (d, $\left.J=8.4 \mathrm{~Hz}, 4 \mathrm{H}\right), 7.55$ (d, $J=$ $8.2 \mathrm{~Hz}, 4 \mathrm{H}), 7.32(\mathrm{~s}, 2 \mathrm{H}), 3.48$ (dt, $J=15.9,7.0 \mathrm{~Hz}, 4 \mathrm{H}), 3.35$ (dt, $J=16.0,7.0 \mathrm{~Hz}, 4 \mathrm{H}), 2.01$ (s, $6 \mathrm{H}), 0.78(\mathrm{t}, J=7.0 \mathrm{~Hz}, 6 \mathrm{H}) .{ }^{13} \mathrm{C}$ NMR $\left(101 \mathrm{MHz}, \mathrm{DMSO}-d^{6}\right) \delta 167.9,154.4,146.2,143.3,137.7$, 135.5, 133.6, 131.6, 130.2, 130.1, 129.6, 68.9, 18.9, 16.0. MALDI-MS: m/z 750.2460 (Calcd m/z 750.2065 for $\mathrm{M}^{+}$). 


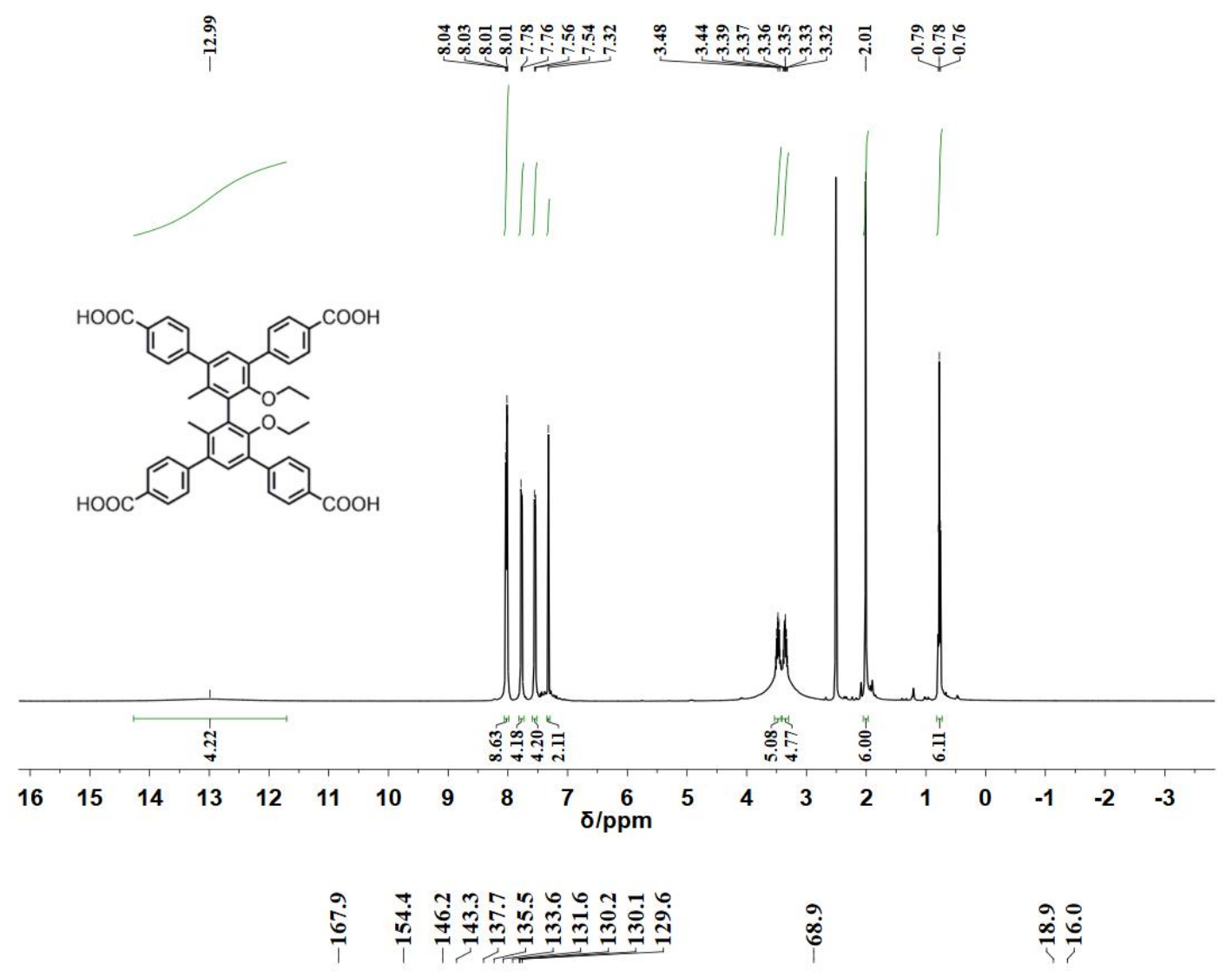<smiles>CCOc1c(-c2ccc(C(=O)O)cc2)cc(-c2ccc(C(=O)O)cc2)c(C)c1-c1c(C)c(-c2ccc(C(=O)O)cc2)c(C)c(-c2ccc(C(=O)O)cc2)c1OCC</smiles>

220 180 160 140 120
$\delta / p p m$ $80 \quad 60$ $40 \quad 20 \quad 0$ 
2.5 Synthesis of the bulky analyte ${ }^{[4]}$

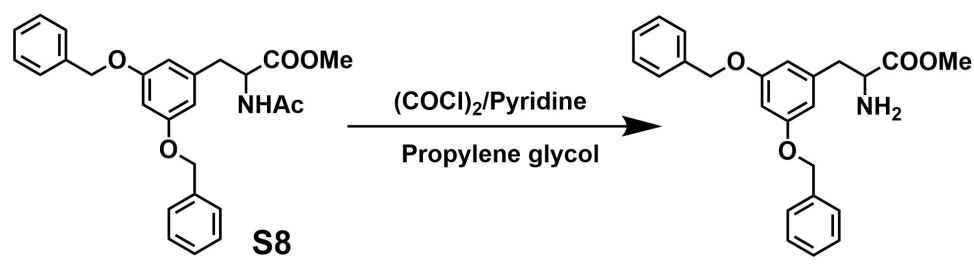

$\mathbf{S 8}$ was synthesized according to our previous report. ${ }^{[3]} \mathrm{A}$ solution of $\mathbf{S 8}(217 \mathrm{mg}, 0.5 \mathrm{mmol})$ in dry THF $(2.0 \mathrm{~mL})$ was treated with pyridine $(0.05 \mathrm{~mL}, 0.6 \mathrm{mmol})$ and cooled to $0{ }^{\circ} \mathrm{C}$. Then, oxalyl chloride $(0.05 \mathrm{~mL}, 0.55 \mathrm{mmol})$ was added dropwise to form a yellow slurry. After stirring at $0{ }^{\circ} \mathrm{C}$ for $30 \mathrm{~min}$., dry propylene glycol $(0.07 \mathrm{~mL}, 1.0 \mathrm{mmol})$ was added in one portion and the reaction warmed to room temperature. The mixture was heated to $60^{\circ} \mathrm{C}$ and treated with $0.3 \mathrm{~mL} \mathrm{MeOH}$ to form an orange solution. Upon cooling to $50{ }^{\circ} \mathrm{C}$, MTBE was added slowly before cooling to room temperature. The resulting slurries were filtered off and washed with MTBE. The resulting solid was dissolved in $2 \mathrm{M} \mathrm{NaOH}$ (aq.), and then was extracted by EtOAc. The combined extracts were washed with brine, dried over anhydrous $\mathrm{Na}_{2} \mathrm{SO}_{4}$, and then concentrated under reduced pressure to give the 3,5-dibenzyloxy-1-phenylalanine methyl ester as a white solid (141 mg, 73\%). ${ }^{1} \mathrm{H}$ NMR $\left(400 \mathrm{MHz}, \mathrm{CDCl}_{3}\right) \delta 7.46-7.35(\mathrm{~m}, 10 \mathrm{H}), 6.55(\mathrm{t}, J=2.1 \mathrm{~Hz}, 1 \mathrm{H}), 6.48(\mathrm{~d}, J=2.2 \mathrm{~Hz}, 2 \mathrm{H}), 5.04(\mathrm{~s}, 4 \mathrm{H})$, 3.84-3.72 (m, 1H), $3.74(\mathrm{~s}, 4 \mathrm{H}), 3.08(\mathrm{dd}, J=13.4,4.5 \mathrm{~Hz}, 1 \mathrm{H}), 2.81(\mathrm{dd}, J=13.4,8.1 \mathrm{~Hz}, 1 \mathrm{H}), 1.84(\mathrm{~s}$, 2H). ${ }^{13} \mathrm{C}$ NMR $\left(101 \mathrm{MHz}, \mathrm{CDCl}_{3}\right) \delta 175.4,160.3,139.7,137.0,128.8,128.2,127.8,108.7,100.8$, 70.3, 55.8, 52.3, 41.5. MALDI-MS: m/z 392.1849 (Calcd m/z 391.1856 for $\left.[\mathrm{M}+\mathrm{H}]^{+}\right)$.

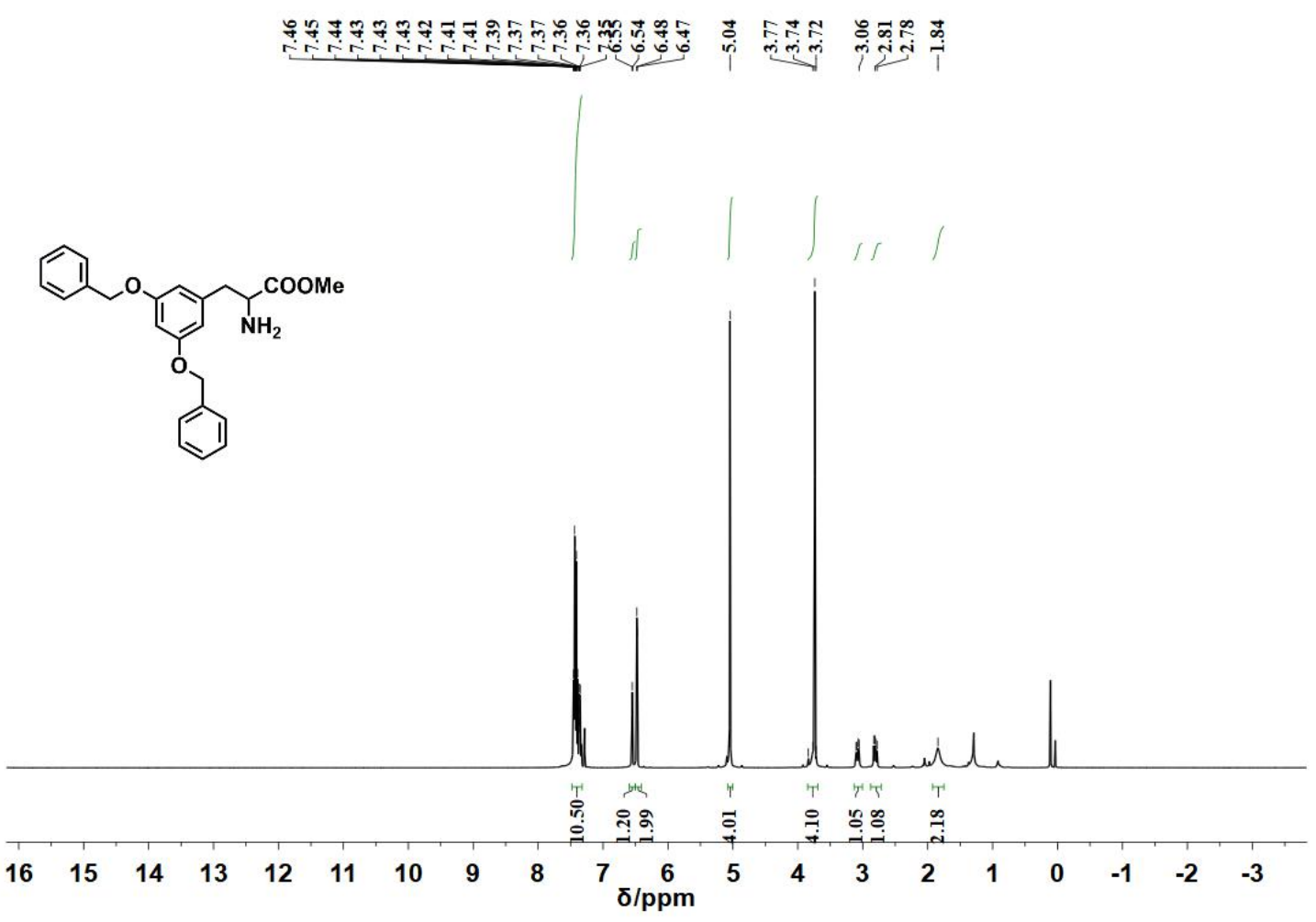




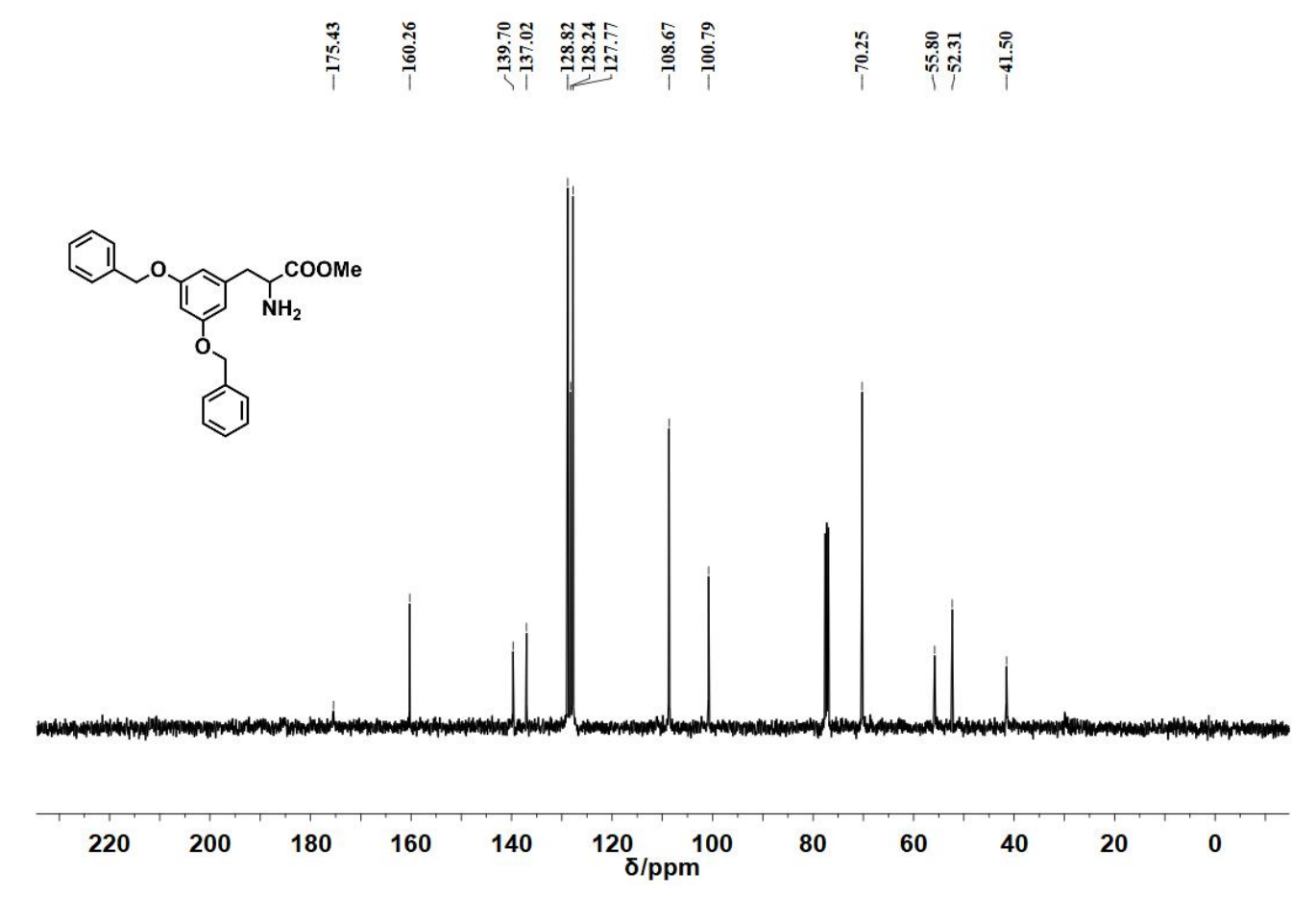

\subsection{Synthesis of MOFs}

Synthesis of CE-1. A mixture of $\mathrm{ZrOCl}_{2} \cdot 8 \mathrm{H}_{2} \mathrm{O}(10 \mathrm{mg}, 0.03 \mathrm{mmol}), \mathrm{H}_{4} \mathbf{L}^{1}(9 \mathrm{mg}, 0.01 \mathrm{mmol})$, DMF $(2.0 \mathrm{~mL})$, and $\mathrm{HCOOH}(1.0 \mathrm{~mL})$ was sealed in a $15 \mathrm{~mL}$ vial with a screw cap and heated at $120^{\circ} \mathrm{C}$ for $24 \mathrm{~h}$. Colorless polyhedral crystals were collected, washed with DMF and acetone, and dried in air. Yield: $90 \%$. Elemental Analysis data of CE-1: Calcd for $\mathrm{C}_{104} \mathrm{H}_{104} \mathrm{O}_{44} \mathrm{Zr}_{6}: \mathrm{C}, 47.95 ; \mathrm{H}$, 4.02; Found: C, 48.11; H, 3.85. FT-IR (KBr, cm-1): 3414(m), 2927(w), 2867(w), 1612(s), 1399(s), 1246(w), 1108(m), 1049(w), 946(w), 865(w), 783(w), 719(w), 653(s), 474(m).

Synthesis of CE-2. A mixture of $\mathrm{ZrOCl}_{2} 8 \mathrm{H}_{2} \mathrm{O}(10 \mathrm{mg}, 0.03 \mathrm{mmol}), \mathrm{H}_{4} \mathbf{L}^{2}(11 \mathrm{mg}, 0.01 \mathrm{mmol})$, DMF $(2 \mathrm{~mL})$, and $\mathrm{HCOOH}(1 \mathrm{~mL})$ was sealed in a $15 \mathrm{~mL}$ vial with a screw cap and heated at 120 ${ }^{\circ} \mathrm{C}$ for $24 \mathrm{~h}$. Colorless polyhedral crystals were obtained, washed with DMF and acetone, and dried in air. Yield: 88\%. Elemental Analysis data of CE-2: Calcd for $\mathrm{C}_{136} \mathrm{H}_{120} \mathrm{O}_{44} \mathrm{Zr}_{6}$ : C, 54.35; H, 4.02; Found: C, 54.74; H, 4.08. FT-IR (KBr, $\left.\mathrm{cm}^{-1}\right)$ : 3419(m), 2927(w), 2865(w), 1658(s), 1607(s), 1416(s), 1386(s), 1250(w), 1099(s), 918(w), 825(m), 758(s), 662(s), 485(m).

Synthesis of CE-3. A mixture of $\mathrm{ZrOCl}_{2} \cdot 8 \mathrm{H}_{2} \mathrm{O}(10 \mathrm{mg}, 0.03 \mathrm{mmol}), \mathrm{H}_{4} \mathbf{L}^{3}(12 \mathrm{mg}, 0.01 \mathrm{mmol})$, DMF $(2 \mathrm{~mL})$, and $\mathrm{CF}_{3} \mathrm{COOH}(0.2 \mathrm{~mL})$ was sealed in a $15 \mathrm{~mL}$ vial with a screw cap and heated at $120{ }^{\circ} \mathrm{C}$ for $24 \mathrm{~h}$. Colorless polyhedral crystals were obtained, washed with DMF and acetone, and dried in air. Yield: $85 \%$. Elemental Analysis data of CE-3: Calcd for $\mathrm{C}_{152} \mathrm{H}_{136} \mathrm{O}_{44} \mathrm{Zr}_{6}$ : C, 56.80; H, 
4.27; Found: C, 57.23; H, 4.32. FT-IR (KBr, $\left.\mathrm{cm}^{-1}\right)$ : 3413(m), 2927(w), 2863(w), 1598(s), 1559(s), 1513(w), 1467(w), 1426(s), 1374(s), 1099(s), 951(w), 863(w), 781(s), 646(s), 449(m).

Synthesis of OET-1. A mixture of $\mathrm{ZrOCl}_{2} \cdot 8 \mathrm{H}_{2} \mathrm{O}(10 \mathrm{mg}, 0.03 \mathrm{mmol}), \mathrm{H}_{4} \mathbf{L}^{4}(12 \mathrm{mg}, 0.01 \mathrm{mmol})$, DMF $(2 \mathrm{~mL})$, and $\mathrm{HCOOH}(1.0 \mathrm{~mL})$ was sealed in a $15 \mathrm{~mL}$ vial with a screw cap and heated at $120^{\circ} \mathrm{C}$ for $24 \mathrm{~h}$. Colorless polyhedral crystals were obtained, washed with DMF and acetone, and dried in air. Yield: $92 \%$. Elemental Analysis data of OET-1: Calcd for $\mathrm{C}_{92} \mathrm{H}_{84} \mathrm{O}_{36} \mathrm{Zr}_{6}$ : C, 47.77; H, 3.66; Found: C, 47.69; H, 3.56. FT-IR (KBr, $\left.\mathrm{cm}^{-1}\right)$ : 3422(s), 2916(m), 2848(m), 1660(s), 1606(s), 1536(w), 1510(w), 1413(s), 1384(w), 1302(w), 1211(w), 1180(w), 1100(m), 1052(m), 1019(w), 866(w), 789(m), 758(w), 716(m), 656(s), 477(m).

\section{General procedure for column packing}

The MOF-based CSP for HPLC was fabricated by the upward stirred slurry method. Before packing into the HPLC column, the MOF powders were ground in a mortal. Then, a mixture of Zr-MOF $(\sim 200 \mathrm{mg})$ and $\mathrm{C}_{18}$ silica gel $(\sim 800 \mathrm{mg})$ was stirred in $\mathrm{MeOH}$ to form a uniform suspension. The filtration MOF-silica mixture was dried under vacuum. And then, a suspension of MOF-silica mixture in $25 \mathrm{~mL} \mathrm{H} \mathrm{H}_{2} \mathrm{O} / \mathrm{MeOH}(9 / 1, \mathrm{v} / \mathrm{v})$ was slurry-packed into a $25 \mathrm{~cm}$ long, $2.1 \mathrm{~mm}$ i.d. stainless steel column by the chromatographic column packing machine (see the picture below) under 40-50 MPa. By varying the pressure to press the slurry into the column, the solid disposed slowly to achieve a better packing, and then the MOF column was obtained. The column was rinsed and equilibrated with the mobile phase before use. HPLC experiments were performed at $25^{\circ} \mathrm{C}$ with a Shimadzu HPLC system (Shimadzu Corporation, Kyoto, Japan). It consists of a 20-A pumps and a variable wavelength ultraviolet detector. The wavelength of ultraviolet detection was $220 \mathrm{~nm}$.

Separation factor $(\alpha)$ and resolution factor $\left(R_{s}\right)$ were obtained from the following equations:

$$
\alpha=\left(\mathrm{t}_{\mathrm{R} 2}-\mathrm{t}_{\mathrm{m}}\right) /\left(\mathrm{t}_{\mathrm{R} 1}-\mathrm{t}_{\mathrm{m}}\right) \quad R_{s}=2\left(\mathrm{t}_{\mathrm{R} 2}-\mathrm{t}_{\mathrm{R} 1}\right) /\left(w_{1}+w_{2}\right)
$$

Where $t_{R 1}$ and $t_{R 2}$ represent the retention times of right-handed or left-handed enantiomers $\left(t_{R 2}>\right.$ $\mathrm{t}_{\mathrm{R} 1}$ ), and $w_{1}$ and $w_{2}$ are the widths of the bases formed by triangulation of the peaks, respectively. The column void time $t_{\mathrm{m}}$ is determined by using 1,3,5-tri-tert-butylbenzene as analyte. 


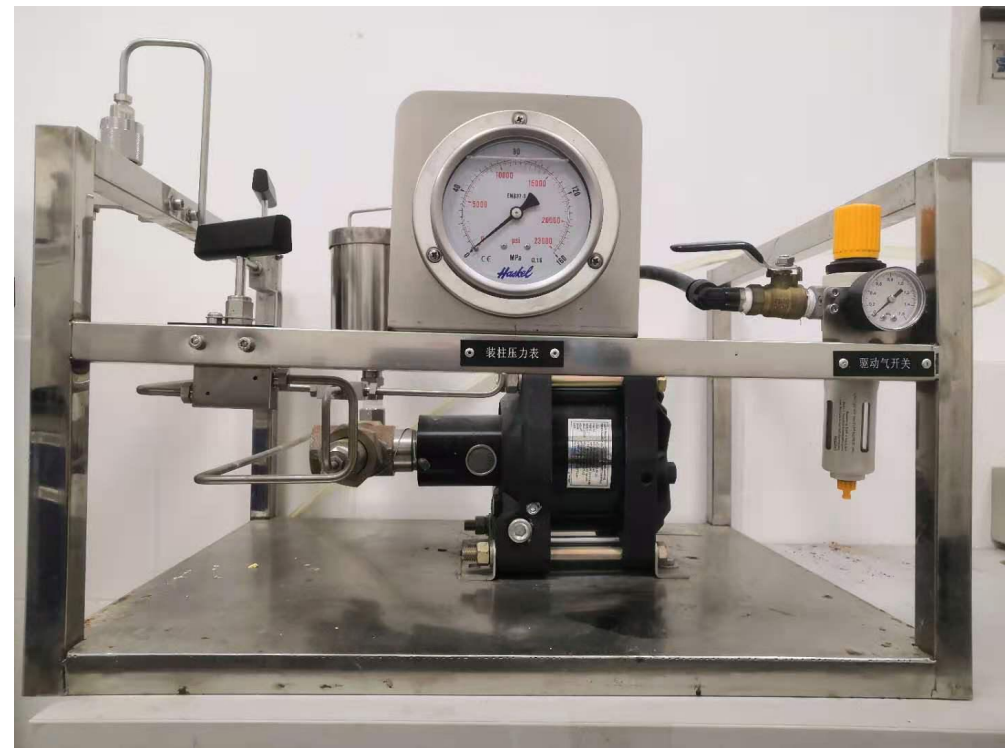

4. Figures S1-S4. ${ }^{1} \mathrm{H}$ NMR of digested MOFs

Figure S1. ${ }^{1} \mathrm{H}$ NMR of digested CE-1

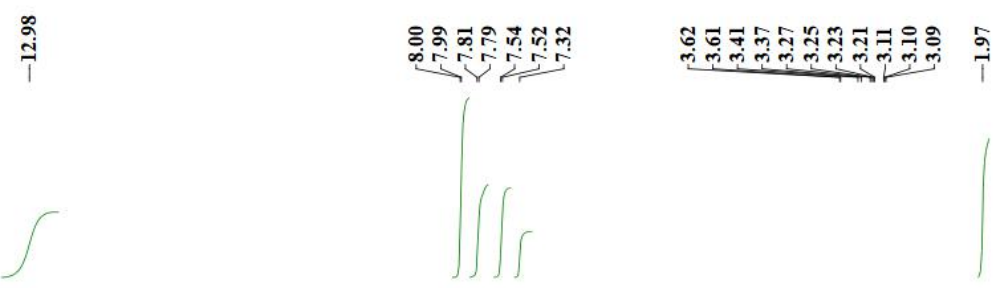

Crown ether group

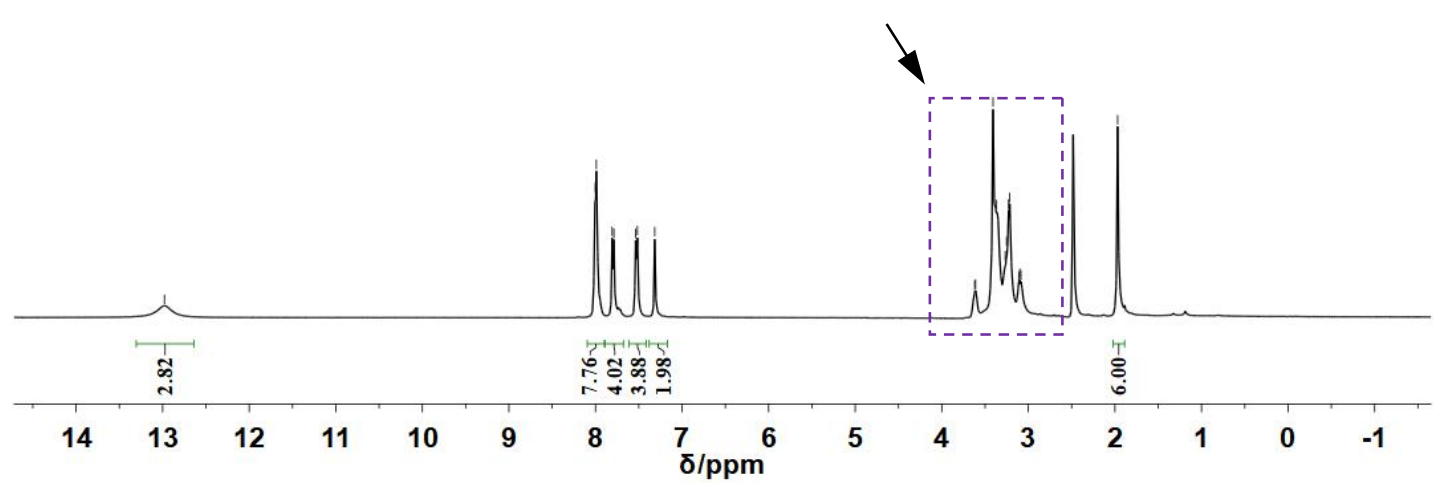

Figure S2. ${ }^{1} \mathrm{H}$ NMR of digested CE-2 


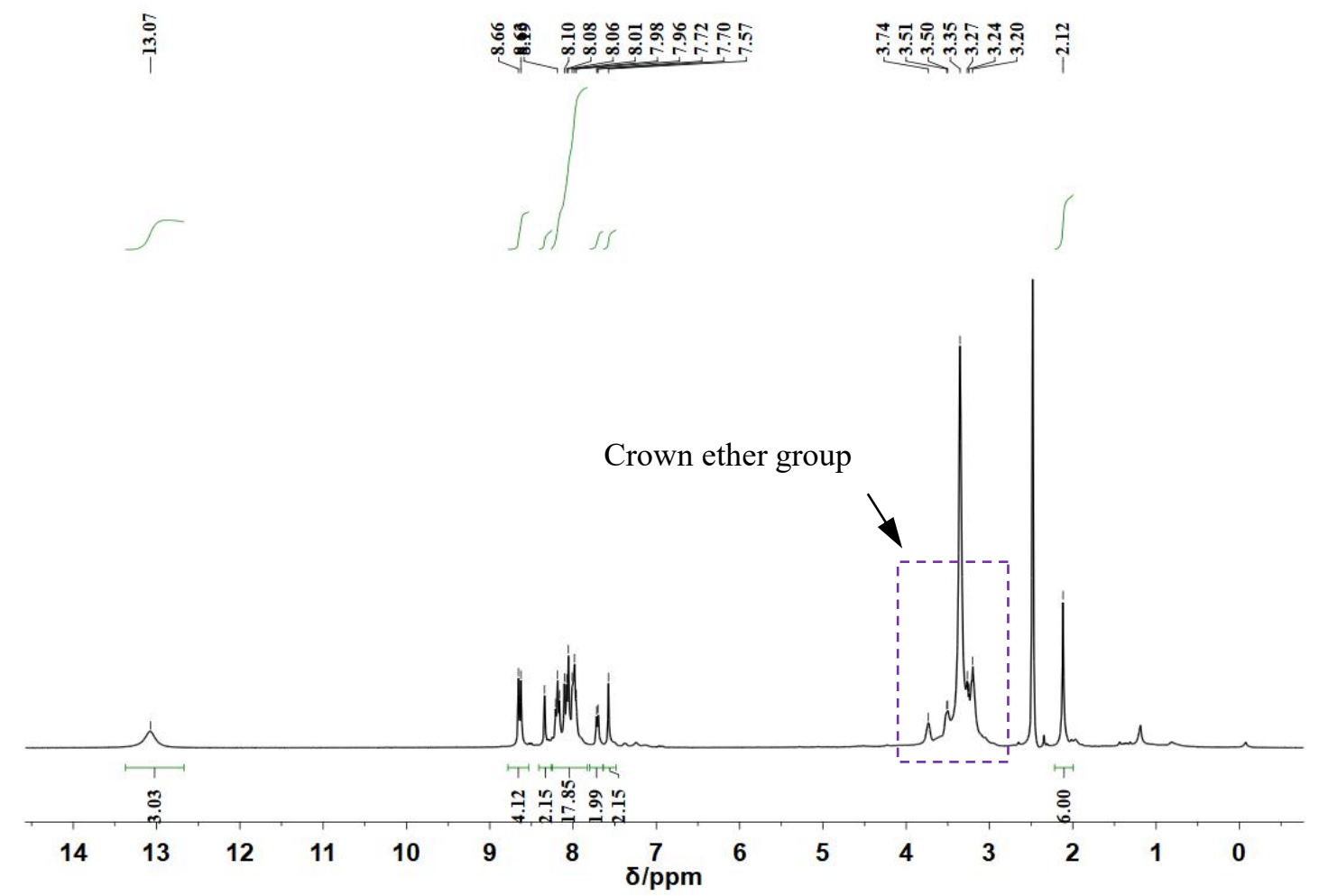

Figure S3. ${ }^{1} \mathrm{H}$ NMR of digested CE-3

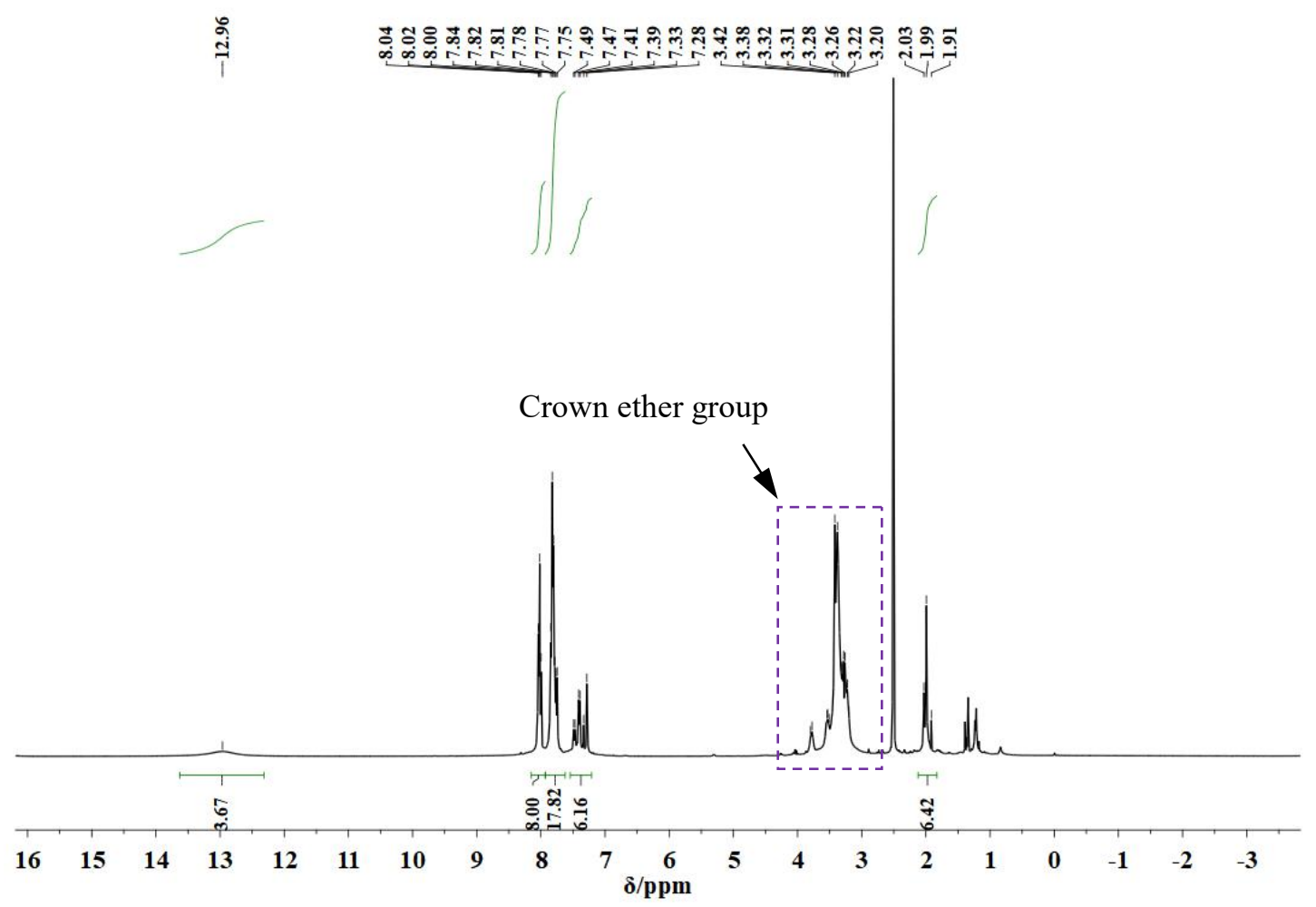


Figure S4. ${ }^{1} \mathrm{H}$ NMR of digested OET-1

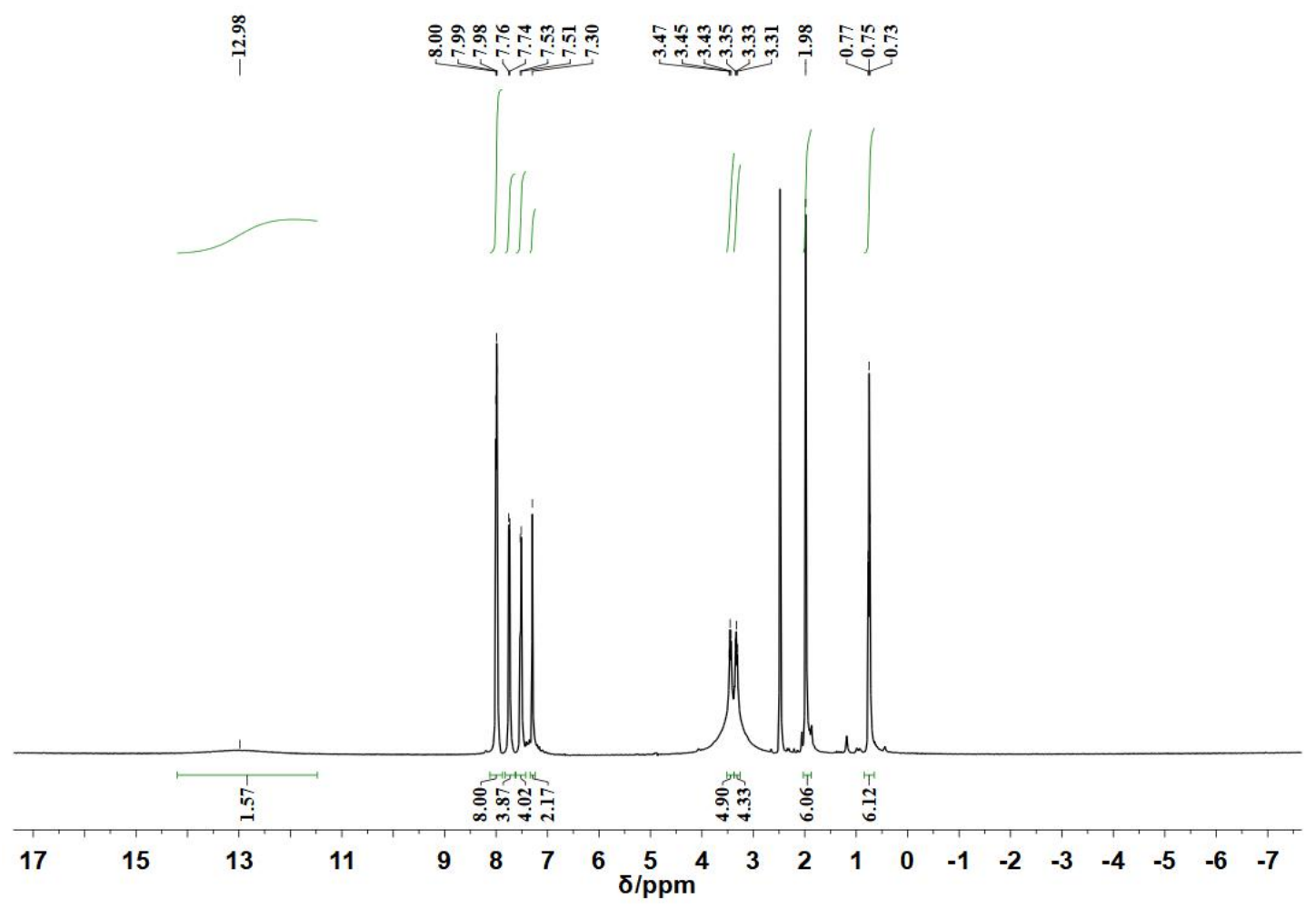

\section{Tables S1 and S2. Dye inclusion experiments}

The activated MOFs (5 mg) were soaked in a saturated solution of methyl orange (MO, $60 \mathrm{mg}$ ) or rhodamine $6 \mathrm{G}$ (R6G, $5 \mathrm{mg}$ ) in methanol for $24 \mathrm{~h}$. After removing the dye adsorbed on the surface of crystals, the resulting red crystals were washed with methanol until the solution became colorless. The washed samples were sonicated with methanol for several times until the crystals became light yellow. The red solutions were diluted to $1000 \mathrm{~mL}$. The absorption experiments were performed on Lambda $20 \mathrm{UV} / \mathrm{Vis}$ Spectrometer. The amount of dyes was determined by comparing the UV absorption with the standard curves.

Creation of a standard curve:

$$
A=\log _{10} \frac{I_{0}}{I_{t}}=\log _{10} \frac{1}{T}=k \cdot l \cdot \mathrm{c}
$$

MO: (1) 20, 8, 4, 2, 1, and $0.5 \mu \mathrm{M}$ MO solutions were prepared, respectively. (2) The absorbance of different concentrations of Methyl orange was determined by UV/Vis spectrometer. Data for known concentrations of MO were used to make the standard curve, plotting concentration on the $\mathrm{X}$ axis, and the assay measurement of absorbance on the $\mathrm{Y}$ axis. According to 
the Beer-Lambert law, the standard curve can be calculated by linear fitting of the data.

R6G: (1) 20, 8, 4, 2, 1 and $0.5 \mu \mathrm{M}$ R6G solutions were prepared, respectively. (2) The absorbance of different concentrations of R6G was determined by UV/Vis Spectrometer. Data for known concentrations of R6G were used to make the standard curve, plotting concentration on the $\mathrm{X}$ axis, and the assay measurement of absorbance on the $\mathrm{Y}$ axis. According to the Beer-Lambert law, the standard curve can be calculated by linear fitting of the data.
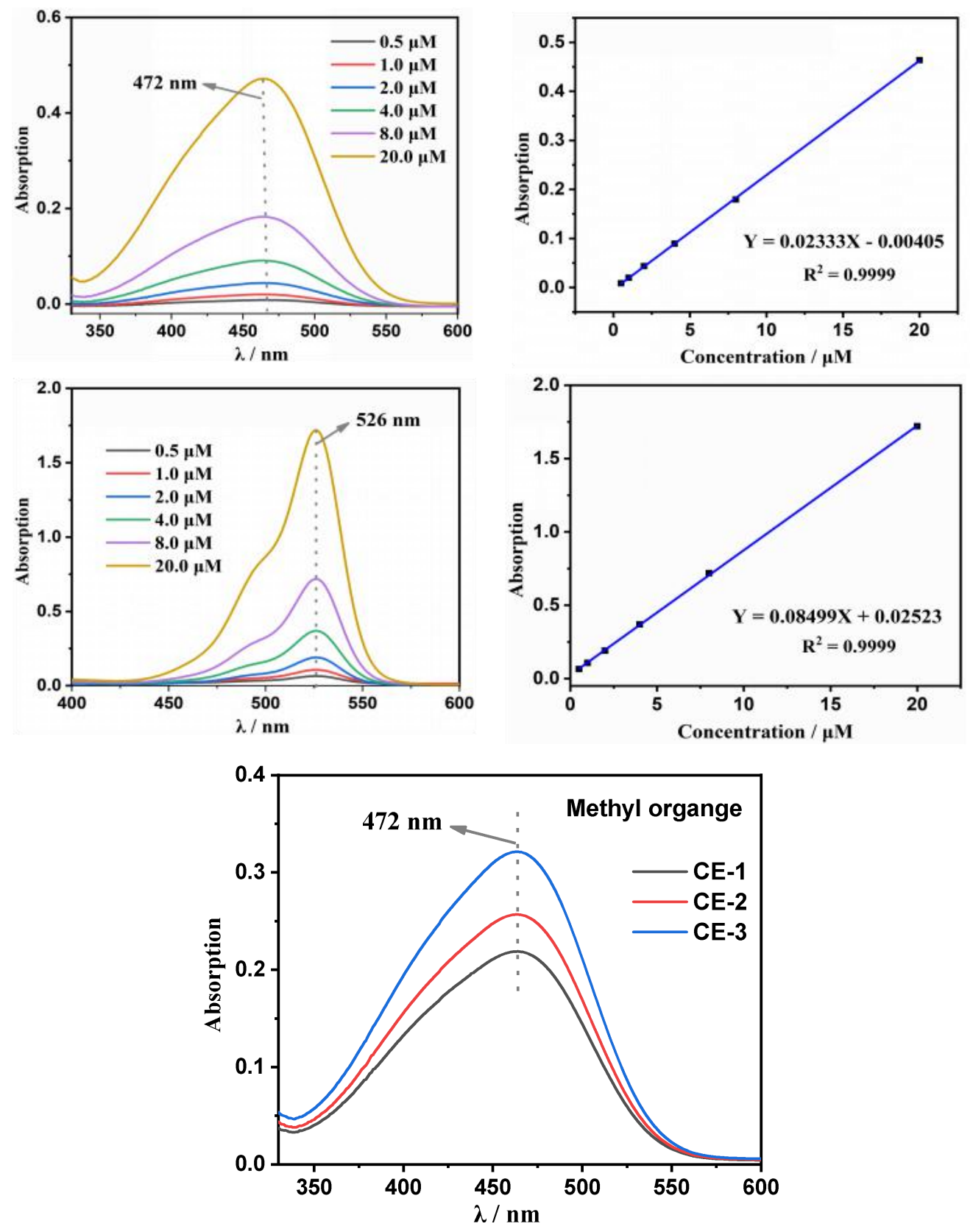


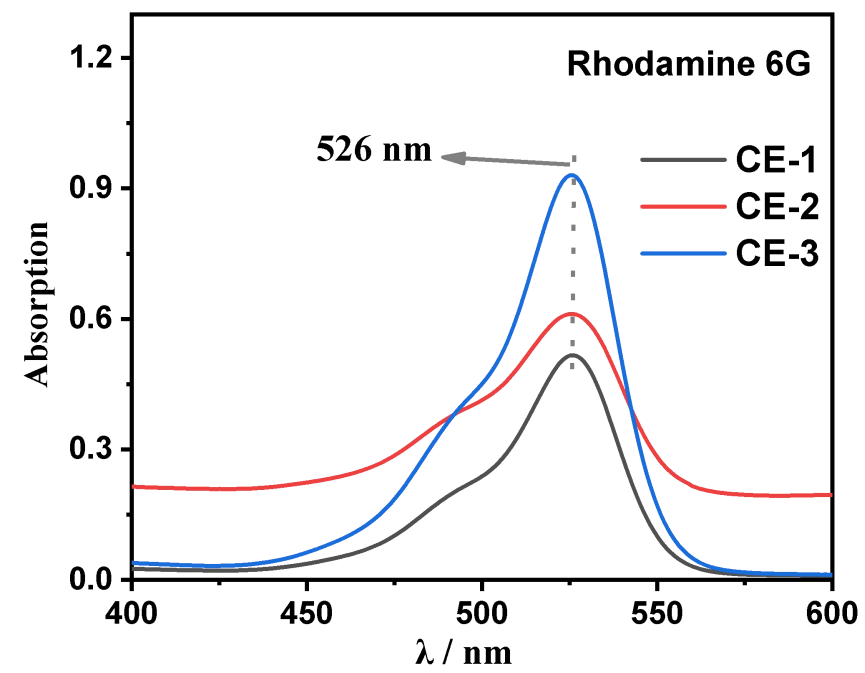

Table S1. The molecular numbers of absorbed dye (per formula unit)

\begin{tabular}{|c|c|c|c|}
\hline & CE-1 & CE-2 & CE-3 \\
\hline Rhodamine 6G & 2.3 & 3.8 & 4.6 \\
\hline Methyl orange & 1.7 & 2.3 & 3.6 \\
\hline
\end{tabular}

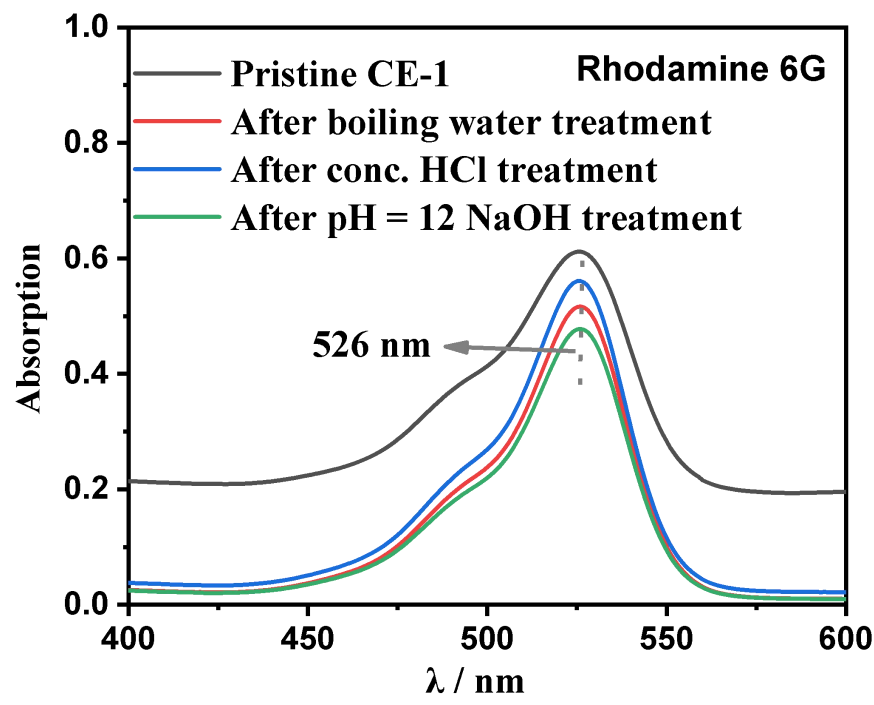



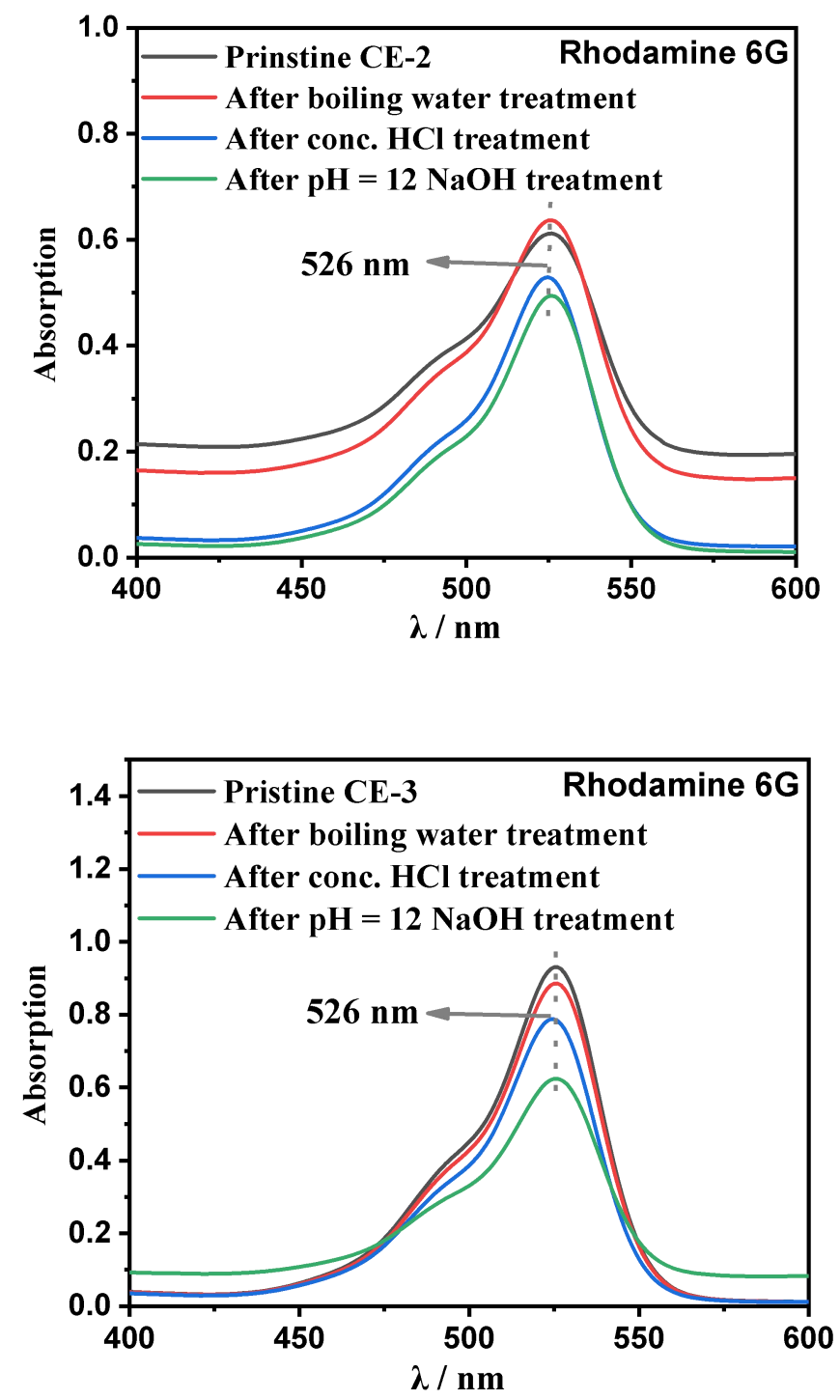

Table S2. The molecular numbers of absorbed R6G (per formula unit)

\begin{tabular}{|c|c|c|c|c|}
\hline & Pristine & $\begin{array}{c}\text { Boling water } \\
\text { treatment }\end{array}$ & $\begin{array}{c}\text { Conc. } \mathrm{HCl} \\
\text { treatment }\end{array}$ & $\begin{array}{c}\mathrm{pH}=12 \mathrm{NaOH} \\
\text { treatment }\end{array}$ \\
\hline CE-1 & 1.7 & 1.6 & 1.4 & 1.3 \\
\hline CE-2 & 2.3 & 2.4 & 2 & 1.8 \\
\hline CE-3 & 3.6 & 3.4 & 3.0 & 2.8 \\
\hline
\end{tabular}


6. Table S3. Crystal data and structural refinement

\begin{tabular}{|c|c|c|c|}
\hline Identification code & CE-1 & CE-2 & CE-3 \\
\hline Empirical formula & $\mathrm{C}_{40} \mathrm{H}_{22} \mathrm{O}_{20} \mathrm{Zr}_{3}$ & $\mathrm{C}_{56} \mathrm{H}_{30} \mathrm{O}_{20} \mathrm{Zr}_{3}$ & $\mathrm{C}_{64} \mathrm{H}_{38} \mathrm{O}_{20} \mathrm{Zr}_{3}$ \\
\hline Formula weight & 1096.23 & 2001.66 & 1400.60 \\
\hline Temperature (K) & 173.0 & 100 & 100 \\
\hline Wavelength $(\AA)$ & 1.54178 & 0.77484 & 0.77484 \\
\hline Crystal system & Orthorhombic & Orthorhombic & Orthorhombic \\
\hline Space group & $F \mathrm{mmm}$ & $F \mathrm{mmm}$ & $F \mathrm{mmm}$ \\
\hline $\mathrm{a}(\AA)$ & $20.8288(14)$ & $20.500(4)$ & $25.379(5)$ \\
\hline $\mathrm{b}(\AA)$ & $32.974(2)$ & $35.660(7)$ & $43.453(9)$ \\
\hline c $(\AA)$ & $33.604(2)$ & $43.190(9)$ & $46.752(9)$ \\
\hline$a\left(^{\circ}\right)$ & 90 & 90 & 90 \\
\hline$\beta\left({ }^{\circ}\right)$ & 90 & 90 & 90 \\
\hline$\gamma\left({ }^{\circ}\right)$ & 90 & 90 & 90 \\
\hline Volume $\left(\AA^{3}\right), \mathrm{Z}$ & 23079(3), 8 & $31573(11), 8$ & $51558(18), 8$ \\
\hline Density (calculated) $\left(\mathrm{g} / \mathrm{cm}^{3}\right)$ & 0.631 & 0.545 & 0.361 \\
\hline Absorption coefficient $\left(\mathrm{mm}^{-1}\right)$ & 2.447 & 0.221 & 0.137 \\
\hline$F(000)$ & 4336 & 5168 & 5616 \\
\hline Reflections collected/ unique & $17629 / 3281$ & $41885 / 5812$ & $15376 / 8210$ \\
\hline Completeness to theta & $50.485,99.8$ & $23.081,97.8$ & $21.968,98.3$ \\
\hline$R_{\text {int }}$ & 0.0948 & 0.1218 & 0.0438 \\
\hline Refinement method & $\begin{array}{c}\text { Full-matrix } \\
\text { least-squares on } \mathrm{F}^{2}\end{array}$ & $\begin{array}{c}\text { Full-matrix } \\
\text { least-squares on } \mathrm{F}^{2}\end{array}$ & $\begin{array}{c}\text { Full-matrix } \\
\text { least-squares on } \mathrm{F}^{2}\end{array}$ \\
\hline Data / restraints / parameters & $3281 / 0 / 154$ & $5812 / 0 / 190$ & $8210 / 5 / 183$ \\
\hline Goodness of fit on $\mathrm{F}^{2}$ & 1.086 & 1.049 & 1.162 \\
\hline Final $\mathrm{R}$ indices $[\mathrm{I}>2 \operatorname{sigma}(\mathrm{I})]$ & $\begin{array}{c}R_{1}=0.0728, w R_{2}= \\
0.2334\end{array}$ & $\begin{array}{c}R_{1}=0.0936, w R_{2}= \\
0.2510\end{array}$ & $\begin{aligned} R_{l}= & 0.0986, w R_{2} \\
& =0.3057\end{aligned}$ \\
\hline $\mathrm{R}$ indices (all data) & $\begin{array}{c}R_{1}=0.1210, w R_{2}= \\
0.2663\end{array}$ & $\begin{array}{c}R_{1}=0.1390, w R_{2}= \\
0.2909\end{array}$ & $\begin{aligned} R_{1}= & 0.1182, w R_{2} \\
& =0.3270\end{aligned}$ \\
\hline Absolute structure parameter & - & - & - \\
\hline Residue peak / hole $\left(\mathrm{e} \AA^{-3}\right)$ & $0.857 /-1.039$ & $1.252 /-0.840$ & $0.696 /-0.571$ \\
\hline
\end{tabular}


7. Table S4. Selected bond lengths and angles

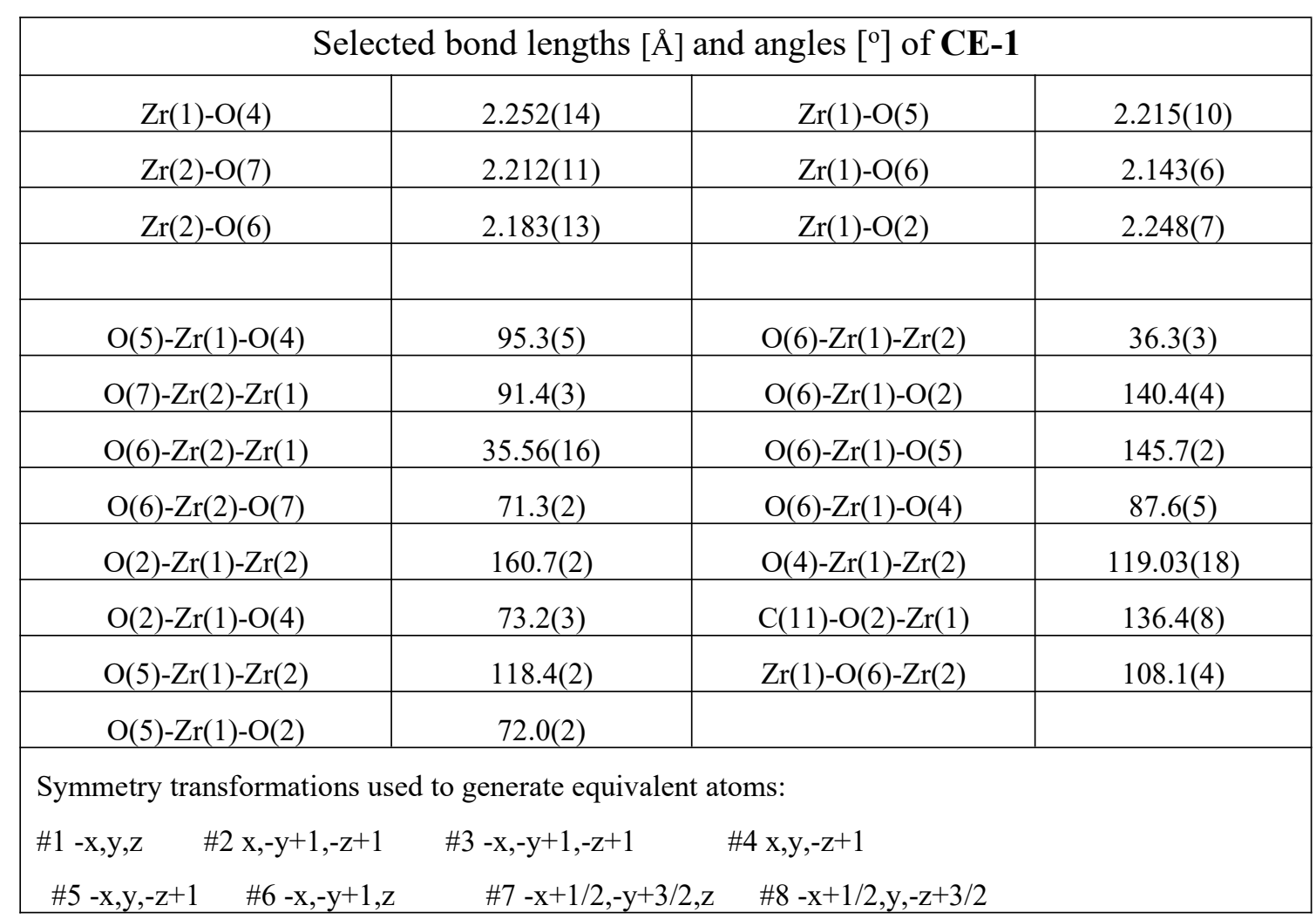

\begin{tabular}{|c|c|c|c|}
\hline \multicolumn{4}{|c|}{ Selected bond lengths $[\AA]$ and angles $\left[^{\circ}\right]$ of CE-2 } \\
\hline $\mathrm{Zr}(1)-\mathrm{O}(4)$ & $2.252(14)$ & $\mathrm{Zr}(1)-\mathrm{O}(5)$ & $2.215(10)$ \\
\hline $\mathrm{Zr}(2)-\mathrm{O}(7)$ & $2.212(11)$ & $\mathrm{Zr}(1)-\mathrm{O}(6)$ & $2.143(6)$ \\
\hline $\mathrm{Zr}(2)-\mathrm{O}(6)$ & $2.183(13)$ & $\mathrm{Zr}(1)-\mathrm{O}(2)$ & $2.248(7)$ \\
\hline $\mathrm{O}(4)-\operatorname{Zr}(1)-\operatorname{Zr}(2)$ & $119.03(18)$ & $\mathrm{O}(6)-\mathrm{Zr}(1)-\mathrm{O}(5)$ & $145.7(2)$ \\
\hline $\mathrm{O}(7)-\mathrm{Zr}(2)-\mathrm{Zr}(1)$ & $91.4(3)$ & $\mathrm{O}(5)-\operatorname{Zr}(1)-\operatorname{Zr}(2)$ & $118.4(2)$ \\
\hline $\mathrm{O}(6)-\operatorname{Zr}(2)-\operatorname{Zr}(1)$ & $35.56(16)$ & $\mathrm{O}(5)-\mathrm{Zr}(1)-\mathrm{O}(2)$ & $72.0(2)$ \\
\hline $\mathrm{O}(6)-\mathrm{Zr}(2)-\mathrm{O}(7)$ & $71.3(2)$ & $\mathrm{O}(5)-\mathrm{Zr}(1)-\mathrm{O}(4)$ & $95.3(5)$ \\
\hline $\mathrm{O}(2)-\operatorname{Zr}(1)-\operatorname{Zr}(2)$ & $160.7(2)$ & $\mathrm{O}(6)-\operatorname{Zr}(1)-\operatorname{Zr}(2)$ & $36.3(3)$ \\
\hline $\mathrm{O}(2)-\mathrm{Zr}(1)-\mathrm{O}(4)$ & $73.2(3)$ & $\mathrm{O}(6)-\mathrm{Zr}(1)-\mathrm{O}(2)$ & $140.4(4)$ \\
\hline $\mathrm{O}(6)-\mathrm{Zr}(1)-\mathrm{O}(4)$ & $87.6(5)$ & $\mathrm{Zr}(1)-\mathrm{O}(6)-\mathrm{Zr}(2)$ & 108.1(4) \\
\hline \multicolumn{4}{|c|}{ Symmetry transformations used to generate equivalent atoms: } \\
\hline $\begin{array}{lr}\# 1-\mathrm{x}, \mathrm{y}, \mathrm{z} & \# 2 \mathrm{x},-\mathrm{y}+1,-\mathrm{z}+1 \\
\# 5-\mathrm{x}, \mathrm{y},-\mathrm{z}+1 & \# 6-\mathrm{x},-\mathrm{y}+1, \mathrm{z} \\
\end{array}$ & $\begin{array}{r}\# 3-x,-y+1,-z \\
\# 7-x+1 / 2,-y \\
\end{array}$ & \multicolumn{2}{|l|}{$\# 4 \mathrm{x}, \mathrm{y},-\mathrm{z}+1$} \\
\hline
\end{tabular}




\begin{tabular}{|c|c|c|c|}
\hline \multicolumn{4}{|c|}{ Selected bond lengths $[\AA]$ and angles $\left[{ }^{\circ}\right]$ of $\mathbf{C E - 3}$} \\
\hline $\mathrm{Zr}(2)-\mathrm{O}(6)$ & $2.202(5)$ & $\mathrm{Zr}(2)-\mathrm{O}(5)$ & $2.127(3)$ \\
\hline $\operatorname{Zr}(1)-\mathrm{O}(5)$ & $2.183(6)$ & $\mathrm{Zr}(2)-\mathrm{O}(4)$ & $2.132(4)$ \\
\hline $\mathrm{Zr}(1)-\mathrm{O}(4)$ & $2.187(5)$ & $\mathrm{Zr}(2)-\mathrm{O}(7)$ & $2.204(8)$ \\
\hline $\mathrm{Zr}(1)-\mathrm{O}(3)$ & $2.167(4)$ & & \\
\hline $\mathrm{O}(5)-\operatorname{Zr}(1)-\operatorname{Zr}(2)$ & $35.28(8)$ & $\mathrm{O}(3)-\mathrm{Zr}(1)-\mathrm{O}(5)$ & $142.17(12)$ \\
\hline $\mathrm{O}(5)-\mathrm{Zr}(1)-\mathrm{O}(4)$ & $70.74(11)$ & $\mathrm{O}(3)-\mathrm{Zr}(1)-\mathrm{O}(4)$ & $142.79(13)$ \\
\hline $\mathrm{O}(4)-\operatorname{Zr}(1)-\operatorname{Zr}(2)$ & $35.47(9)$ & $\mathrm{O}(5)-\operatorname{Zr}(2)-\operatorname{Zr}(1)$ & $36.36(17)$ \\
\hline $\mathrm{O}(3)-\mathrm{Zr}(1)-\mathrm{Zr}(2)$ & $167.00(10)$ & $\mathrm{O}(5)-\mathrm{Zr}(2)-\mathrm{O}(4)$ & $72.9(2)$ \\
\hline $\mathrm{O}(5)-\mathrm{Zr}(2)-\mathrm{O}(7)$ & $88.5(2)$ & $\mathrm{O}(7)-\operatorname{Zr}(2)-\operatorname{Zr}(1)$ & $119.60(9)$ \\
\hline $\mathrm{O}(5)-\mathrm{Zr}(2)-\mathrm{O}(6)$ & $146.22(12)$ & $\mathrm{O}(6)-\operatorname{Zr}(2)-\operatorname{Zr}(1)$ & $119.17(11)$ \\
\hline $\mathrm{O}(4)-\operatorname{Zr}(2)-\operatorname{Zr}(1)$ & $36.52(15)$ & $\mathrm{O}(6)-\mathrm{Zr}(2)-\mathrm{O}(7)$ & $93.4(2)$ \\
\hline $\mathrm{O}(4)-\mathrm{Zr}(2)-\mathrm{O}(7)$ & $145.94(14)$ & $\operatorname{Zr}(2)-O(5)-\operatorname{Zr}(1)$ & $108.4(2)$ \\
\hline $\mathrm{O}(4)-\mathrm{Zr}(2)-\mathrm{O}(6)$ & $87.5(2)$ & $\operatorname{Zr}(2)-O(4)-\operatorname{Zr}(1)$ & $108.00(19)$ \\
\hline \multicolumn{4}{|c|}{ Symmetry transformations used to generate equivalent atoms: } \\
\hline \multicolumn{4}{|c|}{$\# 1-\mathrm{x}+1, \mathrm{y},-\mathrm{z}+1 \quad \# 2-\mathrm{x}+1,-\mathrm{y}+1,-\mathrm{z}+1 \quad \# 3 \mathrm{x},-$} \\
\hline$\# 5-\mathrm{x}+1, \mathrm{y}, \mathrm{z} \quad \# 6 \mathrm{x}, \mathrm{y},-\mathrm{z}+1$ & $\# 7-x+3 / 2,-y+3 /$ & $\# 8-\mathrm{x}+3 / 2, \mathrm{y},-\mathrm{z}+3 / 2$ & \\
\hline
\end{tabular}


8. Figure S5. Additional X-ray crystallographic structures
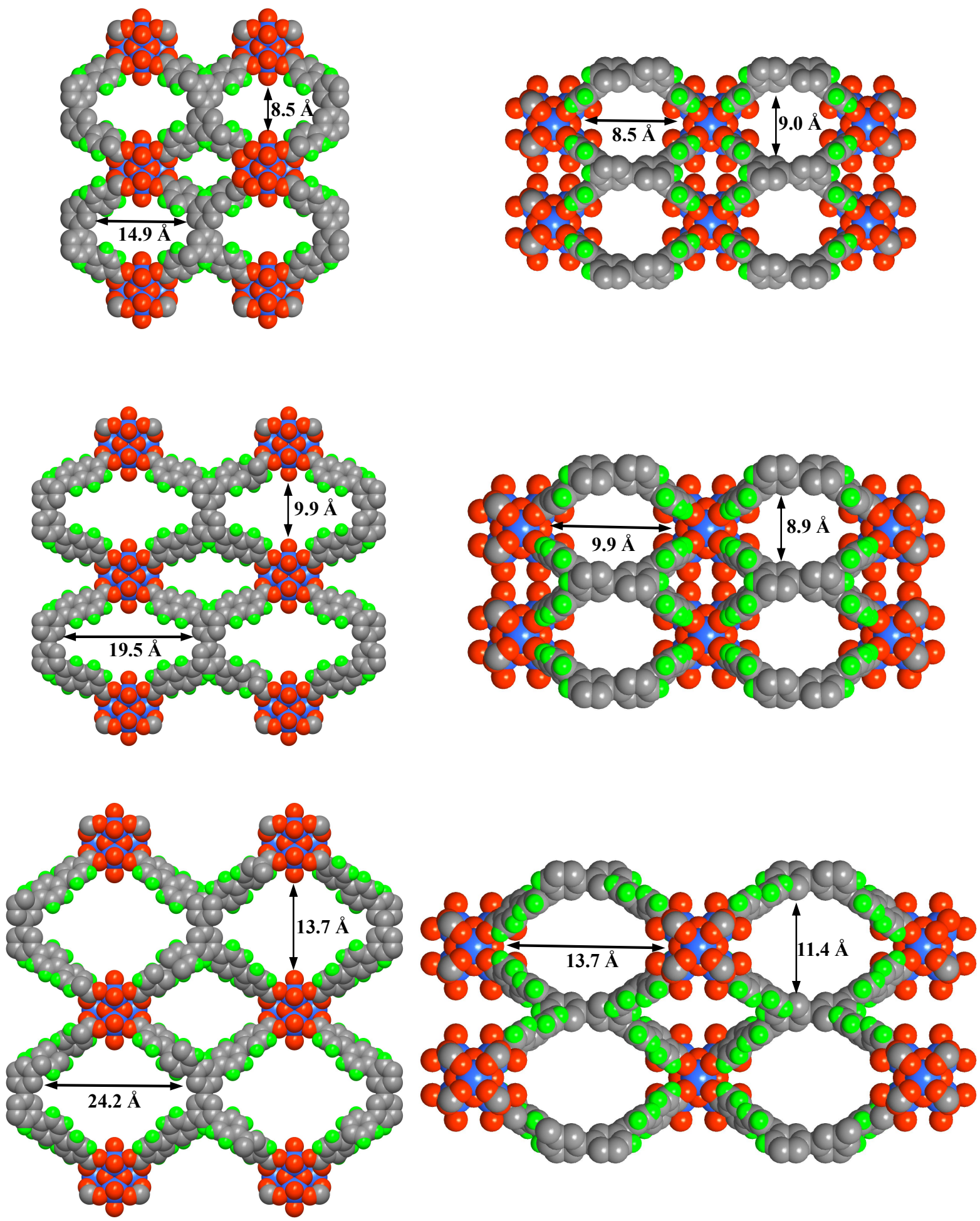
9. Figure S6. CD spectra
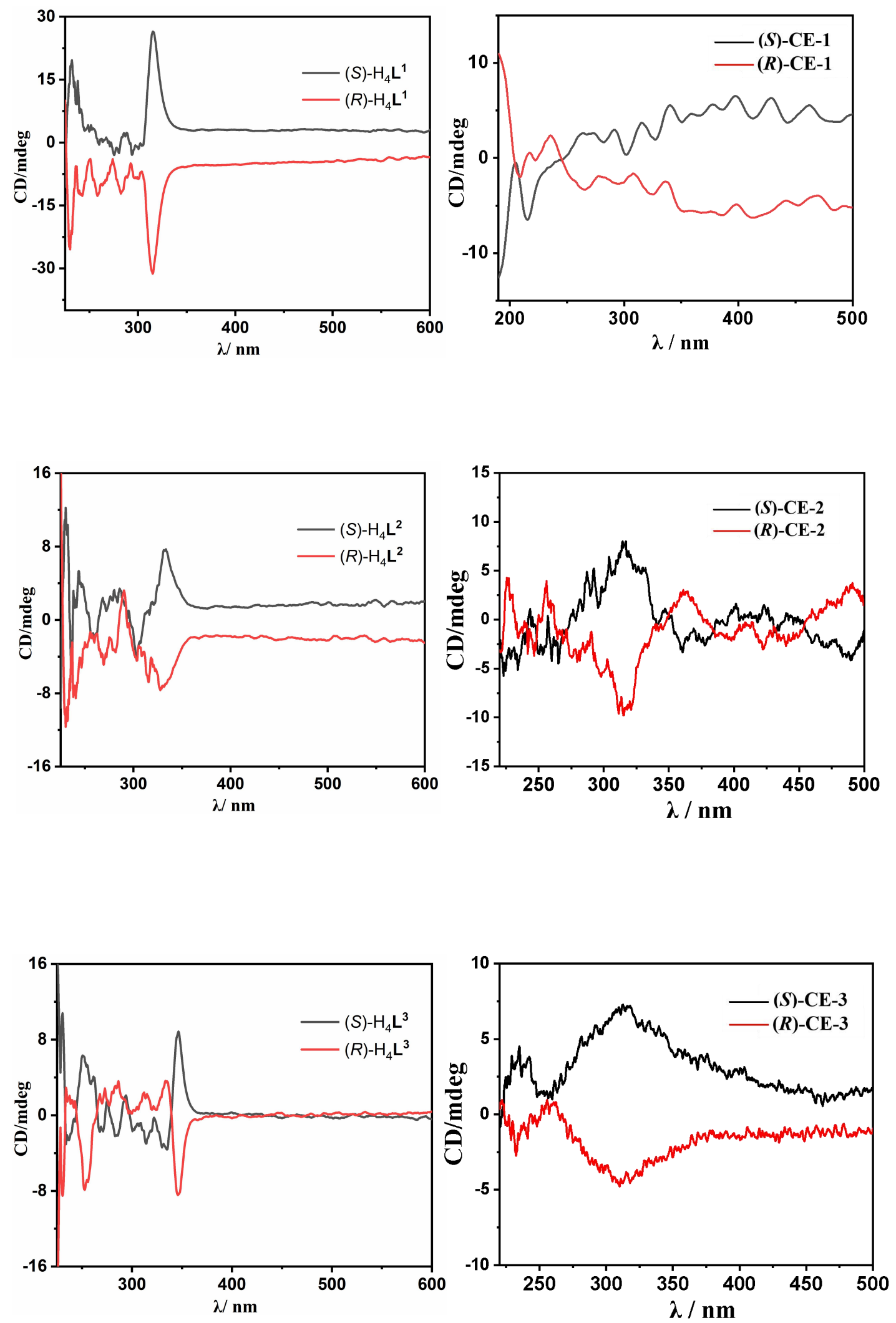
10. Figure S7. FT-IR spectra
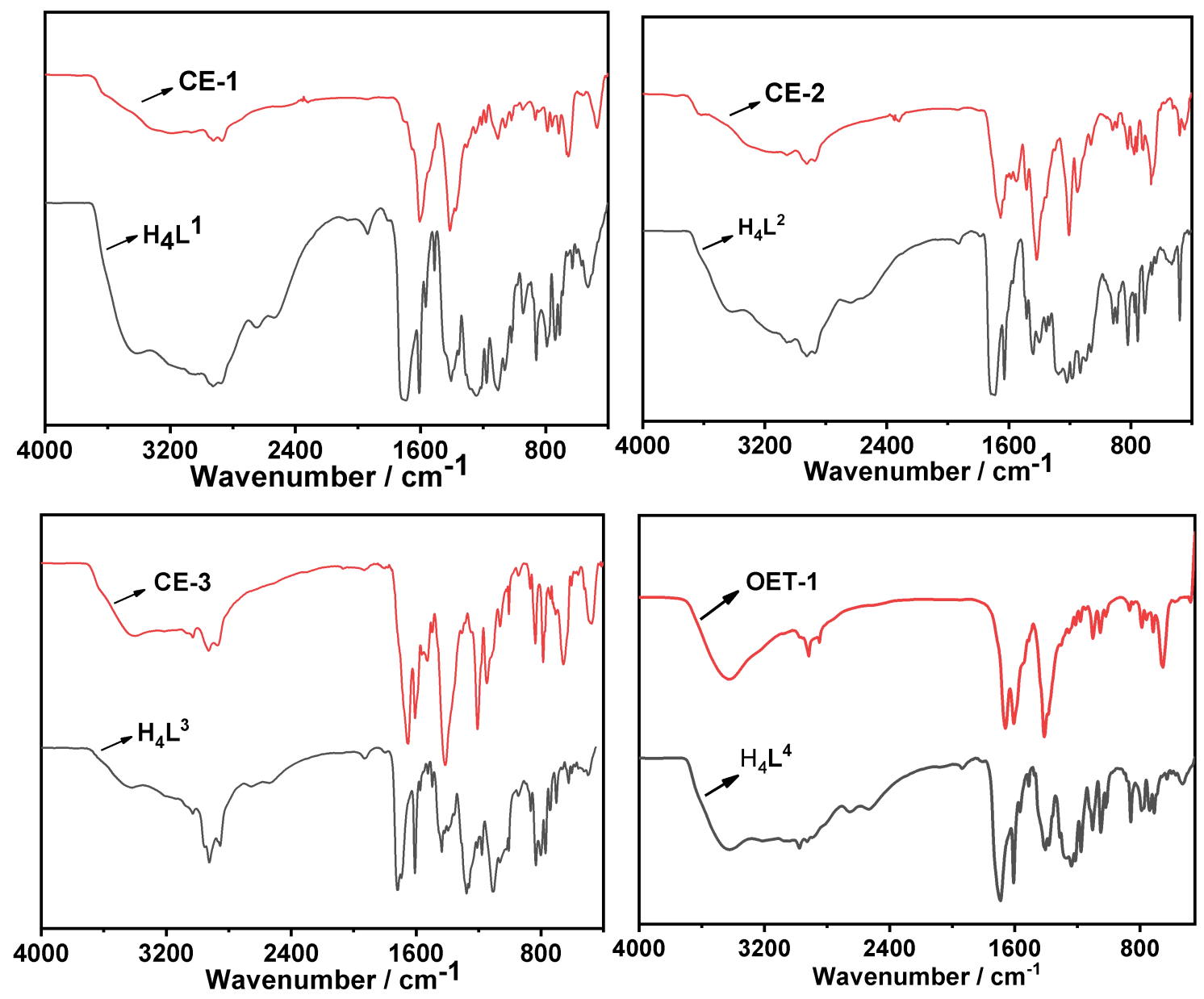
11. Figure S8. Additional PXRD patterns
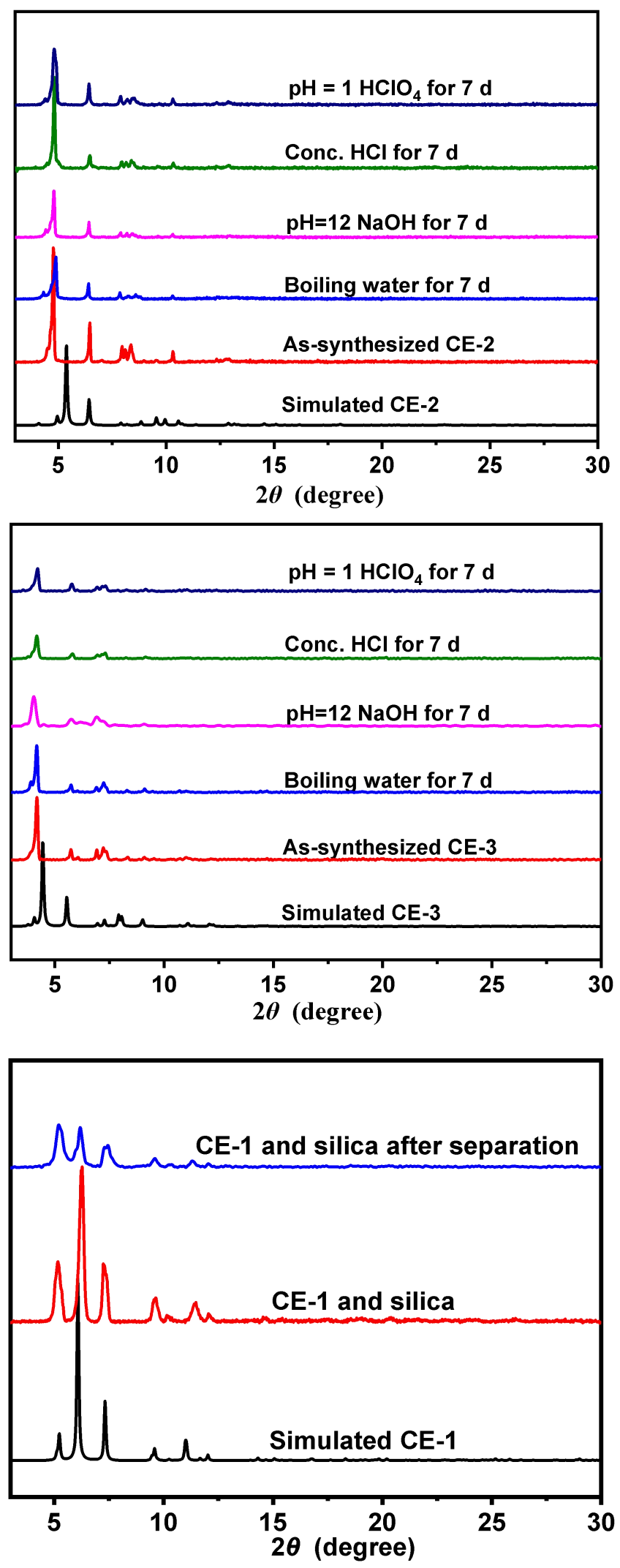


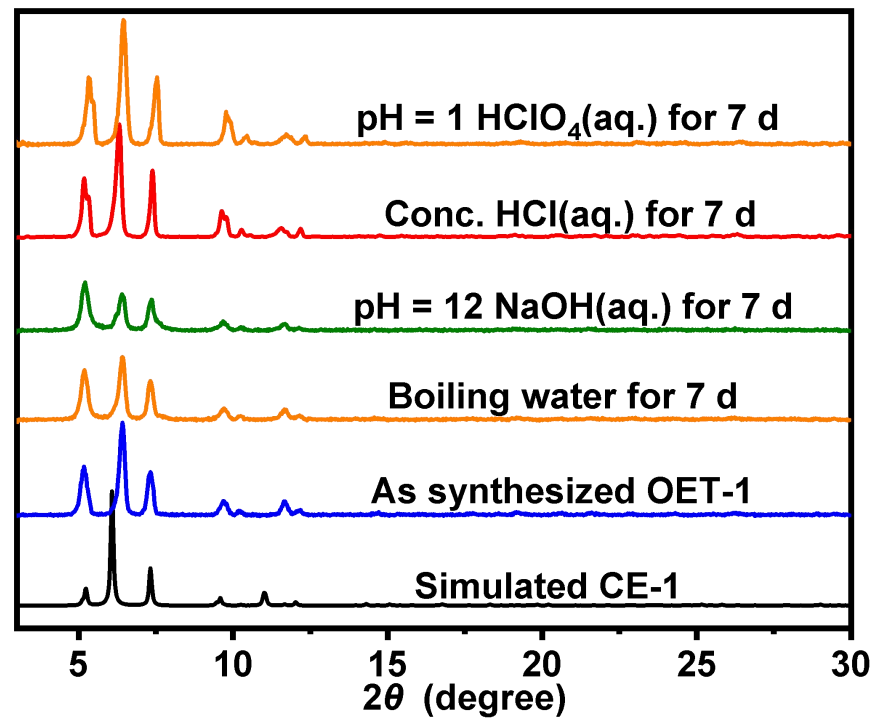

12. Figure $S 9 . N_{2}$ adsorption isotherms
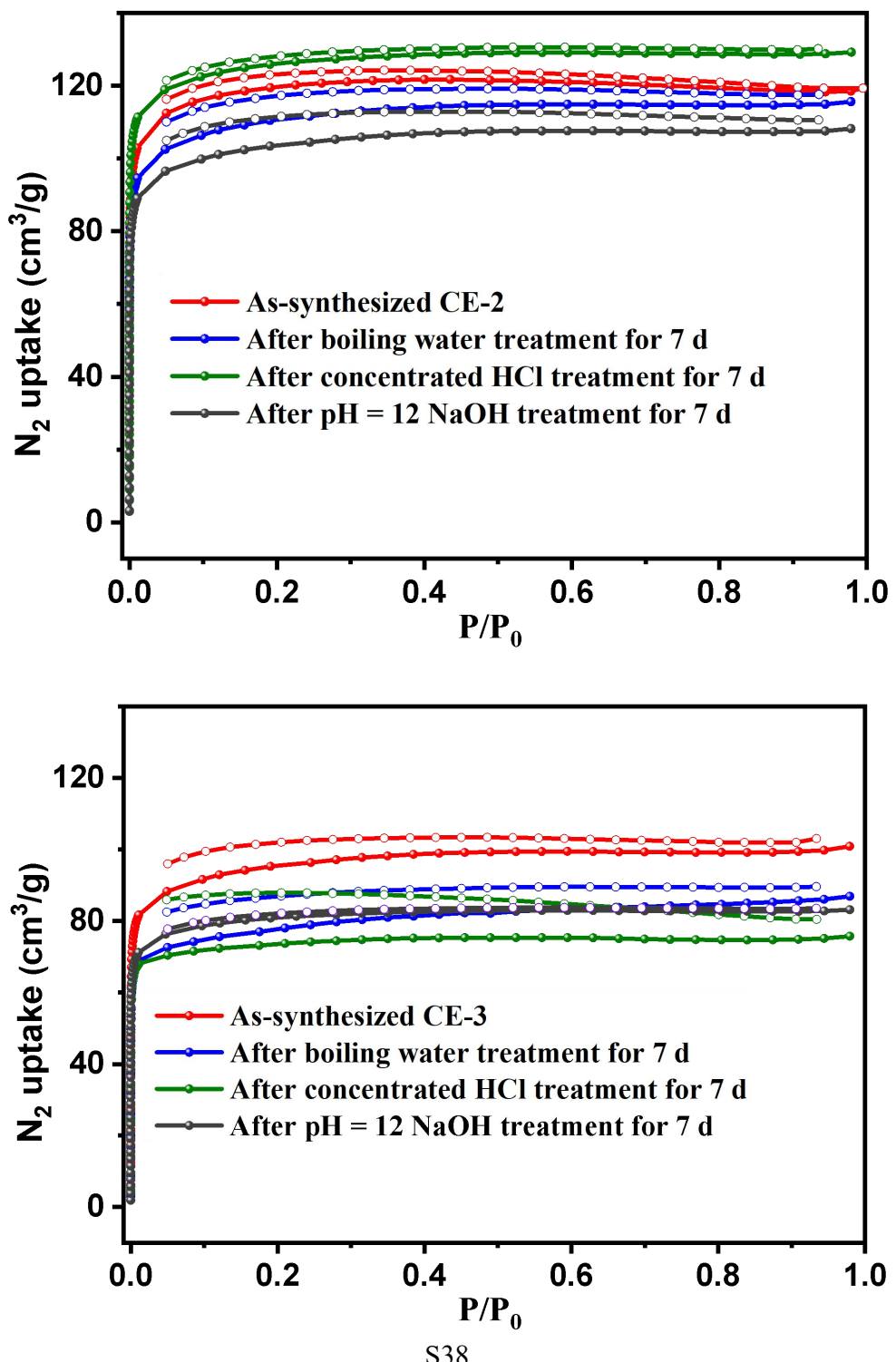


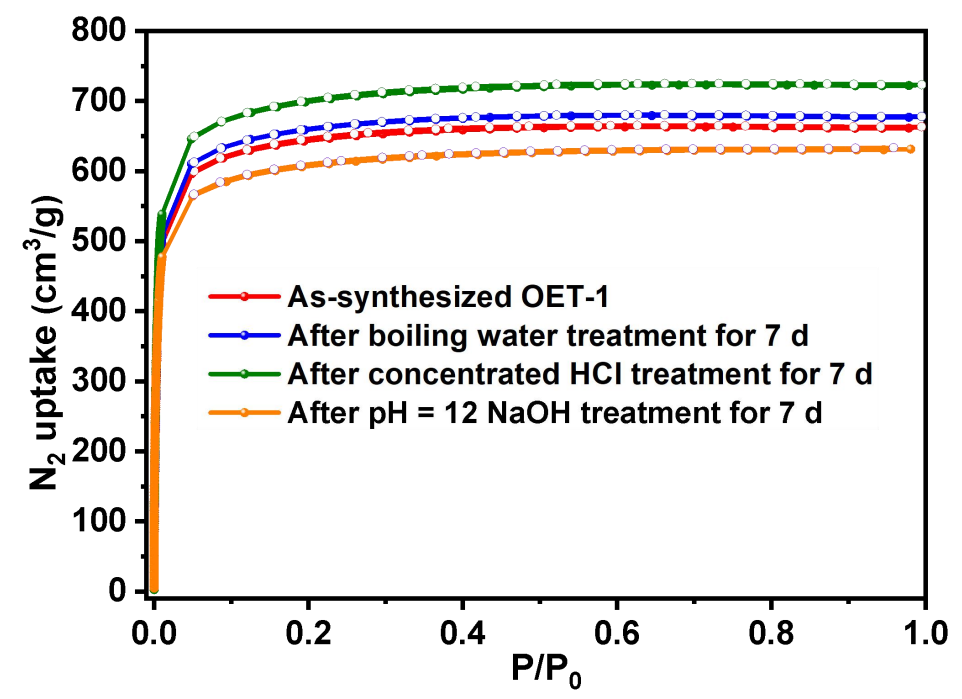

13. Figure S10. SEM images
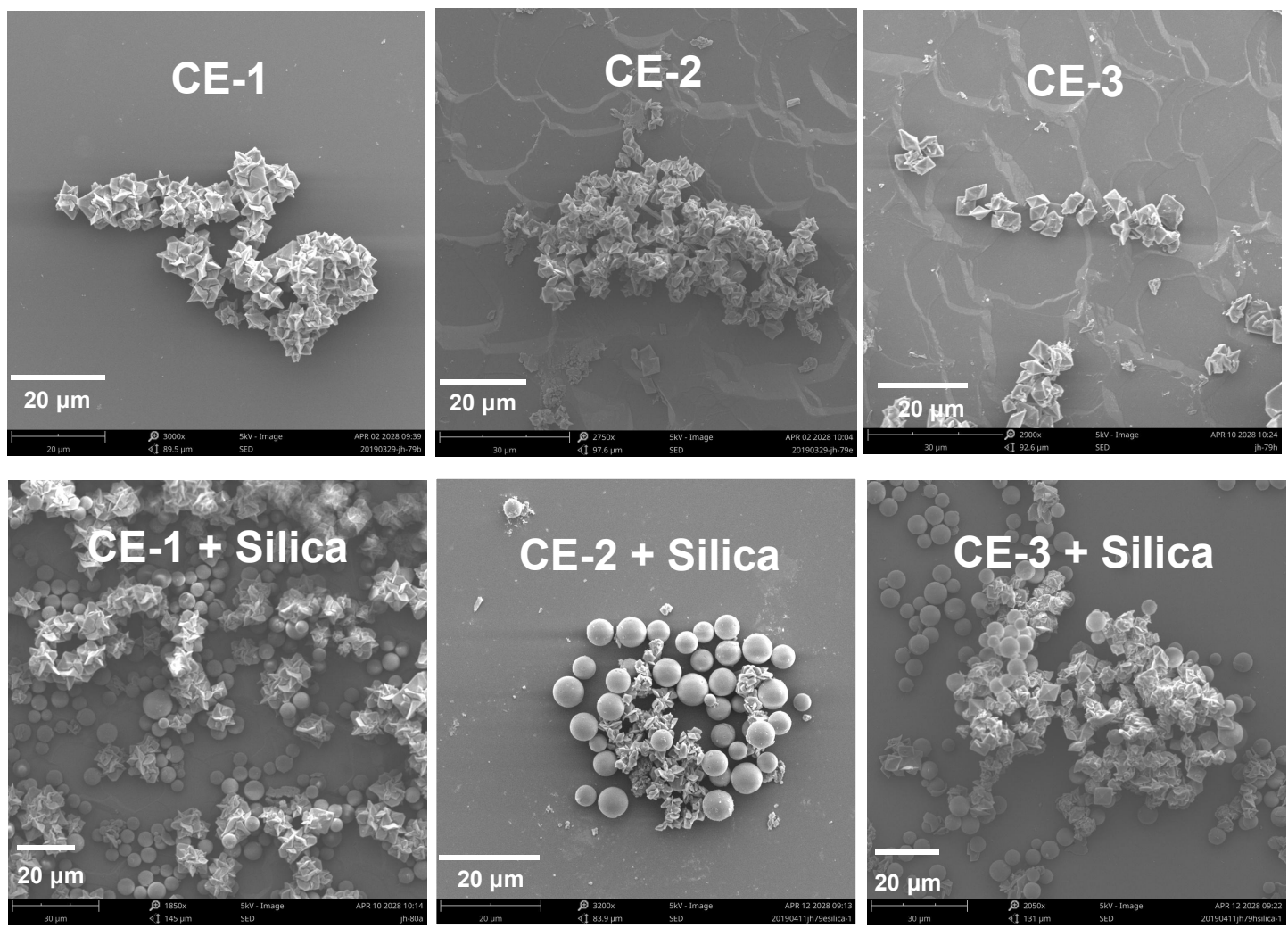
14. Figure S11. Molecular simulation of bulky analyte<smiles>CC(=O)C(N)Cc1cc(OCc2ccccc2)cc(OCc2ccccc2)c1</smiles>

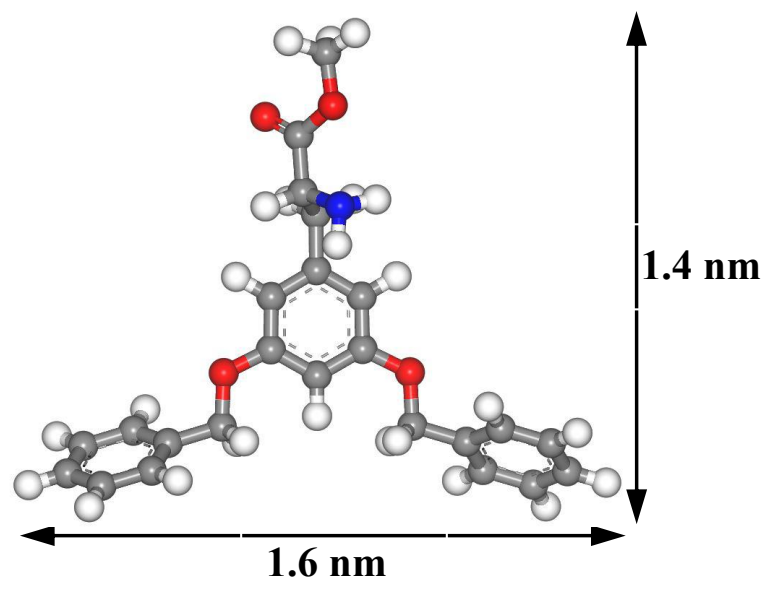

15. Figure S12. Optimization of the separation conditions

Figure S12a. HPLC chromatograms for separation of Phg with CE-1-packed column under different $\mathrm{pH}$ values.

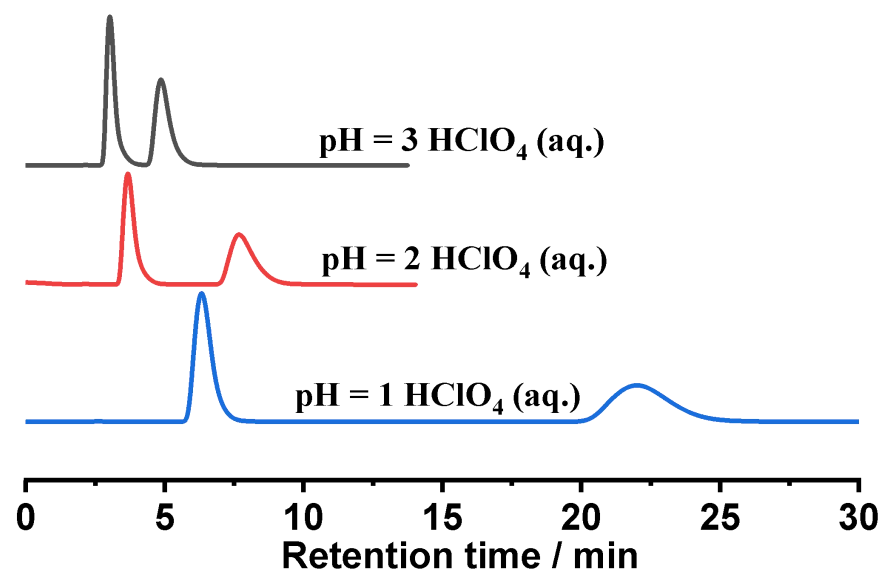

Figure S12b. HPLC chromatograms for separation of Phg with CE-1-packed column under different acid solutions.

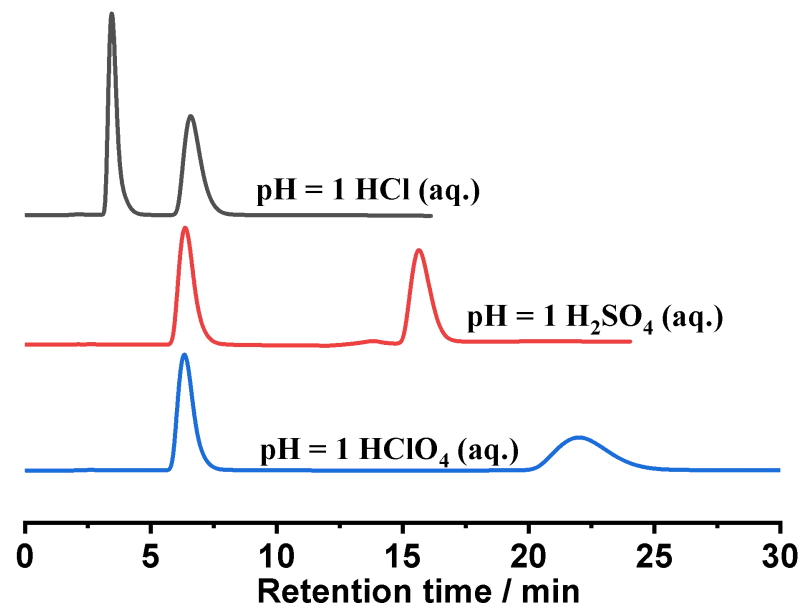


Figure S12c. HPLC chromatograms for separation of Phg with CE-1-packed column at different flow rates.

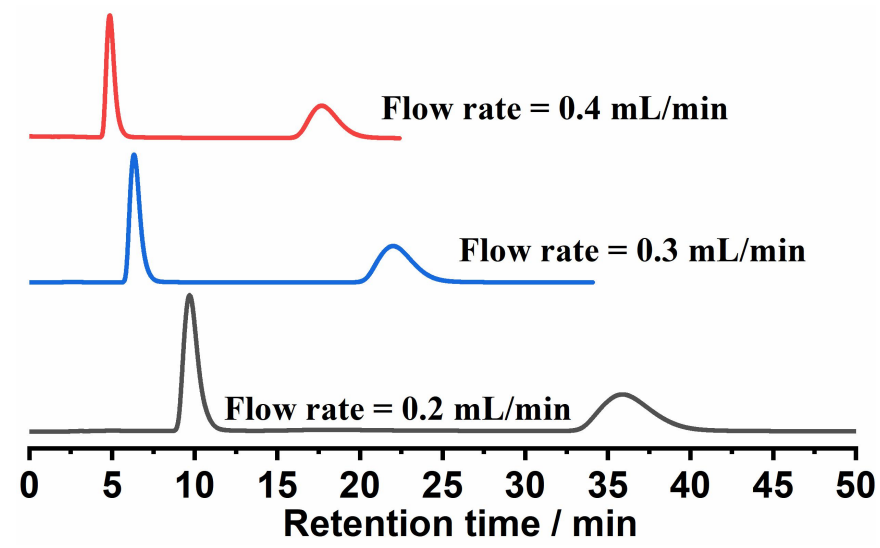

\section{Figure S13. Effect of injected mass}

Injected mass of racemic Phg: 4, 8, 12, 16 and $20 \mu \mathrm{g}$. A linear increase of chromatographic peak area with increased mass of Phg from $4 \mu \mathrm{g}$ to $20 \mu \mathrm{g}$.

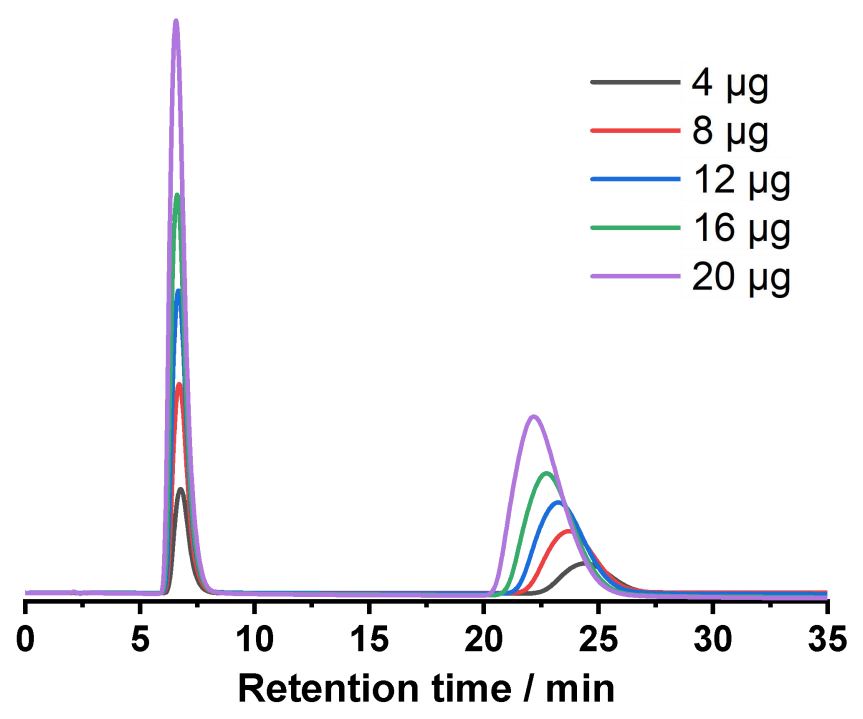




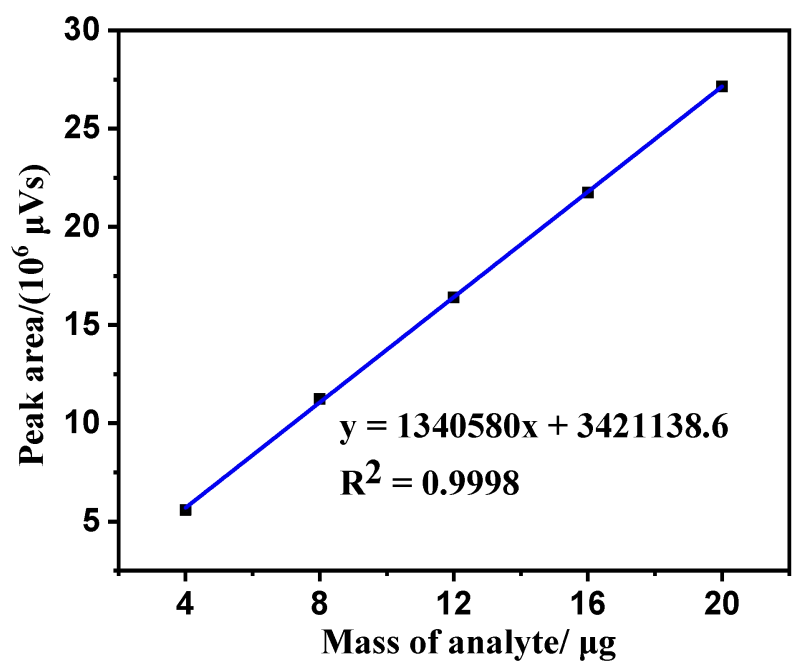

17. Figure S14. Additional HPLC chromatograms for chiral separation

Figure S14a. HPLC chromatograms for separation of six analytes with 1-3 packed columns
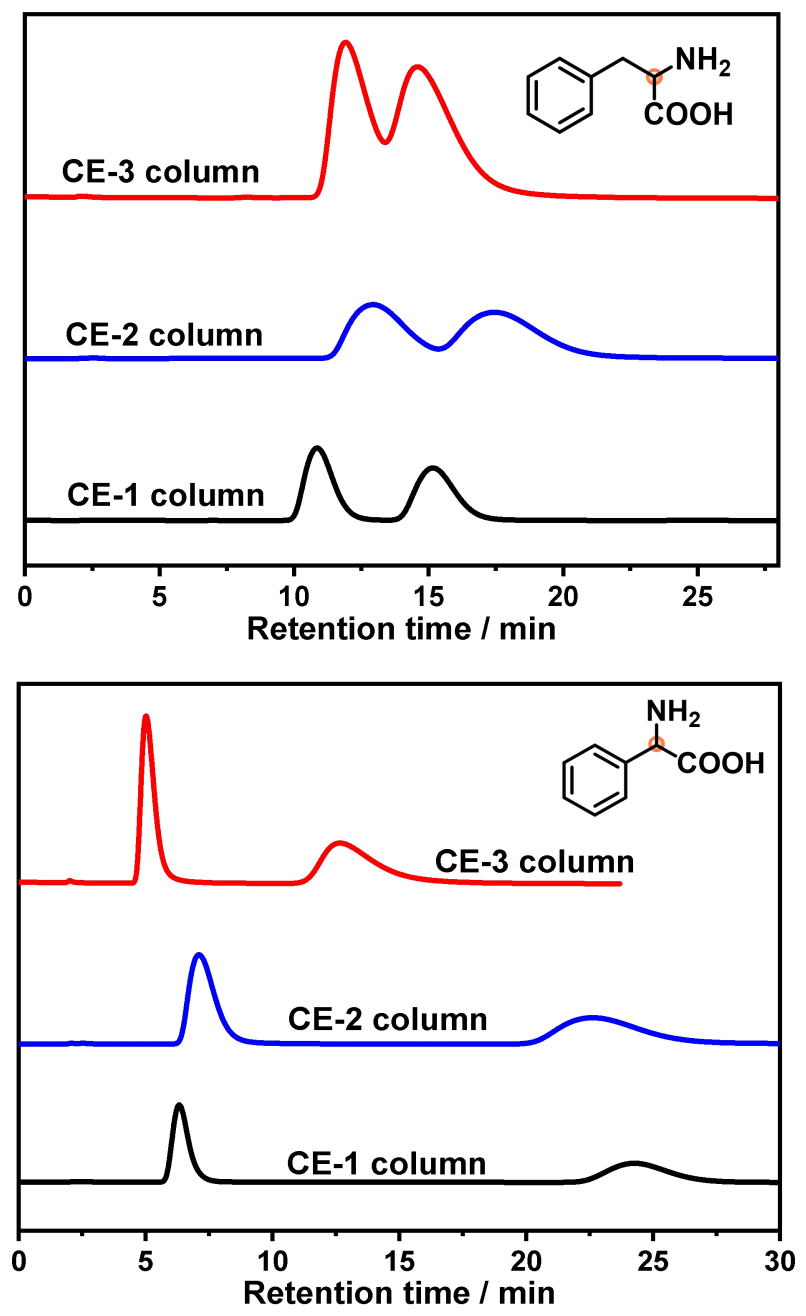

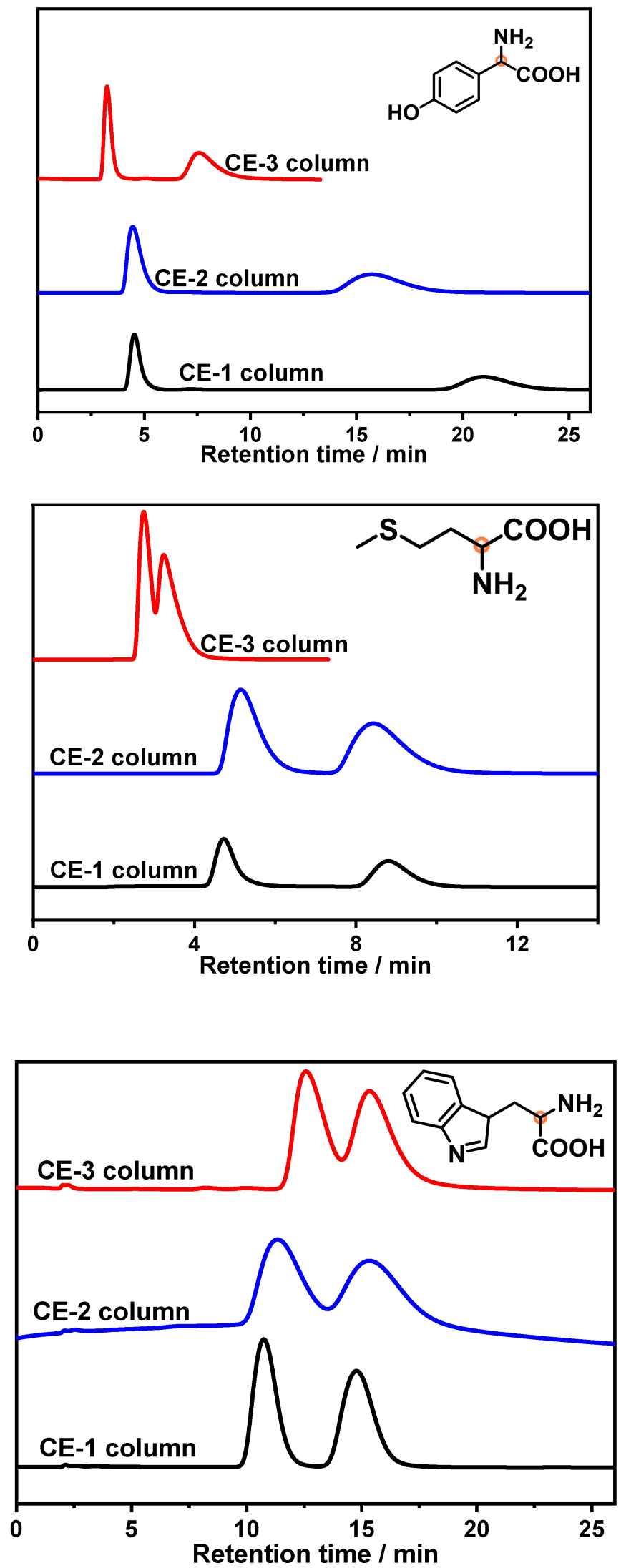


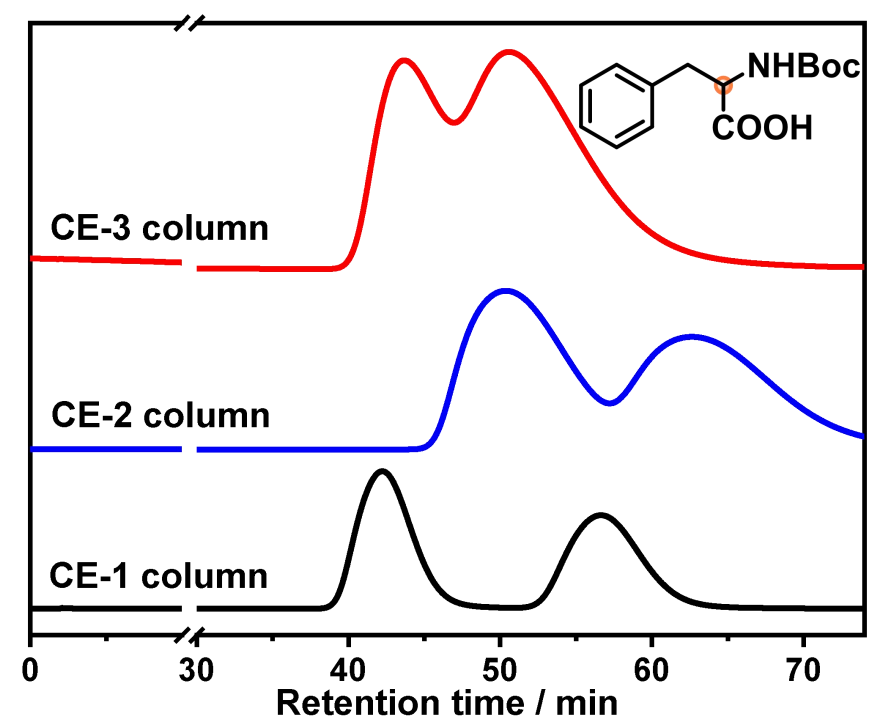

Figure S14b. HPLC chromatograms for separation of six amino acids with $\mathrm{Me}_{4} \mathbf{L}^{1}$ packed column
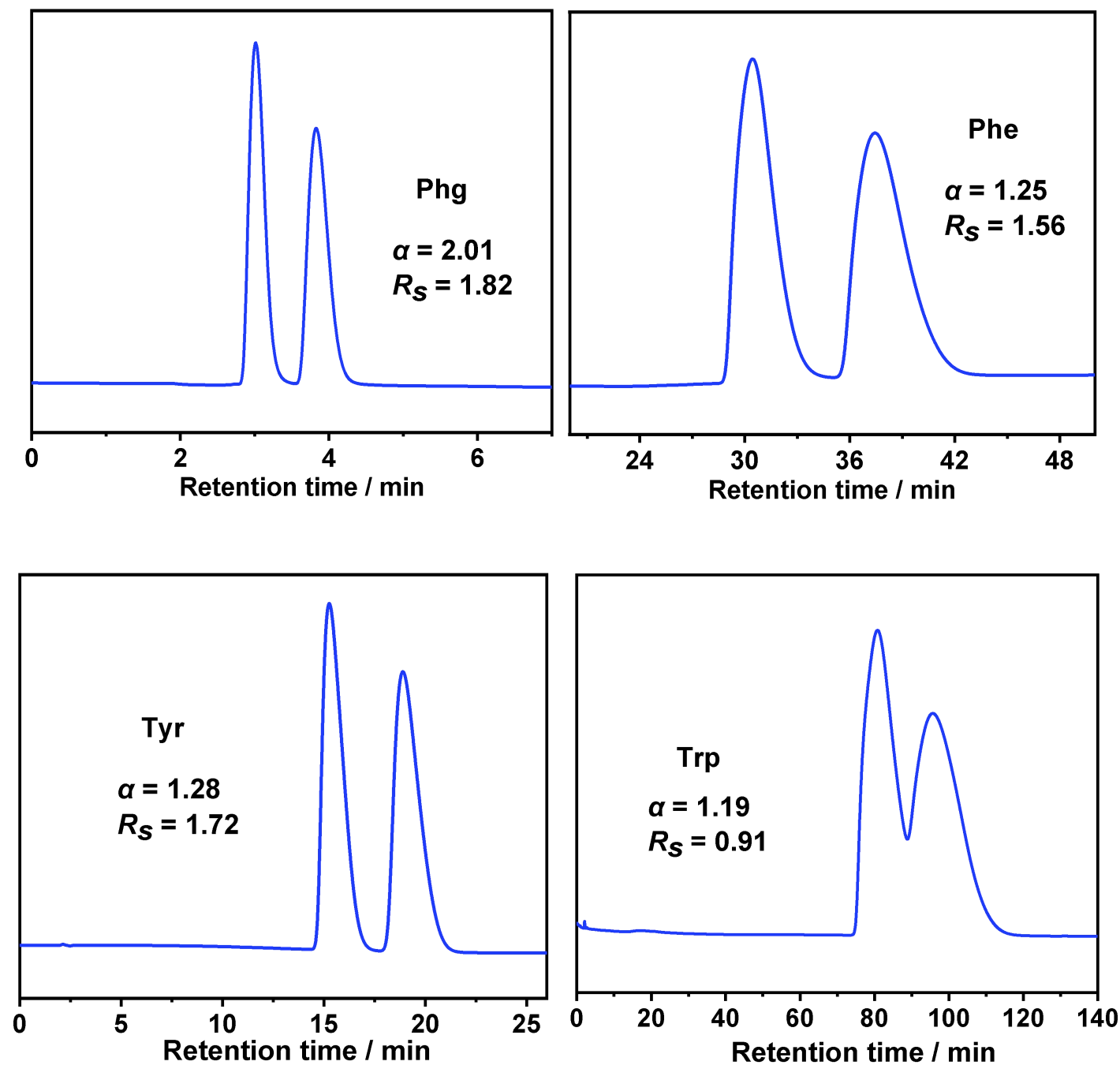

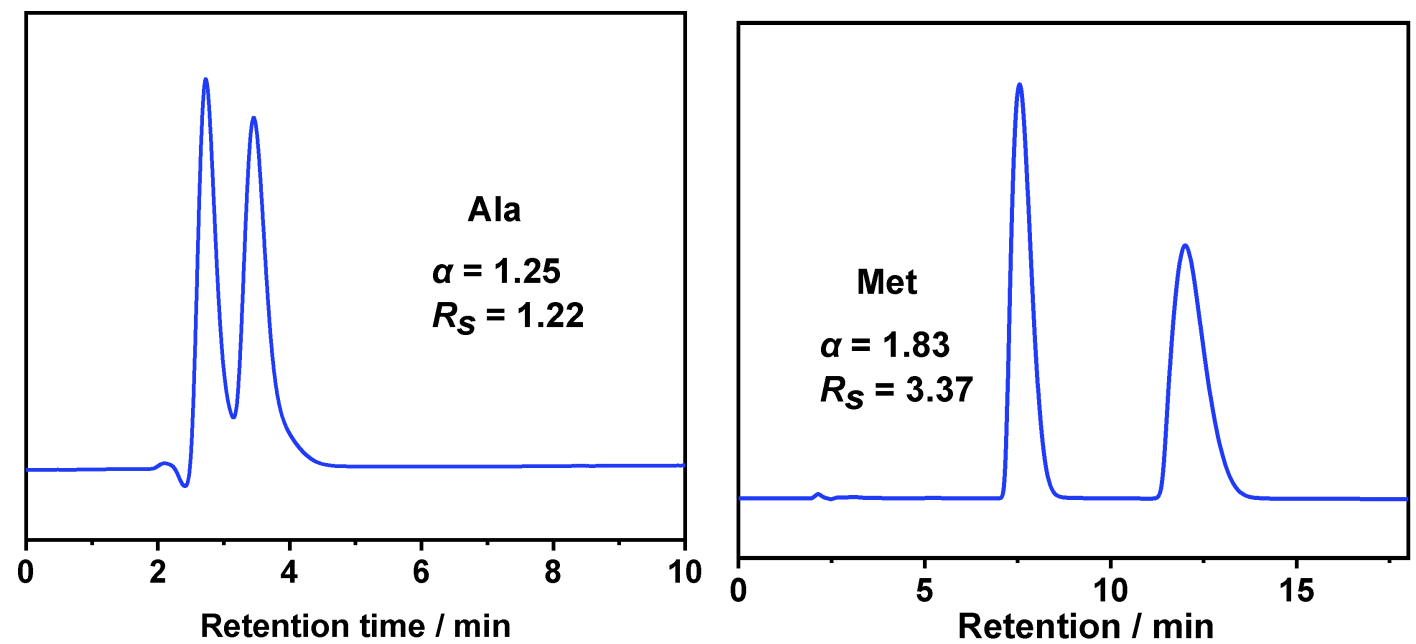

Figure S14c. HPLC chromatograms for separation of six amino acids with OET-1 packed column

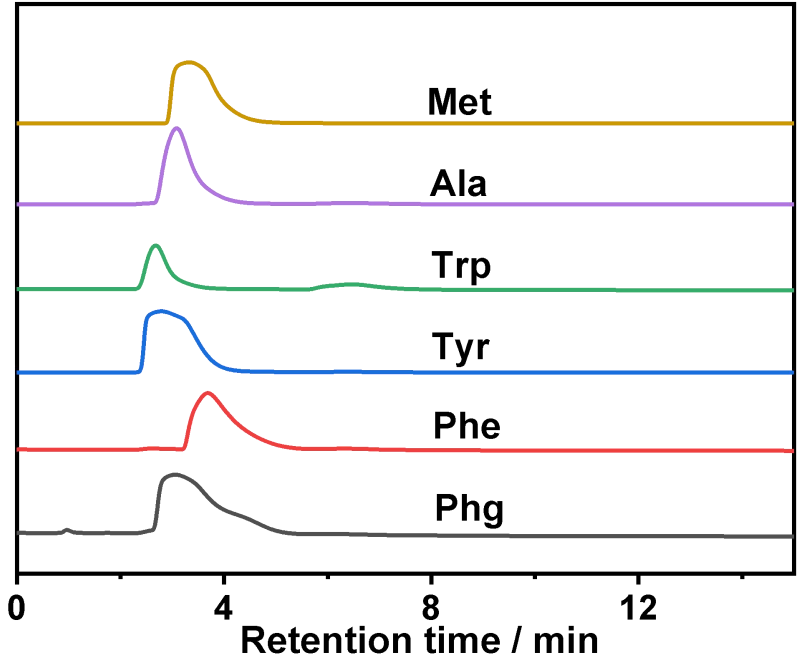

Figure S14d. HPLC chromatograms for the bulky analyte

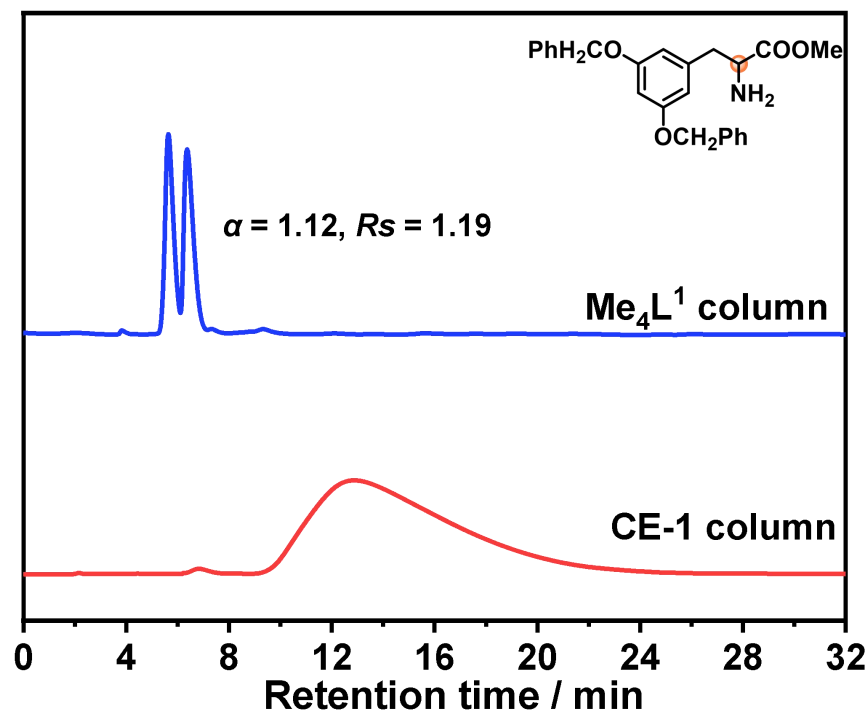


Figure S14e. HPLC chromatograms for six amino acids with $\mathrm{C}_{18}$ silica gel column

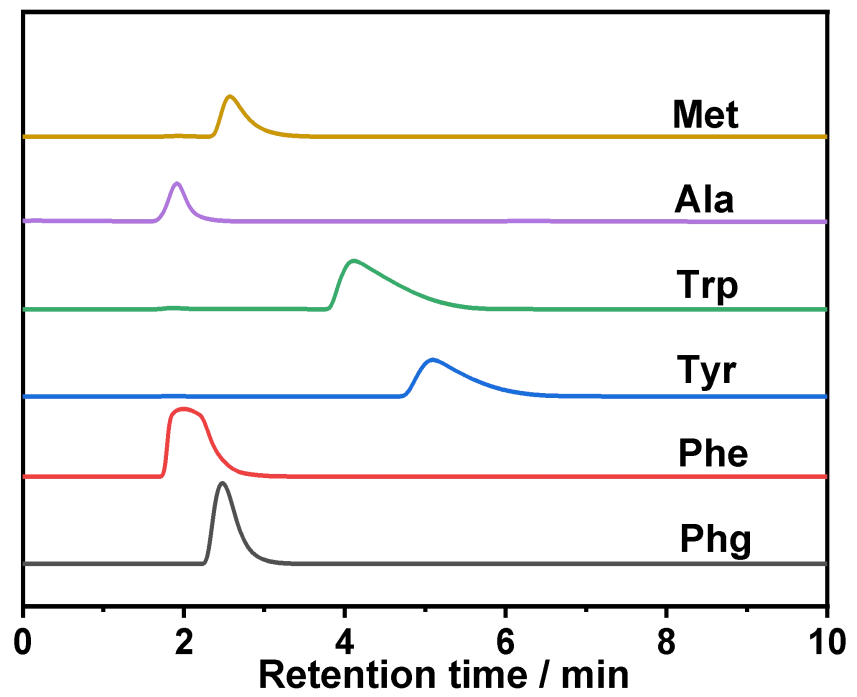

Figure S14f. HPLC chromatograms of Phg on the CE-1 packed column for five replicated experiments

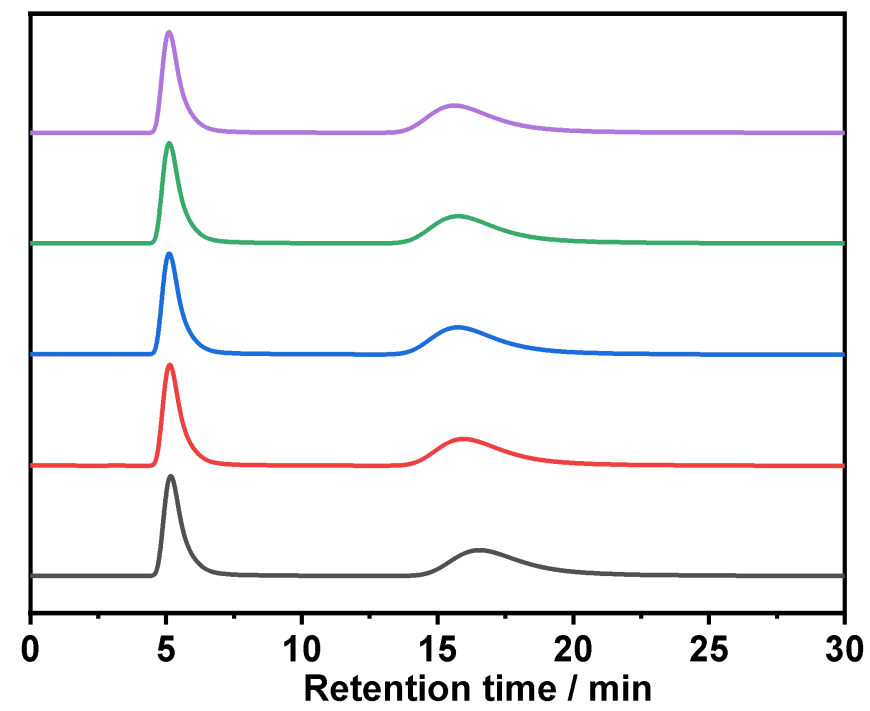


Figure S14g. HPLC chromatograms of Phg-OMe on the CE-1 packed column for five replicated experiments

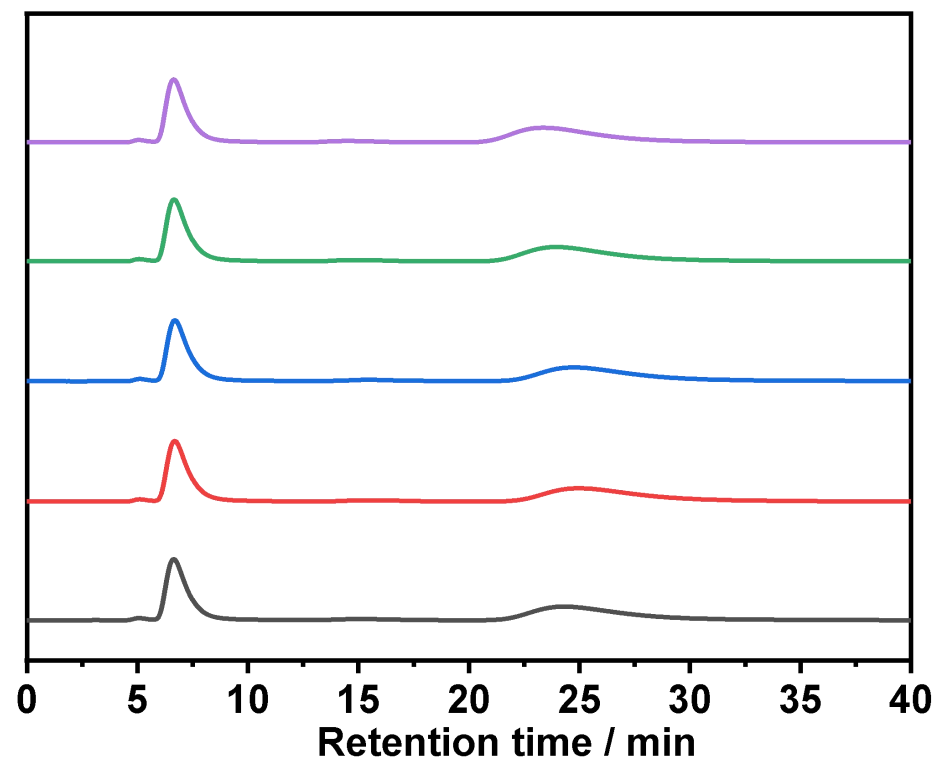

Figure S14h. HPLC chromatograms for another CE-1 column

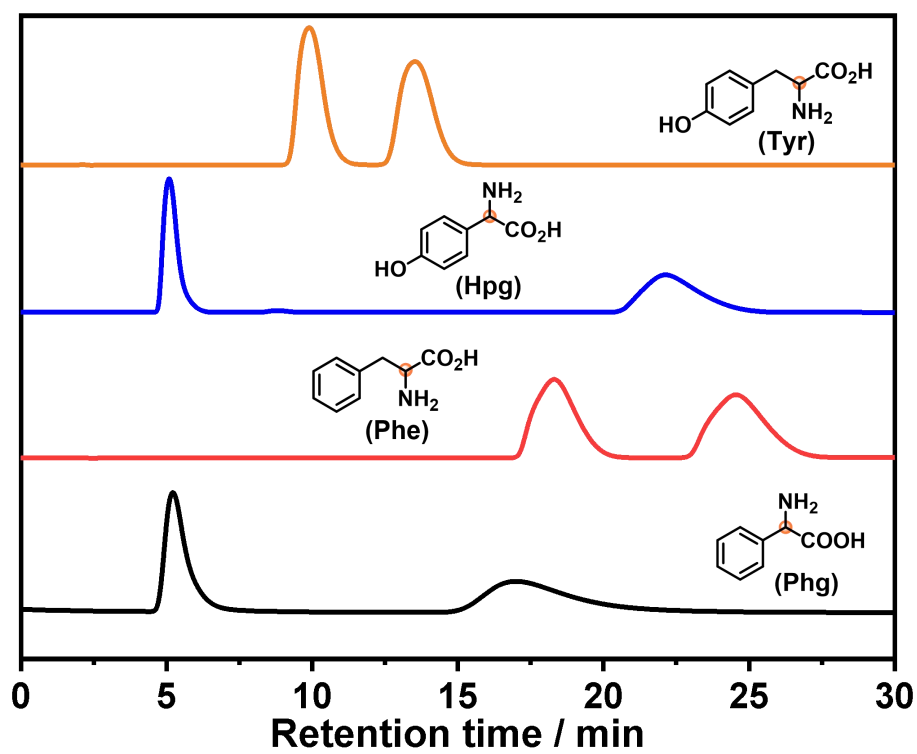



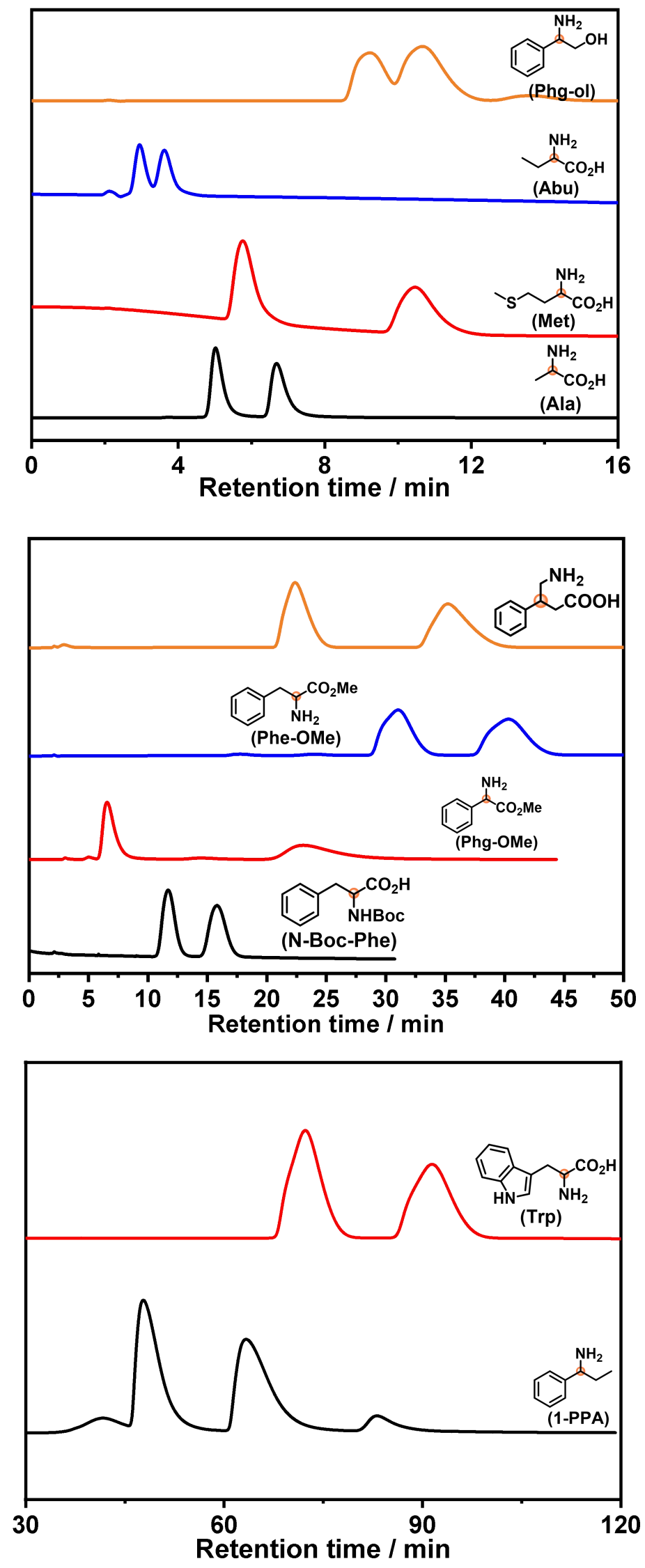
18. Table S5-S8. Summary of selectivity factor $(\alpha)$ and chromatographic resolution factor $\left(R_{S}\right)$

Table S5. Summary of $\alpha$ and $R_{S}$ for CE-1, CE-2 and CE-3 column

\begin{tabular}{|c|c|c|c|c|c|c|}
\hline \multirow{2}{*}{ Analytes } & \multicolumn{2}{|c|}{ CE-1 column } & \multicolumn{2}{c|}{ CE-2 column } & \multicolumn{2}{c|}{ CE-3 column } \\
\hline & $\alpha$ & $R_{s}$ & $\alpha$ & $R_{s}$ & $\alpha$ & $R_{s}$ \\
\hline Phg & 5.25 & 6.31 & 4.16 & 4.04 & 3.66 & 3.20 \\
\hline Phe & 1.49 & 1.85 & 1.42 & 1.00 & 4.33 & 0.79 \\
\hline Met & 2.56 & 3.25 & 2.11 & 1.77 & 1.83 & 0.68 \\
\hline Hpg & 7.77 & 6.59 & 5.96 & 3.97 & 5.33 & 3.06 \\
\hline Trp & 1.36 & 1.85 & 1.25 & 0.84 & 1.17 & 0.49 \\
\hline N-Boc-Phe & 1.47 & 1.84 & 1.44 & 0.93 & 1.26 & 0.96 \\
\hline
\end{tabular}

Table S6. RSD results for Phg separated on CE-1 column

\begin{tabular}{|c|c|c|c|c|c|c|c|c|}
\hline & 1 & 2 & 3 & 4 & 5 & Avg. & SD & RSD \\
\hline $\begin{array}{c}\text { Selectivity } \\
\text { factor }\end{array}$ & 3.746 & 3.680 & 3.654 & 3.659 & 3.663 & 3.680 & 0.0380 & $1.03 \%$ \\
\hline Peak area & 335124 & 336987 & 336722 & 335876 & 332004 & 335343 & 200525 & $0.60 \%$ \\
\hline $\begin{array}{c}\text { Peak height } \\
\text { Theoretical }\end{array}$ & 664700 & 672328 & 671998 & 667676 & 670563 & 669453 & 3229.7 & $0.48 \%$ \\
\hline \begin{tabular}{c} 
plate number \\
\hline
\end{tabular} & 1996 & 1998 & 1997 & 1995 & 2001 & 1997.4 & 2.30 \\
\hline
\end{tabular}

Table S7. RSD results for Phe-OMe separated on CE-1 column

\begin{tabular}{|c|c|c|c|c|c|c|c|c|}
\hline & 1 & 2 & 3 & 4 & 5 & Avg. & SD & RSD \\
\hline $\begin{array}{c}\text { Selectivity } \\
\text { factor }\end{array}$ & 3.801 & 3.849 & 3.887 & 3.843 & 3.791 & 3.834 & 0.0389 & $1.01 \%$ \\
\hline Peak area & $\begin{array}{c}256279 \\
41\end{array}$ & $\begin{array}{c}256577 \\
11\end{array}$ & $\begin{array}{c}256656 \\
95\end{array}$ & $\begin{array}{c}256693 \\
66\end{array}$ & $\begin{array}{c}256231 \\
86\end{array}$ & $\begin{array}{c}256487 \\
80\end{array}$ & $\begin{array}{c}21673 . \\
6\end{array}$ & $0.08 \%$ \\
\hline Peak height & 373210 & 369682 & 372350 & 378594 & 383901 & 375547 & 5682.3 & $1.50 \%$ \\
\hline $\begin{array}{l}\text { Theoretical } \\
\text { plate number }\end{array}$ & 1604 & 1592 & 1598 & 1613 & 1640 & 1609 & 18.8 & $1.17 \%$ \\
\hline
\end{tabular}


Table S8. Summary of $\alpha$ and $R_{s}$ for two separated CE-1 column

\begin{tabular}{|c|c|c|c|c|}
\hline \multirow{2}{*}{ Analytes } & \multicolumn{2}{|c|}{ CE-1 column 1 } & \multicolumn{2}{l|}{ CE-1 column 2 } \\
\cline { 2 - 5 } & $\alpha$ & $R_{s}$ & $\alpha$ & $R_{s}$ \\
\hline Phg & 5.25 & 6.31 & 3.23 & 5.05 \\
\hline Phe & 1.49 & 1.85 & 2.03 & 1.39 \\
\hline Hpg & 7.77 & 6.59 & 7.43 & 7.13 \\
\hline Tyr & 1.60 & 1.99 & 2.07 & 1.48 \\
\hline Ala & 1.53 & 1.23 & 2.56 & 1.61 \\
\hline Met & 2.36 & 3.51 & 3.51 & 2.36 \\
\hline Abu & 1.66 & 1.02 & 1.06 & 2.05 \\
\hline Trp & 1.36 & 1.85 & 1.70 & 1.27 \\
\hline Phg-ol & 1.23 & 0.63 & 0.83 & 1.21 \\
\hline N-Boc-Phe & 1.47 & 1.08 & 1.87 & 1.44 \\
\hline Phg-OMe & 3.23 & 10.21 & 3.63 & 11.78 \\
\hline Phe-OMe & 1.45 & 1.99 & 1.87 & 1.32 \\
\hline Phenibut & 1.74 & 2.46 & 2.62 & 1.64 \\
\hline 1-PPA & 1.54 & 2.34 & 2.06 & 1.34 \\
\hline
\end{tabular}

\section{Figures S15-S20. DFT Calculations}

As shown in Figure S15, there are two configurations of the crown ether groups in (S)-CE-1 with the dihedral angles of two center phenyl rings at about $64^{\circ}$ or $112^{\circ}$, respectively. Figures S17 and S18 are the two-layer ONIOM cluster models with the dihedral angles of two center phenyl rings at $64^{\circ}$ or $112^{\circ}$. The high layer was the crown ether group associated with two phenyl rings and treated by the B3LYP-D3 method; the low layer was frozen and treated by the semi-empirical PM6 method. All the structures were optimized with ONIOM (B3LYP-D3/def2-SVP:PM6) method. Vibrational frequencies were computed at the same level to verify no imaginary frequency in energy minima. The single-point energy calculations were conducted using ONIOM (B3LYP-D3/def2-TZVP:PM6) method. The Gibbs energy $(G)$ was estimated at $298.15 \mathrm{~K}$ by $G=E$ $+G_{\text {corr, }}$ where $E$ is the electronic energy obtained from the single-point energy calculations and $G_{\text {corr }}$ is the thermal correction to Gibbs energy at $298.15 \mathrm{~K}$ obtained from frequency calculations. All the calculations were performed with the Gaussian 16 package. ${ }^{[5]}$ 

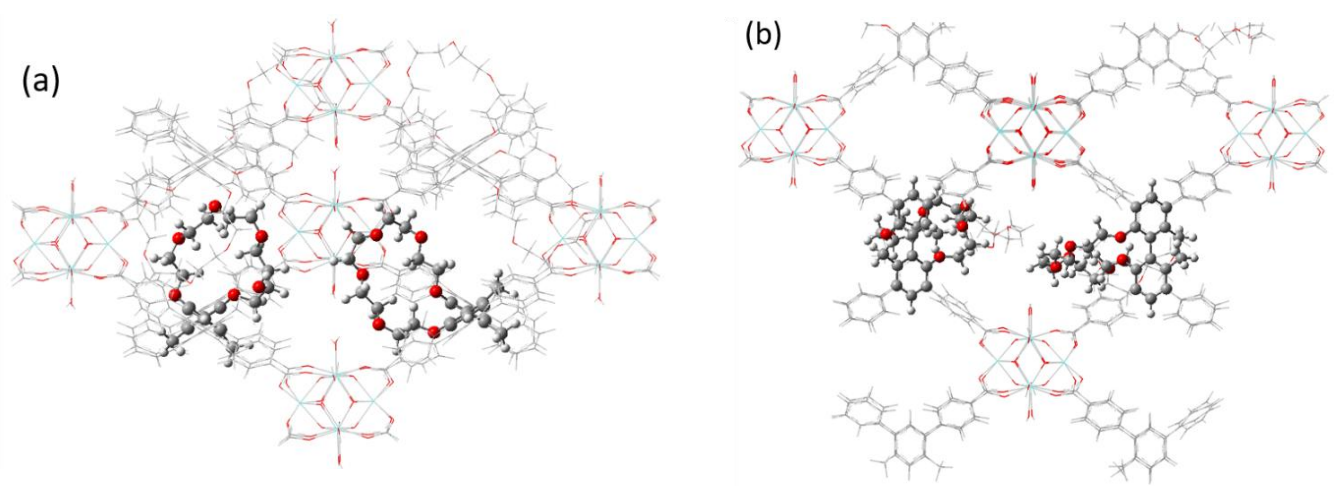

Figure S15. (a) top and (b) side views of (S)-CE-1. C: grey, H: white, O: red and Zr: light blue.

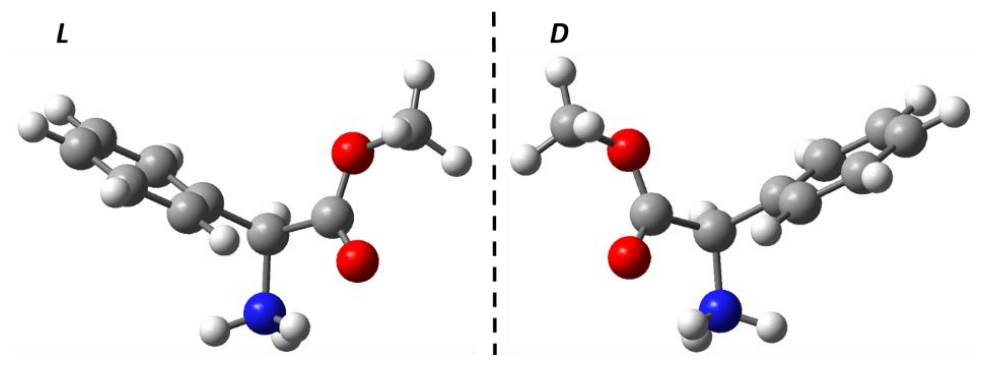

Figure S16. $L$ and $D$-protonated 2-phenylglycine methyl ester. C: grey, H: white, O: red and N: dark blue.
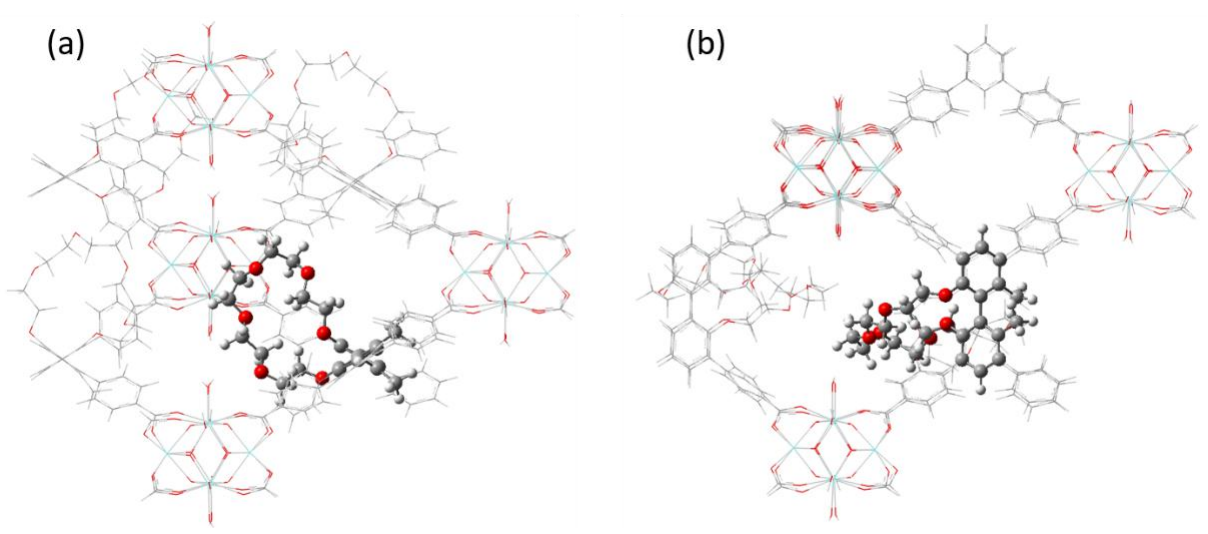

Figure S17. Top (a) and side (b) views of the optimized two-layer ONIOM cluster model with the dihedral angles of two center phenyl rings at $64^{\circ}$. C: grey, H: white, O: red and Zr: light blue. The high and low layers are represented by the ball-stick and wireframe, respectively. 

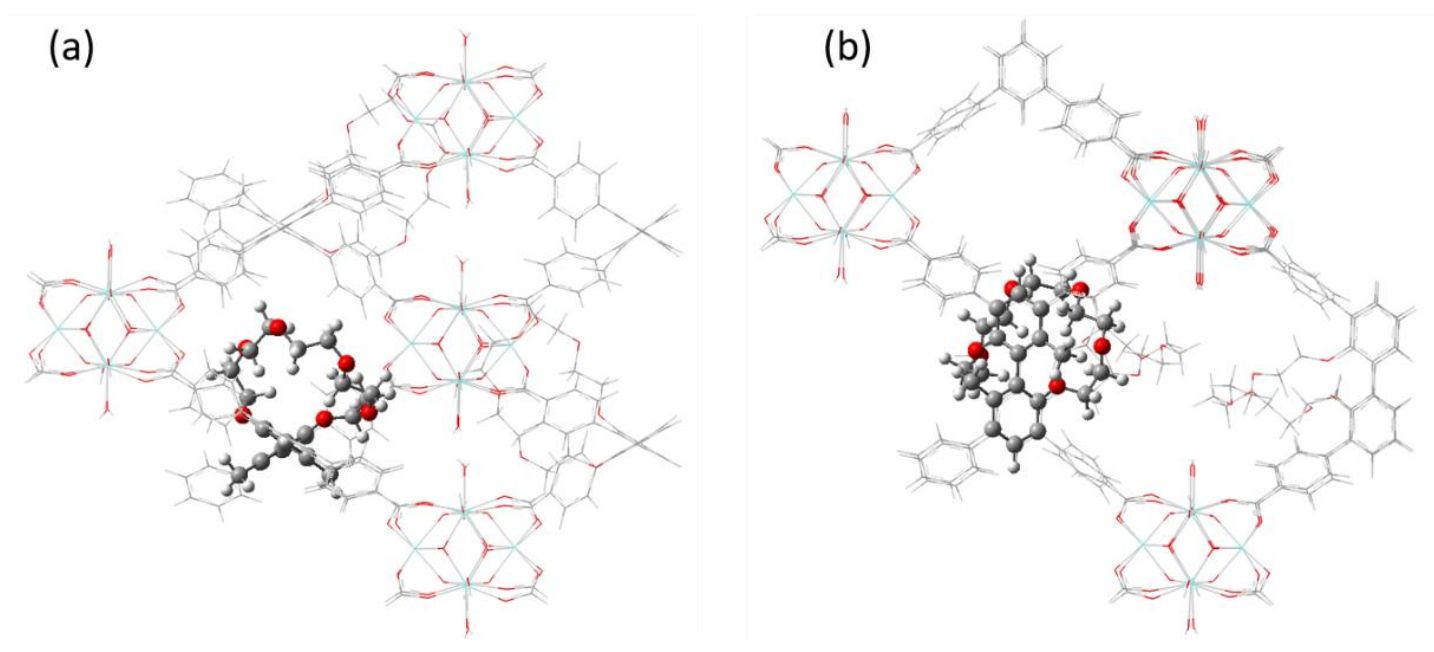

Figure S18. Top (a) and side (b) views of the optimized two-layer ONIOM cluster model with the dihedral angles of two center phenyl rings at $112^{\circ}$. C: grey, H: white, O: red and $\mathrm{Zr}$ : light blue.
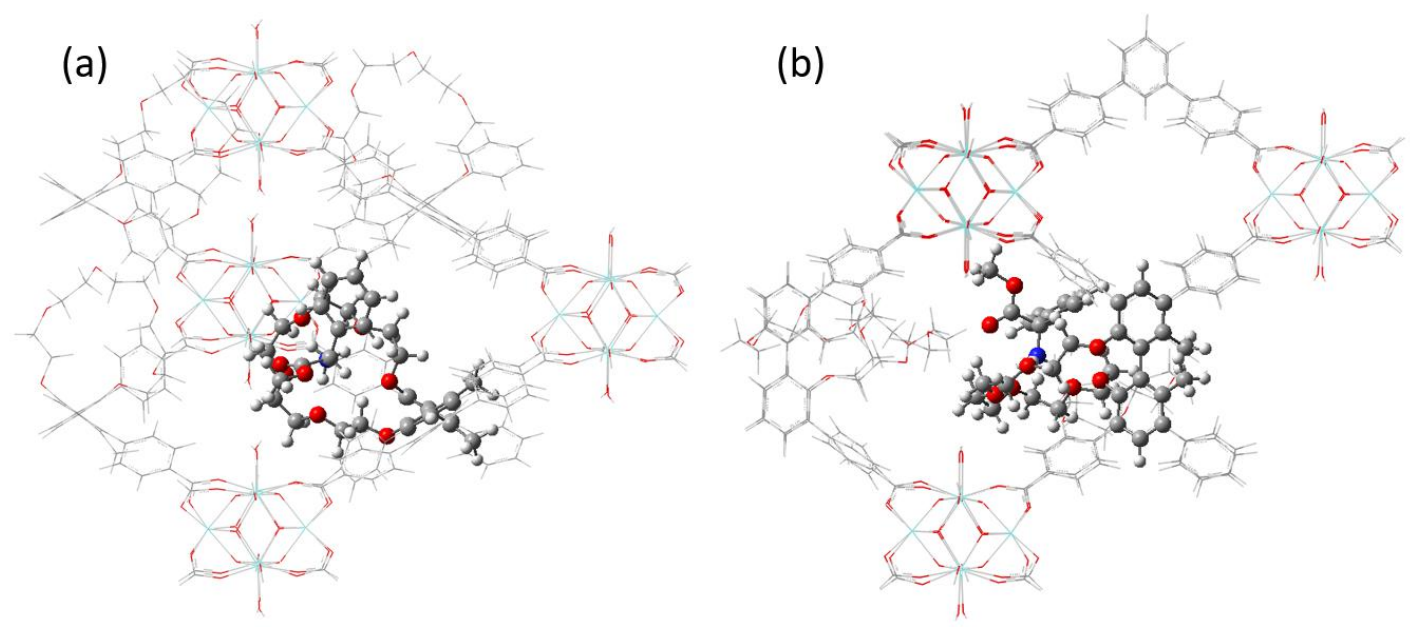

Figure S19. Top (a) and side (b) views of the lowest-energy structure of (S)-CE-1 with L-protonated 2-phenylglycine methyl ester. C: grey, $\mathrm{H}$ : white, O: red, N: dark blue and Zr: light blue. 

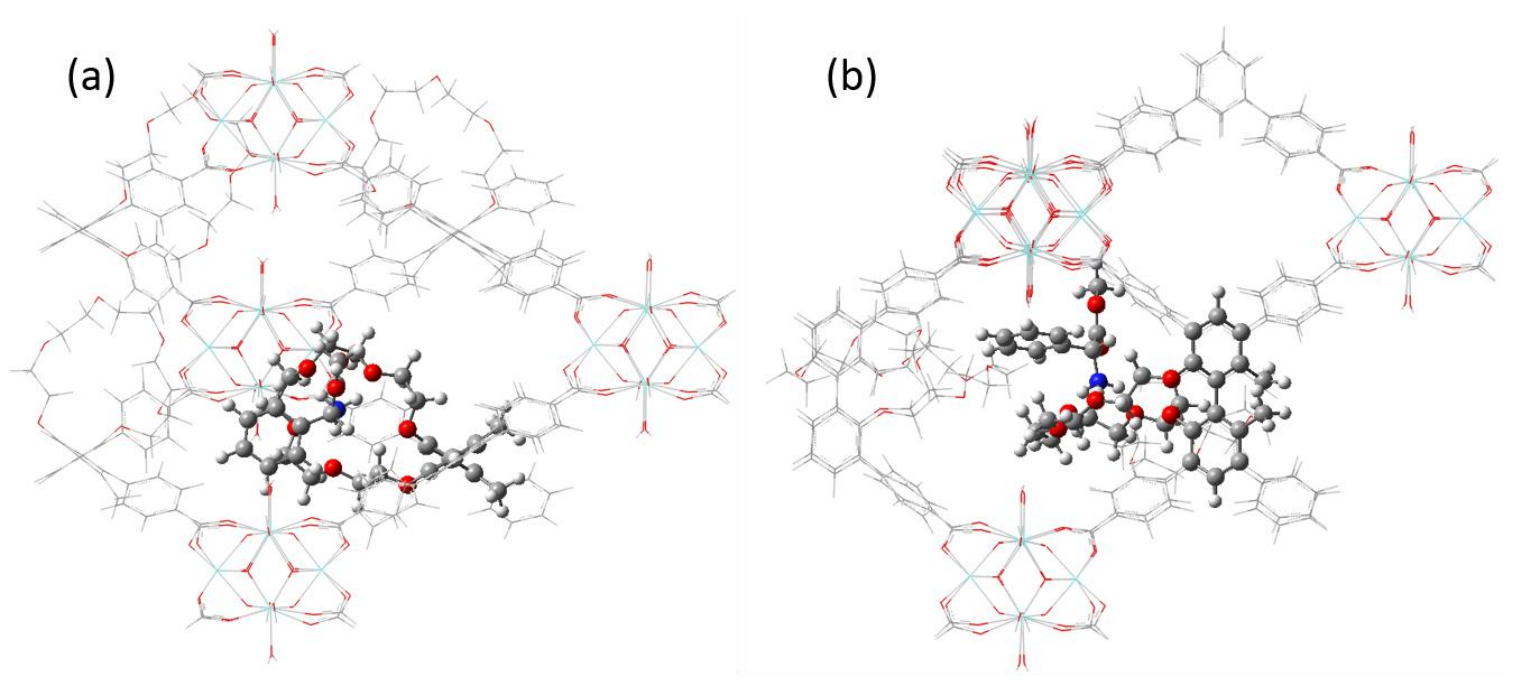

Figure S20. Top (a) and side (b) views of the lowest-energy structure of (S)-CE-1 with $D$-protonated 2-phenylglycine methyl ester. C: grey, H: white, O: red, N: dark blue and Zr: light blue.

20. Figure S21. TGA curve

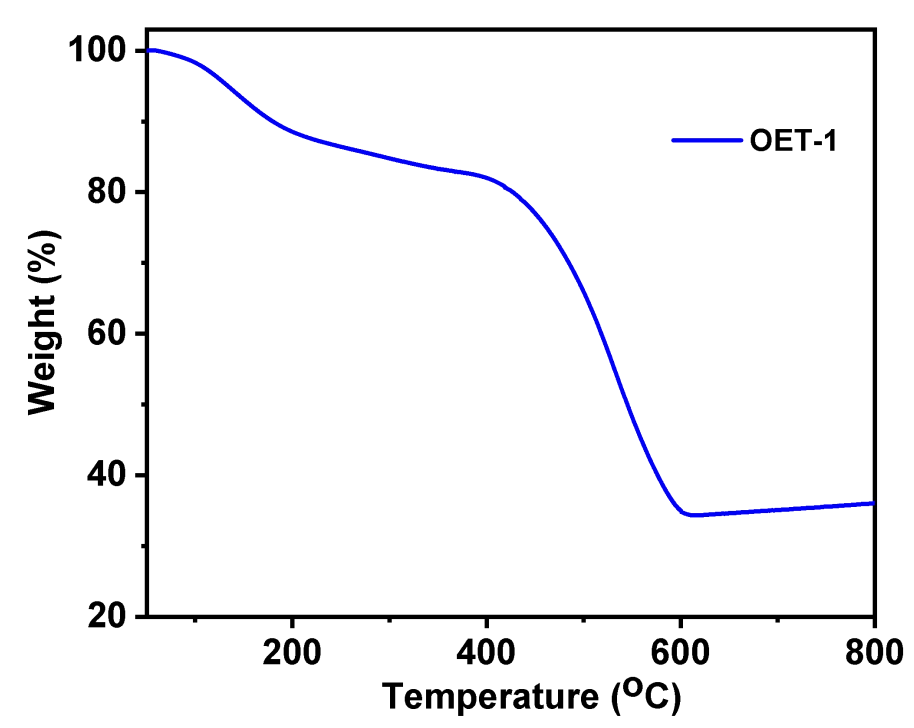




\section{References}

[1] Ma, J.; Kalenak, A. P.; Wong-Foy, A. G.; Matzger, A. J. Rapid Guest Exchange and Ultra-Low Surface Tension Solvents Optimize Metal-Organic Framework Activation. Angew. Chem. Int. Ed. 2017, 56, 14618.

[2] Chen, X.; Jiang, H.; Li, X.; Hou, B.; Gong, W.; Wu, X.; Han, X.; Zheng, F.; Liu, Y.; Jiang. J.; Cui, Y. Angew. Chem. Int. Ed. 2019, 58, 14748.

[3] Jiang, H.; Zhang, W.; Kang, X.; Cao, Z.; Chen, X.; Liu, Y.; Cui, Y. Topology-Based Functionalization of Robust Chiral Zr-Based Metal-Organic Frameworks for Catalytic Enantioselective Hydrogenation. J. Am. Chem. Soc. 2020, 142, 9642.

[4] Koenig, S. G.; Vandenbossche, C. P.; Zhao, H.; Mousaw, P.; Singh, S. P.; Bakale, R. P. A Facile Deprotection of Secondary Acetamides. Org. Lett. 2009, 11, 433-436.

[5] M. J. Frisch, G. W. Trucks, H. B. Schlegel, G. E. Scuseria, M. A. Robb, J. R. Cheeseman, G. Scalmani, V. Barone, G. A. Petersson, H. Nakatsuji, X. Li, M. Caricato, A. V. Marenich, J. Bloino, B. G. Janesko, R. Gomperts, B. Mennucci, H. P. Hratchian, J. V. Ortiz, A. F. Izmaylov, J. L. Sonnenberg, D. Williams-Young, F. Ding, F. Lipparini, F. Egidi, J. Goings, B. Peng, A. Petrone, T. Henderson, D. Ranasinghe, V. G. Zakrzewski, J. Gao, N. Rega, G. Zheng, W. Liang, M. Hada, M. Ehara, K. Toyota, R. Fukuda, J. Hasegawa, M. Ishida, T. Nakajima, Y. Honda, O. Kitao, H. Nakai, T. Vreven, K. Throssell, J. A. Montgomery, Jr., J. E. Peralta, F. Ogliaro, M. J. Bearpark, J. J. Heyd, E. N. Brothers, K. N. Kudin, V. N. Staroverov, T. A. Keith, R. Kobayashi, J. Normand, K. Raghavachari, A. P. Rendell, J. C. Burant, S. S. Iyengar, J. Tomasi, M. Cossi, J. M. Millam, M. Klene, C. Adamo, R. Cammi, J. W. Ochterski, R. L. Martin, K. Morokuma, O. Farkas, J. B. Foresman, and D. J. Fox, Gaussian 16, Revision A.03, Gaussian, Inc., Wallingford CT, 2016. 